\author{
UNIVERSIDADE DE SÃO PAULO \\ INSTITUTO DE QUÍMICA DE SÃO CARLOS \\ QUÍMICA ORGÂNICA E BIOLÓGICA
}

JEAN FRANCISCO ROSA RIBEIRO

Inibidores de Cisteíno Proteases como Candidatos

Terapêuticos para o Tratamento de Doenças Parasitárias

TESE DE DOUTORADO

São Carlos

2018 


\author{
UNIVERSIDADE DE SÃO PAULO \\ INSTITUTO DE QUÍMICA DE SÃO CARLOS \\ QUÍMICA ORGÂNICA E BIOLÓGICA
}

JEAN FRANCISCO ROSA RIBEIRO

\title{
Inibidores de Cisteíno Proteases como Candidatos \\ Terapêuticos para o Tratamento de Doenças Parasitárias
}

Tese apresentada ao Instituto de Química de São

Carlos (IQSC) da Universidade de São Paulo

(USP) como parte dos requisitos para a obtenção do título de doutor em ciências.

\section{Exemplar revisado}

O exemplar original encontra-se em acervo reservado naBiblioteca do IQSC-USP

São Carlos 


\section{AGRADECIMENTOS}

Agradeço a Deus pelo dom da vida e pelos inúmeros benefícios que recebi durante essa jornada até aqui;

Aos meus pais, Ângelo Rosa Ribeiro e Oneida Ferreira Ribeiro, pela dedicação, apoio, confiança e por todo amor que me ofertaram;

A minha esposa, Nádia Melo Borges, minha companheira de jornada, por todo amor, amizade e cumplicidade.

Ao meu orientador Prof. Dr Carlos Alberto Montanari pela paciência, ensinamentos, confiança, empenho e dedicação com minha formação pessoal e profissional;

Aos membros e ex-membros do grupo NEQUIMED pela amizade, discussões, momentos de descontração e pelo excelente trabalho em equipe: Helton, Juliana, Fabiana, Ricardo, Josmar, César, Emanuelle, Geraldo, Igor, Cristian Camilo, Leandro, Erika, Karen, William, Lorenzo, Juliana Gomes, Daniela de Vita, Fernanda e Professor Andrei;

Aos pesquisadores Peter Kenny e Josmar Rodrigues da Rocha por compartilharem suas experiências, ideias e conhecimento durante suas passagens pelo grupo NEQUIMED;

Aos alunos Lorenzo e Fernanda pelo valioso auxílio nos ensaios bioquímicos;

Aos alunos Cristian Camilo, Leandro Avelar, Erika Meñaca, Daniel Gedder, Daniela de Vita e Juliana Gomes pela síntese dos compostos aqui estudados;

Aos amigos e colegas de São Carlos: Daniela, Franciele, Jussara, Lina, Felipe e Alexander pela amizade, apoio e inúmeros momentos de divertimento;

Aos Professores Jonas Emsley e Charles A. Laughton da Universidade de NottinghamInglaterra, pela oportunidade de realizar o estágio de doutorado sanduíche em seus laboratórios, pela grande contribuição nesse trabalho e no meu processo de formação; Aos colegas do laboratório de Biologia Estrutural da Universidade de Nottingham; Ao pós-doutorando, Chan Lee, pelos ensinamentos e a grande ajuda com a resolução das estruturas cristalográficas apresentadas aqui;

Aos pós-doutorandos Monika, Buba, Salin, Selva, Lori, Alex, Simon e Thom pelas discussões, ideias e apoio nessa pesquisa;

Ao CNPq e CAPES pelo suporte financeiro.

A toda Universidade de São Paulo desde os funcionários da limpeza, do restaurante universitário, da segurança patrimonial, secretários, bibliotecários aos Professores dessa instituição.

A todos vocês, a minha imensa gratidão! 


\section{EPÍGRAFE}

"Eu sei que o meu trabalho é uma gota no oceano, mas sem ele o oceano seria menor".

Madre Tereza de Calcutá

“Importante, em verdade, é o homem que está na arena, com a face coberta de poeira, suor e sangue; que luta com bravura, erra e, seguidamente, tenta atingir o alvo. É aquele que conhece os grandes entusiasmos, as grandes devoções e se consome numa causa justa. É aquele que, no sucesso, melhor conhece o triunfo final dos grandes feitos e que, se fracassa, pelo menos falha ousadamente, de modo que o seu lugar jamais será entre as almas tímidas, que não conhecem nem a vitória, nem a derrota". 


\section{RESUMO}

A necessidade urgente de descoberta de terapias mais seguras e eficazes para o tratamento da doença de Chagas e leishmanioses tem motivado a pesquisa por novos inibidores das enzimas cruzaína e CPB, as principais cisteíno proteases do T. cruzi e Leishmania spp., respectivamente. Uma série de 52 compostos nitrílicos que atuam como inibidores covalente-reversíveis de cisteíno proteases foi sintetizada no grupo NEQUIMED/IQSC/USP e avaliada quanto a sua atividade inibitória contra as enzimas cruzaína, CPB de Leishmania mexicana e catepsina L de humanos. Utilizando planejamento molecular baseado em hipótese, mapeamos as relações estrutura-atividade (SARs) desses inibidores através de variações nas posições P1, P2, P3 e P1' do esqueleto dipeptidil nitrílico. A substituição do grupo eletrofílico (warhead) aminonitrila em P1 pelo grupo azanitrila melhorou a afinidade em duas ordens de magnitude para todos os alvos avaliados. Um dos mais potentes inibidores, o análogo azanitrila Neq0690 mostrou uma cinética de ligação lenta com valores de $\mathrm{p} K_{\mathrm{i}}$ de 8,8, 9,3 e 9,7 para cruzaína, catepsina L e $L m C P B$, respectivamente. A substituição bioisostérica da ligação amida entre as posições P2-P3 pelo grupo trifluoroetilamina resultou na síntese do Neq0659, um potente inibidor com um perfil de ação seletivo para as proteases de parasitos. A substituição do grupo metileno em P1 pelo ciclopropano aumentou a afinidade para todas as enzimas. Contudo, uma inibição seletiva da cruzaína e $L m C P B$ foi associada à presença do grupo $(R)$-benzila como substituinte da posição P1 dos derivados $\mathrm{CF}_{3}$ substituídos. Embora os compostos substituídos com leucina, tirosina, triptofano e 3-cloro fenilalanina como substituintes da posição P2 foram relativamente bem tolerados pela cruzaína e catepsina L, uma restrita especificidade foi verificada para $L m C P B$ com pequenos ganhos de afinidade para os inibidores que possuíam os grupos leucina e metil benzoato como substituintes dessa posição. Com relação à posição P3, a inserção do grupo 3terc-butilpirazol e 3-bromo piridina aumentou a afinidade para todos os alvos avaliados enquanto que um ganho seletivo para a $L m C P B$ foi observado para os compostos que possuíam o grupo bifenila nessa posição. Além disso, duas novas estruturas cristalográficas da LmCPB complexada com o Neq0690 e metil metanotiossulfonato (MMTS) foram determinadas com resoluções de 1,3 $\AA$ e 1,5 $\AA$, respectivamente. As estruturas dos co-complexos revelaram os modos de interação $(\mathrm{MoB})$ desses ligantes, bem como as principais características do processo de reconhecimento bimolecular. Isso permitirá o uso de estratégias de planejamento baseado na estrutura do alvo com translação natural para a pesquisa por novos inibidores de cisteíno proteases, com amplo espectro de ação na quimioterapia de doenças a elas relacionadas.

Palavras-chave: Doença de Chagas, Leishmanioses, Câncer, Cisteíno proteases, Cristalografia de raios-X, Dipeptidil nitrilas 


\begin{abstract}
The urgent need for the discovery of safer and more effective therapies for the treatment of Chagas disease and leishmaniasis has motivated the search for new inhibitors of the enzymes cruzain and CPB, the major T. cruzi and Leishmania spp. cysteine proteases, respectively. A series of 52 nitrile-containing compounds acting as covalent-reversible inhibitors of cysteine proteases was synthesized at the NEQUIMED/IQSC/USP Medicinal Chemistry Group and evaluated for their inhibitory activity against the enzymes cruzain, Leishmania mexicana CPB and cathepsin L from humans. Using hypothesis-driven molecular design, we mapped the structure-activity relationships (SARs) of these inhibitors through variations in the P1, P2, P3 and P1' positions of the dipeptidyl nitrile scaffold. The substitution of the aminonitrile by the azanitrile group improved the affinity by two orders of magnitude for all the evaluated targets. One of the most potent inhibitors, the azanitrile analogue dubbed Neq0690 showed a slowbinding kinetics with $\mathrm{p} K_{\mathrm{i}}$ values of $8.8,9.3$ and 9.7 for cruzain, cathepsin $\mathrm{L}$ and LmCPB, respectively. Bioisosteric substitution of the amide moiety between the P2-P3 positions by the trifluoroethylamine group resulted in the synthesis of Neq0659, a potent inhibitor with a selective action profile for parasite proteases. Substitution of the methylene group at P1 by cyclopropane increased the affinity for all enzymes. However, selective inhibition of cruzain and LmCPB was associated with the presence of the (R)-benzyl group as substituent of the P1 position of the substituted CF3 derivatives. Although leucine, tyrosine, tryptophan and 3-chloro phenylalanine substituted compounds as substituents of the P2 position were relatively well tolerated by cruzain and cathepsin L, a restricted specificity was verified for LmCPB with small affinity gains for the inhibitors possessing the leucine and methyl benzoate as substituents of that position. Regarding the P3 position, the insertion of the 3-tert-butylpyrazole and 3-bromo pyridine groups increased the affinity for all evaluated targets whereas a selective gain for LmCPB was observed for the compounds having the biphenyl moiety at that position. In addition, it is noteworthy that two new crystallographic structures of LmCPB complexed with Neq0690 and methyl methanethiosulfonate (MMTS) were determined with resolutions of $1.3 \AA$ and $1.5 \AA$, respectively. The structures of the co-complexes revealed the modes of binding (MoB) of these ligands, as well as the main characteristics of the bimolecular recognition process. This will allow the natural translational target structure strategies for the search for new inhibitors of cysteine proteases with broad spectrum of action in the chemotherapy of related diseases.
\end{abstract}

Keywords: Chagas disease, Leishmaniasis, Cancer, Cysteine proteases, X-ray crystallography, Dipeptidyl nitriles 


\section{LISTA DE FIGURAS}

Figura 1- Estrutura cristalográfica da papaína (PDB: 9PAP) ${ }^{1}$ 15

Figura 2 - Representação do sítio catalítico da cruzaína (em superfície de Van der Walls) colorido segundo a localização de cada subsítios de ligação. O peptídeo mostrado é um substrato da catepsina k (extraído da estrutura de PDB 1BY8), uma vez que, até o momento, não há estrutura cristalográfica da cruzaína ligada a substratos peptídicos disponíveis no PDB. ${ }^{2}$ 16

Figura 3 - Inibidores de cisteíno proteases 17

Figura 4 -Modelo para o processamento e tráfego da enzima cruzaína na forma epimastigota do $T$. cruzi, na presença (CA-1/72 + CPI) e ausência (CA-1/72) de um inibidor de cisteíno protease. A pró-cruzaína ativada no complexo de Golgi se dissocia de seus receptores e é acumulada no interior dos lisossomos/reservossomos. Em condições normais, a enzima madura é parcialmente secretada no meio através de vesículas secretórias. A adição de uma concentração letal de um inibidor de cisteíno protease paralisa o processamento natural da pró-cruzaína nas cisternas de Golgi, conduzindo a morte parasitária por choque osmótico. ${ }^{10}$ 18

Figura 5 - (A) A dupla deleção dos conjuntos de genes cpb e cpa $(\Delta \mathrm{cpa} / \mathrm{cpb})$ alterou a cinética de crescimento in vitro da forma promastigotas de L. mexicana. Mutantes deficientes de cada conjunto de genes isolados ( $\Delta$ cpa e $\Delta \mathrm{cpb}$ ) não apresentaram diferenças fenotípicas significativas quando comparadas com a cepa W.T. Além disso, a restituição do crescimento normal após a reinserção de genes específicos da família CPB (cpb2 e cpb2.8) confirma que a ausência dos genes da família CPA não é suficiente para alterar o curso da infecção pelo parasito. A diminuição da infectividade da cepa contendo a dupla deleção $(\Delta \mathrm{cpa} / \mathrm{cpb})$ em macrófagos humanos é mostrada no gráfico B. O reestabelecimento da capacidade infectiva, aos níveis observados na cepa WT, pela reinserção dos genes cpb2 ou cpb2.8 demonstra o papel dessas cisteíno proteases na patogenicidade de L. mexicana. Pode-se observar os campos representativos (x1000) de macrófagos U-937 infectados por L. mexicana W.T (figura 1) e a cepa contendo a dupla deleção $\Delta \mathrm{cpa} / \mathrm{cpb}$ (figura 2$){ }^{15}$

Figura 6- Papéis distintos da catepsina L secretada e nuclear na disseminação metastática de células tumorais. A catepsina L secretada atua através da degradação de moléculas de adesão celular, proteínas da matriz extracelular, bem como a ativação de 
outras proteases associadas a metástase. A catepsina L nuclear ativa a transcrição de genes relacionados a transição epitelial-mesenquimal e também confere resistência terapêutica via degradação do 53BP1. ${ }^{16}$

Figura 7 - Mecanismo de inibição covalente-reversível de cisteíno proteases por inibidores nitrílicos. O mecanismo concertado envolve a adição nucleofílica da cisteína ativada ao carbono nitrílico seguido da abstração de um próton da histidina catalítica. ${ }^{28}$

Figura 8 - Alinhamento da sequência primária de aminoácidos das enzimas cruzaína, LmCPB2.8 $\triangle$ CTE, LmCPA e catepsina L humana. As regiões de identidade são destacadas em vermelho-escuro enquanto que as regiões similares são mostradas em vermelho claro. Diferenças na composição dos subsítios S2 e S3 podem ser exploradas na busca por inibidores seletivos

Figura 9 - Estrutura molecular do composto prototípico Neq0409 e os esqueletos base de seus análogos estruturais (A) $\mathrm{CF}_{3}$ - substituídos e (B) dipeptidil-azanitrilas estudados nesse trabalho. 25

Figura 10 - Representação esquemática da lei de Bragg. ${ }^{51-52}$...... 30

Figura 11 - A) Nessa representação geométrica da esfera de Ewald, o ponto P que toca a superfície da esfera produz um feixe difratado de módulo $\mathbf{s} / \lambda$. $\mathrm{O}$ vetor espalhamento de módulo $1 / \mathrm{d}_{\mathrm{hkl}}$ está relacionado ao vetor de onda incidente, ao vetor de onda refletido e ao comprimento de onda do feixe incidente. B) A direção do vetor espalhamento de módulo $1 / \mathrm{d}_{\mathrm{hkl}}$ é dada pela união da origem $(0,0,0)$ ao ponto $\mathrm{P}(1,0,1)$. A intersecção do ponto $\mathrm{P}(101)$ com a superfície da esfera satisfaz as condições de Bragg e Laue para a difração. ${ }^{53}$

Figura 12- Sequência proteica codificada pelo gene da pró-cruzaína nativa. O domínio catalítico é formado pelos resíduos 1 a 215 e os resíduos da cauda de histidina Nterminal e o pró-domínio estão numerados de -112 até -1 . 35

Figura 13 - Sequência proteica codificada pelo gene $L m C P B 2.8 \Delta C T E$ com o pródomínio e os resíduos da cauda de histidina N-terminal (-113 a -1) e o domínio catalítico (1 a 201)

Figura 14- Curvas progresso para enzima $L m C P B 2.8 \Delta C T E$ inibida por diferentes concentrações do Neq0687. [Z-Phe-Arg-AMC] $=25 \mu \mathrm{M},[$ LmCPB2.8 $\Delta \mathrm{CTE}]=7 \mathrm{nM} .41$ 
Figura 15- Mecanismo geral de inibição lentamente reversível para reações catalisadas por enzimas (E para a enzima livre, I para o inibidor e $\mathrm{S}$ para o substrato) 42

Figura 16- Mecanismo A de um inibidor de ligação lenta. 42

Figura 17- Mecanismo B de um inibidor de ligação lenta, envolvendo uma etapa de isomerização.

Figura 18- gráfico das taxas de velocidade obtidas no equilíbrio do estado estacionário, $\mathrm{v}_{0}$ e $\mathrm{v}_{\mathrm{i}}$, versus a [Neq0689] para a reação catalisada pela LmCPB2.8 $\Delta$ CTE. O inserto é um gráfico da constante de pseudo-primeira ordem $\mathrm{k}_{\mathrm{obs}}$ versus [Neq0689]. A relação linear obtida indica que esse inibidor através do mecanismo $\mathbf{A}$ de inibição lenta. 44

Figura 19 - Cristais obtidos a partir dos ensaios de co-cristalização da enzima LmCPB2.8 $\Delta$ CTE com o composto prototípico Neq0409. A e B corresponde aos cristais provindos da otimização da condição A (tabela 1, PACT D11). C e D corresponde aos cristais obtidos a partir da otimização da condição B (tabela 1, PACT H5).

Figura 20 - Em A1, cristais de morfologia cúbica referentes a LmCPB2.8 $\triangle \mathrm{CTE}$ cocristaliza com o inibidor MMTS obtidos a partir dos ensaios de triagem (condição C, tabela 1). Em A2 e A3 estão os cristais produzidos a partir da otimização desta condição. Em B1, é apresentado o cristal de morfologia hexagonal referente a enzima LmCPB2.8 $\Delta$ CTE co-cristalizada com o Neq0690 obtido a partir da condição D (tabela 1). B2 e B3 correspondem a otimização dessa condição para a produção de cristais gigantes.

Figura 21 - A: Teste de expressão da enzima cruzaína W.T. Trilhas 2 e 3 referem-se a amostras do lisado coletadas após $48 \mathrm{~h}$ e $60 \mathrm{~h}$ de expressão, respectivamente. As trilhas 7 e 8 referem-se à fração citosólica de amostras coletadas em 48h e 60h de expressão; B: Principais frações coletadas a partir da coluna de gel filtração. Destaca-se a cruzaína madura com aproximadamente $23 \mathrm{kDa}$ e fragmentos peptídicos provenientes da auto proteólise enzimática em aproximadamente $13 \mathrm{kDa}$ e $10 \mathrm{kDa}$. 50

Figura 22 - A) Teste de expressão da CPB2.8 $\triangle$ CTE de L. mexicana. CIT: fração solúvel do lisado; F19-F29: correspondem as frações coletadas a partir da coluna de Níquel; A: forma zimogênica da $\operatorname{LmCPB} 2.8 \Delta \mathrm{CTE}(\sim 36 \mathrm{kDa})$; B: forma intermediária da enzima de $\sim 27 \mathrm{kDa}$; C: forma madura da enzima de $\sim 23 \mathrm{kDa}$. B) Processo de ativação da pró- $L m \mathrm{CPB} 2.8 \Delta \mathrm{CTE}$. Trilhas 1 e 2 correspondem as amostras colhidas 
antes e depois do processo de ativação que correspondem, respectivamente, as formas zimogênica $(\sim 36 \mathrm{kDa})$ e madura $(\sim 23 \mathrm{kDa})$ da enzima.

Figura 23 - Identificação das formas zimogênica (A) e madura (B) da enzima $L m$ CPB2.8 $\Delta$ CTE, usando espectrometria de massas de alta resolução. Fragmentos peptídicos obtidos a partir do espectro de fragmentação MS/MS das bandas de $36 \mathrm{kDa}$ e $23 \mathrm{kDa}$ previamente tratadas com tripsina foram pesquisados contra a sequência primária da forma zimogênica da enzima. As regiões de correspondência são mostradas em vermelho.

Figura 24- Na esquerda, uma visão esquemática do esqueleto molecular base da dipeptidil-nitrilas e as posições onde as modificações estruturais foram realizadas. $\mathrm{Na}$ direita, o modo de interação do Neq0409 com a enzima cruzaína, destacando o posicionamento dos grupos em P1, P2 e P3 ocupando os subsítios S1, S2 e S3. ${ }^{69}$........ 54

Figura 25 - Ajuste dos dados na curva de Michaelis-Meten e valor de Ki do composto prototípico Neq409 contra cruzaína. O gráfico de Lineweaver-Burk evidencia o mecanismo competitivo de inibição desse inibidor.

Figura 26 - Ajuste dos dados cinéticos na curva de Michaelis-Meten e o valor de $\mathrm{K}_{\mathrm{i}}$ para o composto Neq0633 contra a catepsina L humana. O gráfico de Lineweaver-Burk evidencia seu mecanismo competitivo de inibição

Figura 27- formação do complexo reversível isotiossemicarbazida a partir do ataque da cisteína ativada ao nitrogênio nitrílico. $\mathrm{O}$ carbono nitrílico está ligado a um nitrogênio que possui um par de elétrons livre. Após o ataque do grupo tiolato, um trigonal planar isotiossemicarbazida aduto é formado. A estabilização por ressonância do complexo deixa o nitrogênio imínico mais básico e sua protonação pode justificar a grande diferença de afinidade entre as dipeptidil nitrilas e seus aza análogos. ${ }^{34}$

Figura 28 - Gráfico de Ramachandran para as estruturas do complexo LmCPBNeq0690 e LmCPB-MMTS. Para o complexo LmCPB-MMTS - 97\% dos resíduos estão em regiões favorecidas do diagrama, $2 \%$ em regiões permitidas e $1 \%$ em regiões desfavoráveis (Ala147 e Glu107). Para o complexo LmCPB-Neq0690 - 97\% dos resíduos estão em regiões favorecidas do diagrama, $2,8 \%$ em regiões permitidas e $0,2 \%$ em regiões desfavoráveis (Gly159). 70

Figura 29 - Padrão de Enovelamento da enzima LmCPB2.8 $\triangle$ CTE com destaque para os elementos helicoidais (em verde) e folhas- $\beta$ (em azul). As pontes dissulfeto estão 
coloridas de amarelo e a tríade catalítica composta pelos resíduos Cys26, His164 e Asn184 (em vermelho) está localiza em uma fenda entre os domínios L e R da enzima.

Figura 30- Alinhamento estrutural da $L m \mathrm{CPB} 2.8 \Delta \mathrm{CTE}$ com as enzimas cruzaína (PDB 3KKU), catepsina L (PDB 2XU1) e catepsina B (3AI8) com foco nos resíduos que compõe o subsítio S2. No quadrante inferior direito destaca-se o loop 196-199 da catepsina B, uma característica estrutural que estende o volume do subsítio S2 dessa enzima 73

Figura 31-Representação das enzimas LmCPB2.8 $\triangle$ CTE (A), catepsinas L humana (B), cruzaína (C), e catepsinas B humana (D) com base no potencial eletrostático de superfície. Em destaque o subsítio S2.

Figura 32 - MOB do Neq0690 em complexo com a $L m C P B 2.8 \Delta C T E$ com mapa de densidade eletrônica $2 \mathrm{~F}_{\text {obs }}-\mathrm{F}_{\text {calc }}$ contornados ao nível de $1 \sigma$. O inibidor se liga de forma covalente a cisteína catalítica (Cys26). As ligações de hidrogênio são representadas por pontilhados de cor preta 76

Figura 33 - Sobreposição do MOB do Neq0690 com o análogo estrutural ligado a catepsina L (código PDB 3HHA) em superfície de Van der Waals da LmCPB2.8 $\triangle$ CTE. Átomos de carbono estão coloridos em verde para o composto Neq0690 e em azul claro para o análogo. Os principais aminoácidos da $L m C$ PB2.8 $\Delta$ CTE estão numerados. 77

Figura 34- A reversibilidade do Neq0690 (em vermelho) para LmCPB2.8 $\Delta$ CTE foi testada medindo-se a recuperação da atividade enzimática após uma rápida e extensa diluição do complexo enzima-inibidor. O inibidor foi incubado a uma concentração 10x maior que o seu valor de $\mathrm{K}_{\mathrm{i}}$ com $0,7 \mu \mathrm{M}$ de LmCPB2.8 $\Delta$ CTE (100x a concentração requerida para o ensaio de atividade enzimática) por 30 minutos. A mistura foi, então, diluída por um fator de 100x no tampão de reação, contendo o substrato Z-Phe-ArgAMC na concentração final de $7 \mu \mathrm{M}$. Como controles foram usados o Neq0570 (reversível - em verde) e o inibidor E-64 (irreversível - em preto). A recuperação da atividade enzimática após a diluição do complexo Neq0690-LmCPB sugere um mecanismo de inibição reversível para o Neq0690. 78

Figura 35 - Mecanismo de inibição de cisteíno proteases pelo MMTS. A reação pode ser revertida pela adição de agentes redutores como o DTT. ${ }^{84-63}$ 79 
Figura 36 - Estrutura cristalográfica da enzima LmCPB2.8 $\triangle \mathrm{CTE}$ em complexo com o MMTS. O mapa diferença $\mathrm{F}_{\mathrm{obs}}-\mathrm{F}_{\text {calc }}$ à $3 \sigma$ é mostrado para contornos positivos (em verde) e negativos (em vermelho). Em azul é exibido o mapa de densidade $2 \mathrm{~F}_{\mathrm{o}}-\mathrm{F}_{\mathrm{c}}$ contornados a $1 \sigma$. A figura $\mathbf{A}$ mostra os principais resíduos do sítio ativo, com destaque a alcanotiolação dos resíduos Cys26 e Cys205 pelo inibidor MMTS. A figura B mostra a cisteína catalítica em dois estados: livre e covalentemente ligada ao MMTS com uma ocupação de $50 \%$. A figura C mostra o resíduo de Cys205 covalentemente ligado ao MMTS. 80

Figura 37 - Sobreposição estrutural dos complexos LmCPB-Neq0690 (em dourado) e LmCPB-MMTS (em prata). A ligação do MMTS ao resíduo de aminoácido Cys205(B) altera a conformação da Tyr210(B), comprometendo a estrutura do subsítio S2 da enzima $L m C P B 2.8 \Delta$ CTE.

Figura 38 - Sobreposição estrutural dos complexos LmCPB-Neq0690 (em dourado) e LmCPB-MMTS (em prata). A figura destaca a ausência da alça composta pelos resíduos TYR149-LYS160 no complexo LmCPB-MMTS. A alta flexibilidade da extremidade formada pode justificar a conformação proibitiva adotada pelo resíduo Met147(B) observada no diagrama de Ramachandran.

Figura 39 - Sobreposição estrutural dos complexos $L m$ CPB-Neq0690 (em dourado) e LmCPB-MMTS (em prata). A figura destaca as modificações estruturais causadas pela interação do íon sulfato com dois seguimentos da cadeia polipeptídica do complexo LmCPB-MMTS formados pelos resíduos 109-111 e 85-86. Essa perturbação estrutural é responsável pelas alterações conformacionais do resíduo Glu107(B) observadas no diagrama de Ramachandran. O inserto detalha padrão de interação de ligação de hidrogênio entre o íon sulfato e os resíduos de aminoácidos Thr86, His85, Gly111, Val110 e V109.

Figura 40 - Detalhamento do padrão de interação por ligação de hidrogênio entre o íon sulfato e os resíduos aminoácidos His164, Trp27 e Cys26 presentes no subsítio S1' da $L m \mathrm{CPB} 2.8 \Delta \mathrm{CTE}$. 83 


\section{LISTA DE TABELAS}

Tabela 1- Condições de cristalização identificadas nos experimentos de triagens com Kits comercialmente disponíveis.

Tabela 2 - Valores de pKi para cruzaína, catepsina L e $1 \mathrm{mCPB} 2.8 \Delta \mathrm{CTE} /{ }^{\mathrm{apKi}}=-$ $\log (\mathrm{Ki} / \mathrm{M}){ }^{\text {bIncert }} .=\mathrm{desvpad} /\left(\mathrm{Ki}^{*} \ln (10)\right)$

Tabela 3 - Valores de pKi para cruzaína, catepsina L e LmCPB2.8 $\Delta$ CTE / ${ }^{\mathrm{apKi}}=-$ $\log (\mathrm{Ki} / \mathrm{M}) ;{ }^{\text {bIncert }}=\operatorname{desvpad} /\left(\mathrm{Ki}^{*} \ln (10)\right)$

Tabela 4 - Valores de pKi para cruzaína, catepsina L e LmCPB2.8 $\Delta$ CTE / ${ }^{\text {apKi }}=-$ $\log (\mathrm{Ki} / \mathrm{M}) ;{ }^{\text {bIncert }}=\operatorname{desvpad} /\left(\mathrm{Ki}^{*} \ln (10)\right)$

Tabela 5 - Valores de kon e koff para todos os aza-análogos testados contra as enzimas cruzaína, catepsina L humana e LmCPB2.8 $\Delta$ CTE.

Tabela 6 - Estatísticas referentes à coleta de dados e ao refinamento dos modelos para a LmCPB2.8 $\Delta$ CTE em complexo com os inibidores Neq0690 e MMTS.

Tabela 7- Composição dos subsítios $\mathrm{S} 3$, S2, S1 e S1' das enzimas LmCPB2.8ACTE, Cruzaína, HsCatepsina L e HsCatepsina B 


\section{SUMÁRIO}

1. INTRODUÇÃ

1.1. As cisteíno proteases da família da papaína .................................................... 15

1.2. Cisteíno proteases como alvos enzimáticos para o tratamento da doença de

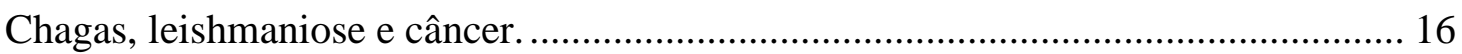

1.3. A Nitrila como "warhead" de inibidores de cisteíno proteases ......................... 22

1.4. Planejamento de fármacos baseado em hipótese e as classes de inibidores

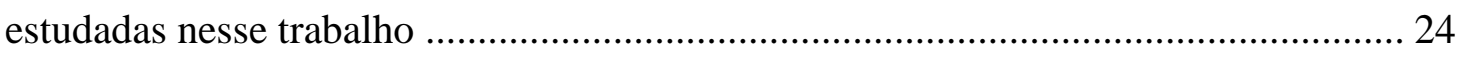

1.5. Cristalização e determinação estrutural das estruturas cristalográficas dos complexos LmCPB-Neq0690 e $L m$ CPB-MMTS ...................................................... 26

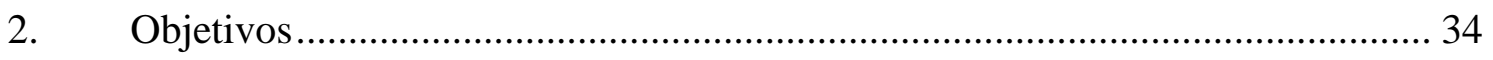

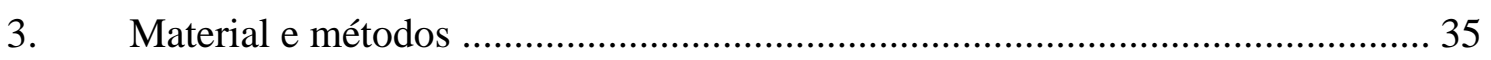

3.1. Construção da enzima cruzaína e $L m$ CPB2.8 $\Delta$ CTE usadas nesse trabalho ....... 35

3.2. Protocolo de expressão das enzimas estudadas nesse trabalho ......................... 36

3.3. Ativação das enzimas cruzaína (W.T) e $L m$ CPB2.8 4 CTE .............................. 37

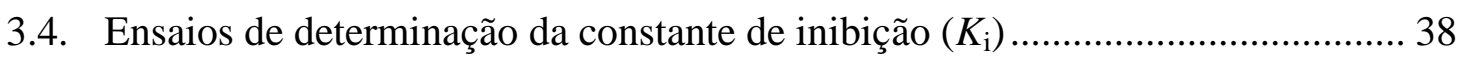

3.5. Caracterização cinética de inibidores através da análise da curva progresso ..... 39

3.5.2. Determinação dos parâmetros cinéticos de inibidores de ligação lenta ............. 40

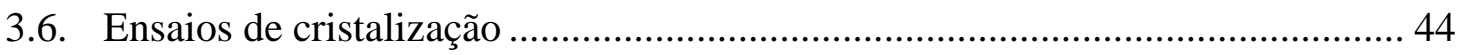

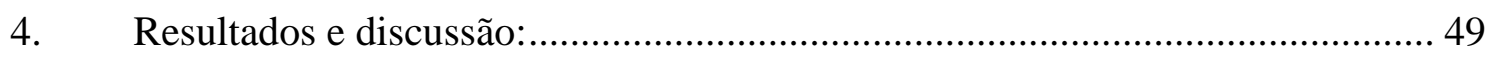

4.1. Expressão, ativação e purificação da enzima cruzaína W.T............................... 49

4.2. Expressão, purificação e ativação da enzima $L m C P B 2.8 \Delta C T E$ de L. mexicana 50

4.3. Estudos de inibição enzimática.

4.3.1. Avaliação das relações estrutura-atividade (SAR) para os derivados dipeptidil nitrílicos estudados nesse trabalho.

4.3.2. Avaliação das relações estrutura-atividade (SAR) para os derivados $\mathrm{CF}_{3^{-}}$ substituídos 
4.3.3. Avaliação das relações estrutura-atividade (SAR) de derivados dipeptidil azanitrílicos. 65

4.4. Elucidação estrutural e análise do modo de interação dos inibidores Neq0690 e MMTS. 68

4.4.1. Qualidade das estruturas cristalográficas e aspectos gerais ................................ 68

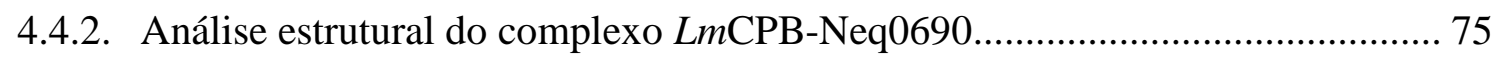

4.4.3. Análise estrutural do complexo LmCPB-MMTS …........................................ 78

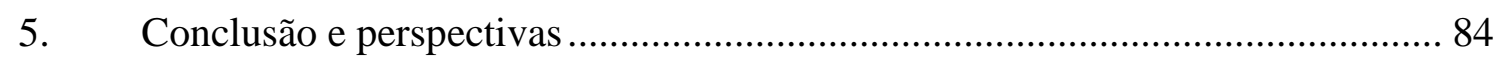

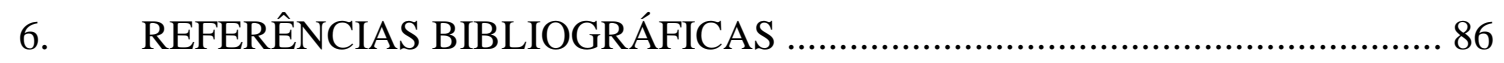




\section{INTRODUÇÃO}

\subsection{As cisteíno proteases da família da papaína}

As cisteíno proteases da família da papaína são, em sua maioria, endopeptidases que hidrolisam a ligação amida através de uma tríade catalítica formada pelos resíduos cisteína, histidina e asparagina (algumas vezes substituída pelo aspartato). Um quarto resíduo, a Gln19, está envolvido na estabilização da cavidade do oxiânio que se forma durante a catálise, sendo considerado um resíduo acessório. Estruturalmente, essa família de enzimas possui dois domínios: o primeiro é principalmente helicoidal (domínio L) e o segundo é composto por folhas $\beta$ antiparalelas (domínio $\mathrm{R}$ ). O sítio catalítico está localizado em uma fenda formada entre os dois domínios principais, onde se encontram os resíduos de aminoácidos envolvidos no processo catalítico, ordenados sequencialmente para a papaína como Gln19, Cys25, His159 e Asn175 (Figura 2). ${ }^{1}$

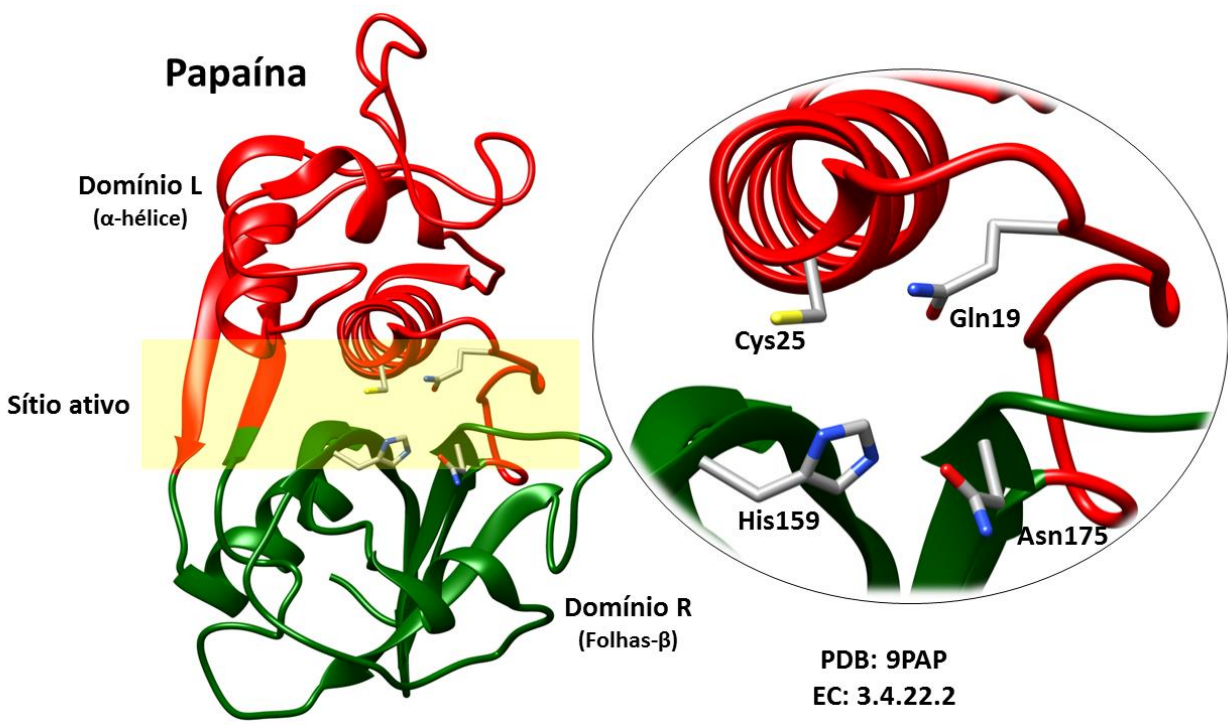

Figura 1- Estrutura cristalográfica da papaína (PDB: 9PAP) ${ }^{1}$

De forma geral, o sítio catalítico dessa família de enzimas pode ser dividido em sete subsítios de acordo com a classificação de Schechter e Berger. Assim, na direção C-terminal existem quatro subsítios (S4, S3, S2, S1) que interagem com os resíduos de aminoácidos do substrato peptídico nas posições P4, P3, P2, P1, enquanto que na direção N-terminal existem três subsítios (S1', S2' e S3') que acomodam os respectivos resíduos de aminoácidos P1', P2' e P3' do substrato peptídico, conforme representado na figura $2 .^{2-3}$ 


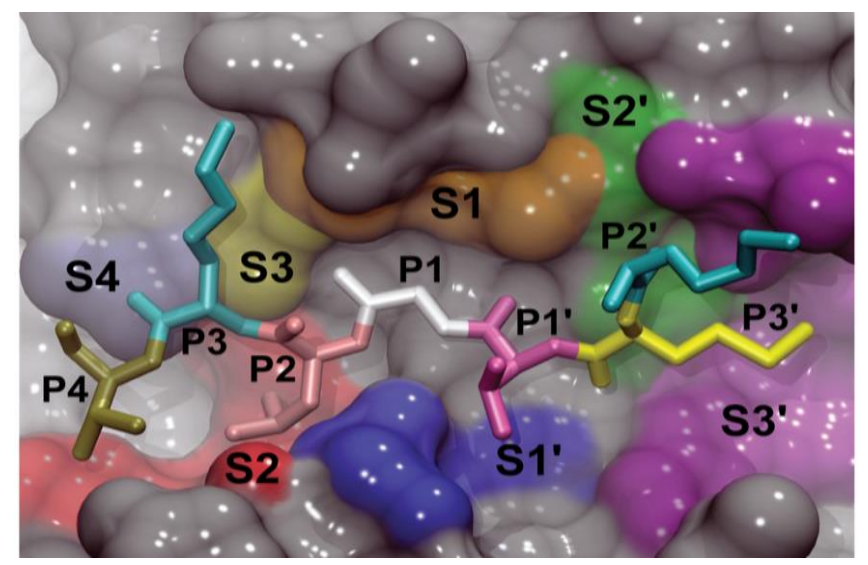

Figura 2 - Representação do sítio catalítico da cruzaína (em superfície de Van der Walls) colorido segundo a localização de cada subsítios de ligação. O peptídeo mostrado é um substrato da catepsina k (extraído da estrutura de PDB 1BY8), uma vez que, até o momento, não há estrutura cristalográfica da cruzaína ligada a substratos peptídicos disponíveis no PDB. ${ }^{2}$

A grande maioria das proteases da família da papaína é inicialmente expressa como uma pró-proteína inativa, sendo necessária a clivagem da sua porção N-terminal para a sua ativação. ${ }^{3}$ Esse processo ocorre no interior do complexo de Golgi em condições especificas de concentração, $\mathrm{pH}$ e temperatura.

Estudos recentes têm fornecido informações surpreendentes acerca da bioquímica e funções celulares dessa família de enzimas. Nos seres humanos, as catepsinas são geralmente encontradas no interior dos lisossomos e estão envolvidas em diferentes processos in vivo como remodelamento ósseo (catepsina k), reconhecimento imunológico (catepsinas S, L, V e F), homeostase epidérmica, apoptose, processamento de proteínas intracelulares (catepsina C, B e L) e de pró-hormônios. ${ }^{4-5}$ Além disso, existe uma vasta literatura que indica a participação de cisteíno proteases na patogênese de muitas doenças parasitárias, onde atuam principalmente no processamento de nutrientes e como fatores de virulência. ${ }^{6-7}$ Por esses motivos, vários representantes dessa classe são alvos validados para o tratamento de doenças como câncer, osteoporose, distúrbios da imunidade, leishmaniose, malária e a doença de Chagas.

\subsection{Cisteíno proteases como alvos enzimáticos para o tratamento da doença de Chagas, leishmaniose e câncer.}

Vários estudos realizados na década de 90 demonstram a eficácia terapêutica de inibidores de cisteíno proteases (figura 3) em modelos experimentais de doenças como o câncer, doença de Chagas e leishmaniose..$^{7-8}$ 
<smiles>CN1CCN(C(=O)N[C@@H](Cc2ccccc2)C(=O)N[C@@H](/C=C/S(=O)(=O)c2ccccc2)CCc2ccccc2)CC1</smiles>

(1)

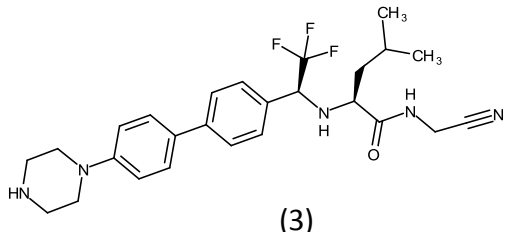

(3)

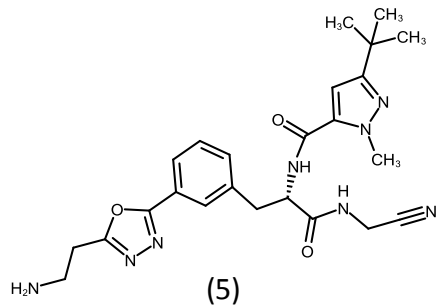

(5)<smiles>COc1ncccc1Nc1nc(C#N)nc(NC2CCCCC2)n1</smiles>

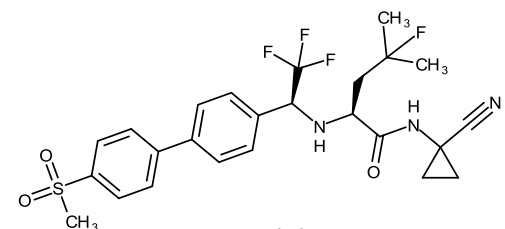

(2)

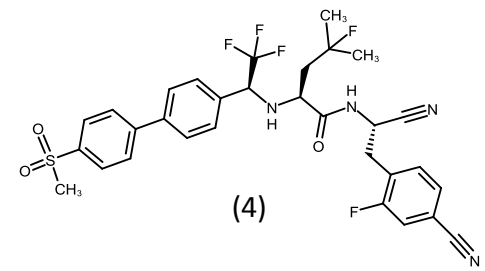<smiles>COc1nc(C#N)nc(N(Cc2ccc3c(c2)OCO3)C2CCCCC2)n1</smiles><smiles>C=C([C@@H](CC(C)C)NC(=O)c1ccc2c(c1)OCCO2)N(C)C#N</smiles>

(8)

Figura 3 - Inibidores de cisteíno proteases

O K777 (1, figura 3) originalmente caracterizado pelo Sandler Center for Research in Tropical Parasitic Disease na Universidade da Califórnia, São Francisco foi considerado o mais promissor inibidor da cruzaína já desenvolvido. Esse inibidor se liga irreversivelmente a cruzaína através da adição nucleofílica da cisteína catalítica ao grupo vinil sulfona presente em sua estrutura. ${ }^{9}$ Em estudos in vivo realizados em modelos de camundongos infectados com T. cruzi, o K777 foi capaz de bloquear as etapas de diferenciação celular e eliminar a parasitemia nos animais tratados. ${ }^{6-7}$ Engel $e$ colaboradores descreveram as principais modificações ultra estruturais relacionadas à ação desse composto contra a forma epimastigota do T. cruzi (figura 4). Tais modificação foram motivadas pelo acúmulo de prócruzaína no complexo Golgi, decorrente do bloqueio de seu auto processamento catalítico. ${ }^{10}$ Embora o K777 não tenha sido capaz de promover a cura parasitológica em modelos de doença aguda em cães, uma redução significativa ao dano cardíaco induzido pelo T.cruzi foi 
observado. Infelizmente, o desenvolvimento desse inibidor foi interrompido após ser constatada uma baixa tolerabilidade a dose terapêutica nos estudos pré-clínicos com primatas e cães. $^{11}$

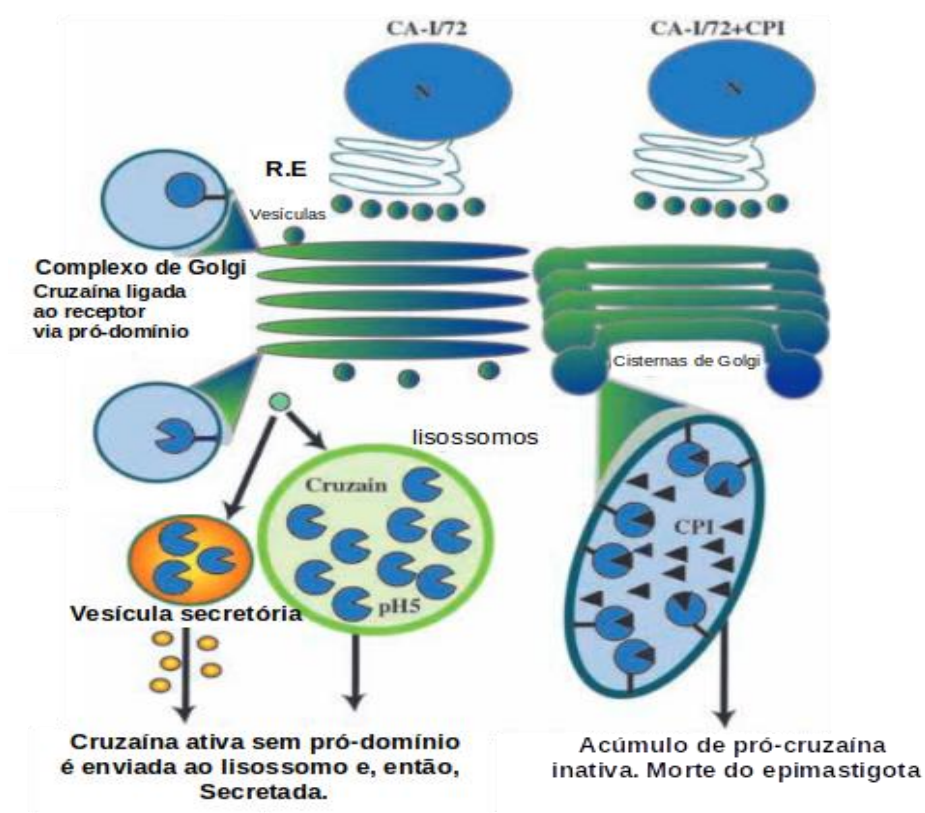

Figura 4 -Modelo para o processamento e tráfego da enzima cruzaína na forma epimastigota do T. cruzi, na presença (CA1/72 + CPI) e ausência (CA-1/72) de um inibidor de cisteíno protease. A pró-cruzaína ativada no complexo de Golgi se dissocia de seus receptores e é acumulada no interior dos lisossomos/reservossomos. Em condições normais, a enzima madura é parcialmente secretada no meio através de vesículas secretórias. A adição de uma concentração letal de um inibidor de cisteíno protease paralisa o processamento natural da pró-cruzaína nas cisternas de Golgi, conduzindo a morte parasitária por choque osmótico. ${ }^{10}$

Um mecanismo de ação bastante similar foi observado quando inibidores de cisteíno proteases foram testados contra Leishmania major. Esses compostos não somente provocaram a morte do parasito in vitro, como também curaram a infecção em células do tipo BALB/c de camundongos. Neste caso, o acúmulo de material proteico não-processado, no megassomo e no bolsão flagelar do parasito, foi constatada para todos os inibidores de cisteíno proteases que atuavam em enzimas estruturalmente semelhantes às catepsinas L e B. ${ }^{8}$ Embora o gênero Leishmania expressa três famílias de genes de cisteíno proteases ( $c p a, c p b$ e $c p c$ ), estudos de validação genética realizados em $L$. mexicana fornecem evidências importantes do envolvimento de cisteíno proteases de classe $\mathrm{b}(c p b)$ na virulência do parasito (figura 5). Mutantes de L. mexicana produzidas pela dupla deleção dos genes $c p a$ e $c p b(\Delta \mathrm{cpa} / \mathrm{cpb})$ apresentaram uma grande redução na capacidade de infecção in vitro quando comparadas às cepas selvagens. Mottram e colaboradores demostraram que a reexpressão da isoforma CPB2.8 foi capaz de restaurar a infectividade em macrófagos para os níveis anteriormente 
observados na cepa selvagem, sugerindo que essa enzima poderia modular a capacidade infectiva do parasito. ${ }^{12-13}$ Outros estudos demonstraram que inibidores de diferentes isoformas da CPB reduziram a virulência de Leishmania mexicana em modelos animais e evitaram os danos patológicos causados pela infecção sem, contudo, produzirem toxicidade a curto prazo nos animais tratados. ${ }^{14-8}$
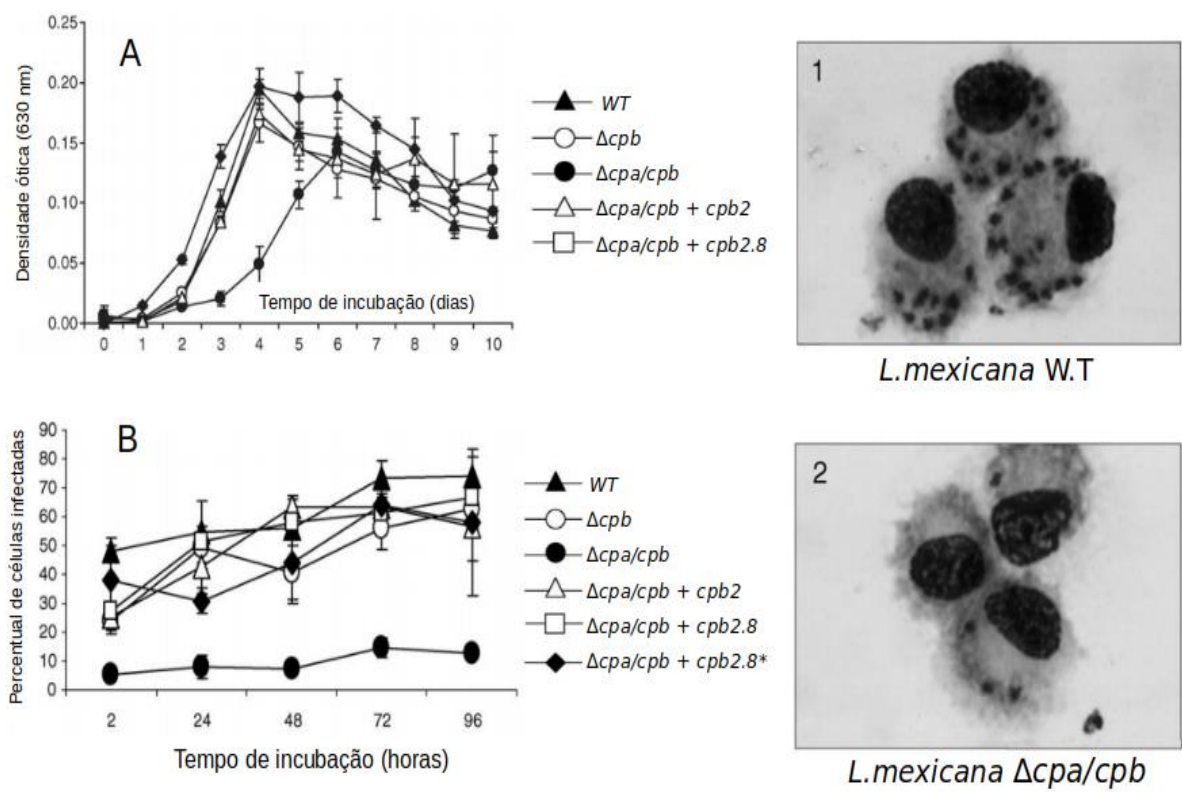

Figura 5 - (A) A dupla deleção dos conjuntos de genes cpb e cpa $(\Delta \mathrm{cpa} / \mathrm{cpb})$ alterou a cinética de crescimento in vitro da forma promastigotas de L. mexicana. Mutantes deficientes de cada conjunto de genes isolados ( $\Delta$ cpa e $\Delta$ cpb) não apresentaram diferenças fenotípicas significativas quando comparadas com a cepa W.T. Além disso, a restituição do crescimento normal após a reinserção de genes específicos da família CPB (cpb2 e cpb2.8) confirma que a ausência dos genes da família CPA não é suficiente para alterar o curso da infecção pelo parasito. A diminuição da infectividade da cepa contendo a dupla deleção $(\Delta \mathrm{cpa} / \mathrm{cpb})$ em macrófagos humanos é mostrada no gráfico B. O reestabelecimento da capacidade infectiva, aos níveis observados na cepa WT, pela reinserção dos genes cpb2 ou cpb2.8 demonstra o papel dessas cisteíno proteases na patogenicidade de L. mexicana. Pode-se observar os campos representativos (x1000) de macrófagos U-937 infectados por L. mexicana W.T (figura 1) e a cepa contendo a dupla deleção $\Delta \mathrm{cpa} / \mathrm{cpb}$ (figura 2). ${ }^{15}$

Outro cenário onde cisteíno proteases possuem um especial interesse envolve os estudos na área do câncer e metástase. Várias enzimas proteolíticas da família da papaína estão relacionadas com a progressão de tumores malignos, em especial a catepsina L (figura 6). ${ }^{16}$ Essa enzima está presente no interior dos lisossomos onde participa do processamento de proteínas intracelulares. ${ }^{17}$ Contudo, células tumorais superexpressam a catepsina L e a secretam para meio extracelular, onde atua na proteólise de componentes da matriz extracelular e membrana basal como a laminina, colágeno (tipos I, II e IV), fibronectina e elastina. A E-caderina, uma proteína de adesão celular, é proteoliticamente processada pela catepsina L e sua propriedade adesiva é significantemente reduzida durante a metástase. ${ }^{18-19}$ 
Além disso, a catepsina L é responsável pela amplificação da cascata proteolítica, ativando pró-formas de outras proteases associadas à progressão de tumores como o ativador de plasminogênio uroquinase e catepsina D. ${ }^{20-21}$

Uma isoforma nuclear da catepsina L está envolvida no processamento proteolítico e ativação do fator de transcrição $\mathrm{CDP} / \mathrm{Cux}$, fortemente associado com câncer de mal prognóstico. Esse fator de transcrição exibe uma maior afinidade ao DNA após ser enzimaticamente hidrolisado, o que resulta em uma vantagem replicativa e metastática para as células tumorais pela ativação de genes relacionados a transição epitelial-mesenquimal. Esse processo permite que uma célula epitelial polarizada, que normalmente interage com a membrana basal por meio de sua superfície, sofra modificações bioquímicas e morfológicas que resultam na aquisição de um fenótipo de célula mesenquimal, cuja a capacidade de migração, invasão e resistência a apoptose são aumentadas. Outra função importante da catepsina L nuclear envolve sua ação proteolítica sobre o 53BP1, um regulador da resposta celular ao dano do DNA que protege a célula da ação letal promovida pelo acúmulo de DNA não reparado. Isso melhora a capacidade de reparo do DNA em células tumorais, atribuindo a elas resistência a radiação e a ação de agentes quimioterápicos como a cisplatina, inibidores de PARP e mitomicina $\mathrm{C}$ (figura 6). ${ }^{22}$ Estudos em modelos pré-clínicos mostraram que inibidores da catepsina L são capazes de retardar o crescimento tanto de tumores recentemente implantados quanto aqueles já estabelecidos. ${ }^{23}$ Esses compostos atenuam a reabsorção óssea e hipercalcemia relacionadas ao câncer de osso, bem como reduzem significantemente a disseminação metastática. ${ }^{24}$ 


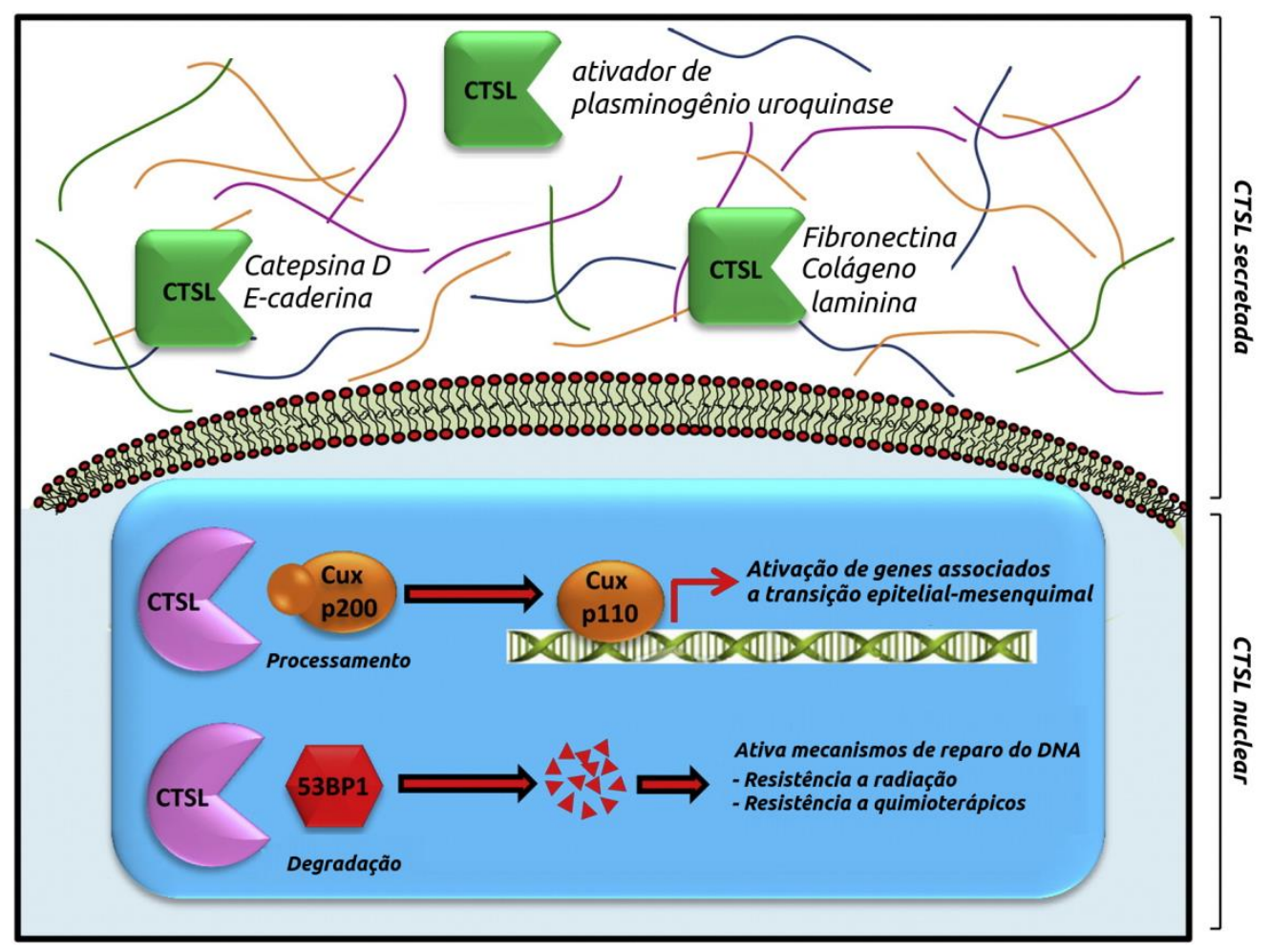

Figura 6- Papéis distintos da catepsina L secretada e nuclear na disseminação metastática de células tumorais. A catepsina L secretada atua através da degradação de moléculas de adesão celular, proteínas da matriz extracelular, bem como a ativação de outras proteases associadas a metástase. A catepsina L nuclear ativa a transcrição de genes relacionados a transição epitelial-mesenquimal e também confere resistência terapêutica via degradação do 53BP1. ${ }^{16}$

Embora esses e vários outros estudos indiquem como promissor o uso de inibidores de cisteíno proteases como alternativa terapêutica para várias doenças em humanos, algumas questões permanecem ainda não resolvidas. A primeira delas refere-se à estratégia de inibição adotada na maioria dos trabalhos publicados na literatura que envolve, frequentemente, o uso de inibidores covalente irreversíveis como cetonas, vinil sulfonas, halometil cetonas, diazocetonas, epóxidos entre outros. Esses grupos eletrofílicos altamente reativos são conhecidos genericamente como warheads e agem através de um mecanismo inespecífico de ação, envolvendo modificações covalentes de resíduos nucleofílicos presentes no sítio ativo de várias enzimas. Além disso, esse tipo de mecanismo de inibição tem sido evitado, uma vez que está relacionado a sérios problemas farmacocinéticos, imunogenicidade e ao efeito off target. $^{25-26}$

Uma alternativa ao uso de inibidores irreversíveis surgiu com a descoberta de novos "warheads" capazes de se ligar de forma covalente reversível a cisteína catalítica. Dentre esses grupos, destaca-se a nitrila que tem sido usada como grupo de reconhecimento químico em inibidores sintetizados no grupo NEQUIMED. ${ }^{27}$ 


\subsection{A Nitrila como "warhead" de inibidores de cisteíno proteases}

Nitrilas (figura 3) se ligam de forma covalente reversível ao grupo tiol de cisteíno proteases através de um mecanismo concertado que conduz a formação de um intermediário tioimidato (figura 8). ${ }^{27}$

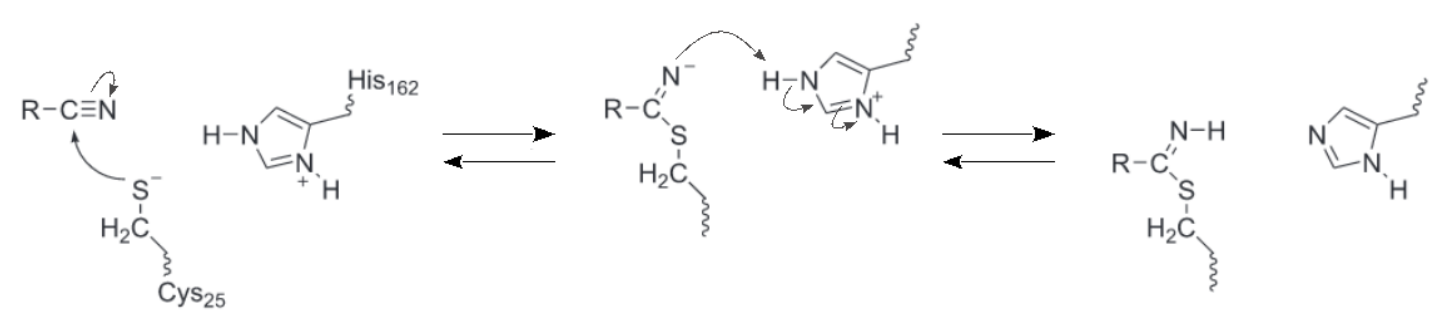

Figura 7 - Mecanismo de inibição covalente-reversível de cisteíno proteases por inibidores nitrílicos. O mecanismo concertado envolve a adição nucleofílica da cisteína ativada ao carbono nitrílico seguido da abstração de um próton da histidina catalítica. ${ }^{28}$

O odanacatib (2, figura 3), um potente inibidor da catepsina $\mathrm{K}$ desenvolvido pela Merck \& Co alcançou a fase clínica III para o tratamento de osteoporose em mulheres pósmenopausa. Esse inibidor possui o grupo aminonitrila como warhead, mas seu desenvolvimento foi interrompido após a constatação de um aumento estatisticamente relevante dos casos de acidente vascular cerebral durante os estudos clínicos. ${ }^{29}$ Análogos estruturais do odanacatib foram identificados como inibidores potentes da enzima cruzaína e a atividade antiparasitária in vivo dos compostos $\mathbf{3}$ e $\mathbf{4}$ foram reportadas em modelo murino de infecção aguda pelo T.cruzi. ${ }^{30}$

A catepsina $\mathrm{L}$ também tem sido explorada como alvo de inibidores nitrílicos. O composto 5 (figura 3 ) foi encontrado como sendo o mais potente da literatura com $\mathrm{IC}_{50}$ de 1,26 nM. ${ }^{31}$ Além disso, o composto 6 (figura 3) contendo o grupo 1,3,5-triazina-2-carbonitrila foi ativo contra catepsina $\mathrm{L}\left(K_{\mathrm{i}}=9 \mathrm{nM}\right)$ e a rodesiana $\left(K_{\mathrm{i}}=2 \mathrm{nM}\right) .^{32}$ Esse mesmo grupo eletrofílico foi também observado no composto $\mathbf{7}$, recentemente descrito como inibidor da $L m$ CPB2.8 $\Delta$ CTE $\left(K_{\mathrm{i}}\right.$ de $570 \mathrm{nM}^{33}$

As azanitrilas têm emergido como uma classe promissora de inibidores de cisteíno proteases. Esses compostos surgem da substituição isoeletrônica dos grupos $\mathrm{C}_{\alpha} \mathrm{H}$ de aminonitrilas por átomos de nitrogênio que, por razões de estabilidade química, são geralmente metilados. ${ }^{34}$ Esses inibidores agem através de um mecanismo tempo-dependente e são classificados como inibidores de ligação lenta (do inglês, slow binding). ${ }^{35}$ Vários estudos 
têm demonstrado a atividade dessa classe de compostos contra catepsinas humanas. ${ }^{34-36}$ Recentemente, no entanto, uma série de 21 aza derivados foi testada contra a enzima cruzaína e o composto 8 (figura 3 ) se mostrou o mais potente da série com um $\mathrm{IC}_{50}$ de $0,34 \mathrm{nM}^{37}$

Esses e outros estudos têm indicado que inibidores contendo o grupo nitrila como warhead podem ser empregados no contexto de doenças como leishmanioses ( $L m \mathrm{CPB} 2.8 \Delta \mathrm{CTE}$ ), doença de Chagas (cruzaína) e câncer (catepsina L). Isso se deve ao alto grau de similaridade estrutural existente entre esses alvos enzimáticos que, embora compartilhem o mesmo mecanismo catalítico, apresentam especificidades distintas por seus substratos naturais. $\mathrm{O}$ alinhamento da sequência primária de aminoácidos da LmCPB2.8 $\Delta$ CTE, $L m C P A$, cruzaína e catepsina L humana (figura 8) revela que os subsítios S1 e S1' são altamente conservados. No entanto, pequenas diferenças na composição dos subsítios S2 e S3 podem ser exploradas na busca por seletividade entre esses alvos. O Grupo de Química Medicinal/IQSC/USP tem se dedicado ao estudo do mecanismo covalentereversível de inibidores nitrílicos em cisteíno proteases. Acreditamos que esses compostos podem ser utilizados como sondas químicas para explorar pequenas diferenças no processo de reconhecimento bimolecular, fornecendo informações úteis para o desenvolvimento de inibidores mais potentes e seletivos. 
$\mathrm{S}_{1}$

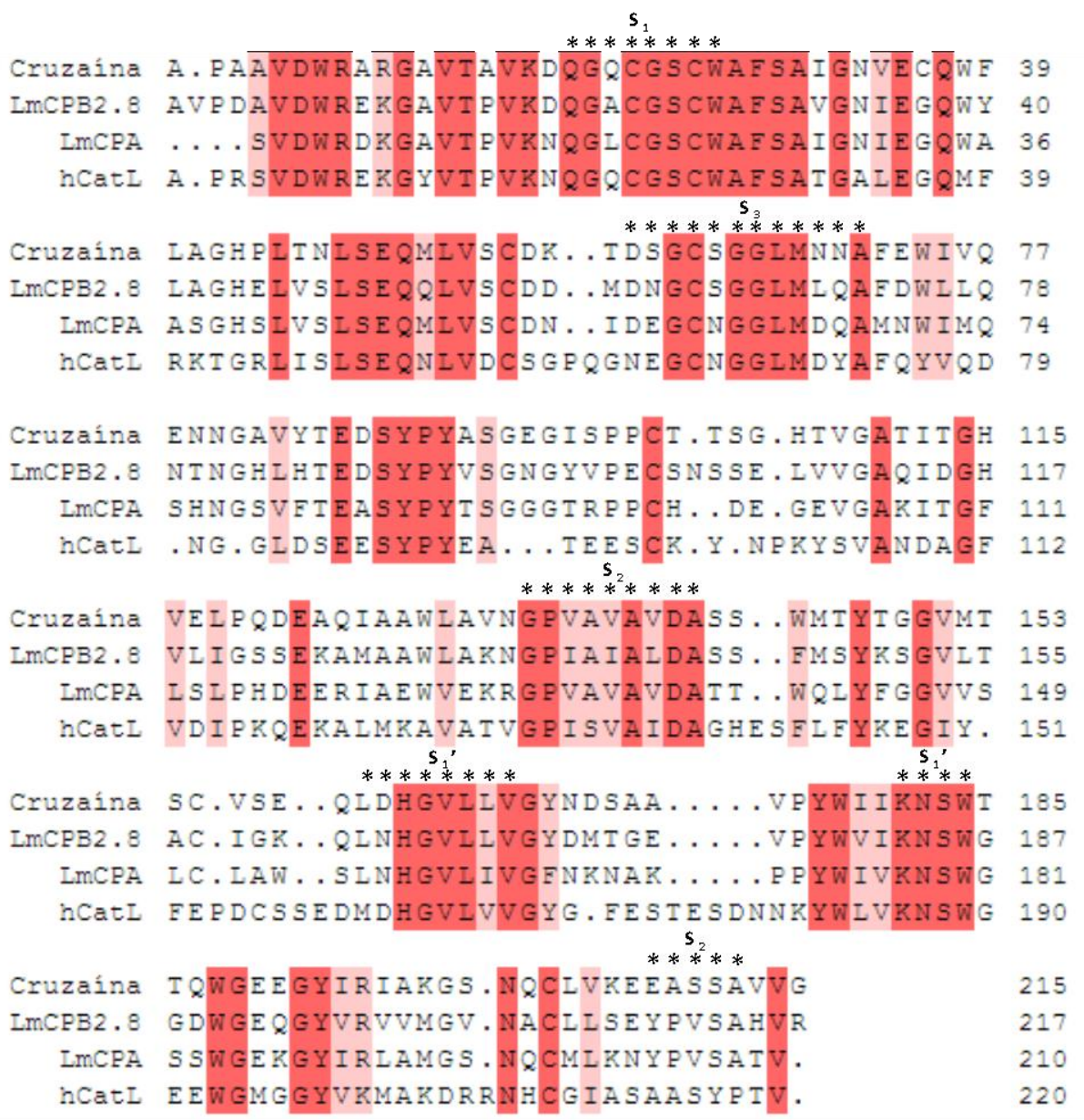

Figura 8 - Alinhamento da sequência primária de aminoácidos das enzimas cruzaína, LmCPB2.8 $\Delta$ CTE, LmCPA e catepsina L humana. As regiões de identidade são destacadas em vermelho-escuro enquanto que as regiões similares são mostradas em vermelho claro. Diferenças na composição dos subsítios S2 e S3 podem ser exploradas na busca por inibidores seletivos.

\subsection{Planejamento de fármacos baseado em hipótese e as classes de inibidores estudadas nesse trabalho}

A otimização de um inibidor enzimático, especialmente em termos de sua potência e seletividade, envolve um processo cíclico e interativo de planejamento, síntese e avaliação biológica de seus análogos estruturais. ${ }^{38} \mathrm{O}$ objetivo inicial é identificar os determinantes estruturais da ação de um inibidor frente ao seu alvo enzimático através do estabelecimento de uma relação entre a estrutura química e a atividade biológica (SAR). Dessa forma, é possível desenvolver hipóteses relacionadas as interações essenciais que esse ligante estabelece com a enzima alvo. Essas hipóteses orientam um novo ciclo de planejamento e modificações estruturais, conduzindo, em última instância, o desenvolvimento de análogos com propriedades aperfeiçoadas. Muitas vezes esse processo de otimização é subsidiado com informações estruturais fornecidas por técnicas como RMN, modelagem computacional e cristalografia de Raios- $\mathrm{X}$, sendo essa última a mais utilizada na atualidade. A cristalografia de 
raios-X possibilita a determinação do modo de interação (do inglês MOB, mode of binding) de um ligante frente a seu alvo, fornecendo uma descrição precisa da posição, orientação, bem como o padrão de interações que ele estabelece no interior do sítio de ligação. Dentre os alvos estudados neste trabalho, apenas a $L m \mathrm{CPB} 2.8 \Delta \mathrm{CTE}$ não possui estrutura cristalográfica disponível no PDB (do inglês, Protein Data Bank) até o momento. Isso representa um fator extremamente limitante para o uso de estratégias de planejamento baseadas na estrutura do alvo (SBDD, do inglês Structure -Based Drug Desing) geralmente empregadas nas etapas de otimização de inibidores.

As dipeptidil nitrilas são amplamente estudadas como inibidores covalentes reversíveis de catepsinas humanas e foram usadas como ponto de partida nesse trabalho. $\mathrm{O}$ Neq0409 (figura 9), um potente inibidor de catepsinas K e S, foi escolhido como composto prototípico devido à versatilidade de seu esqueleto base, onde as posições P1, P2 e P3 podem ser facilmente modificadas através de rotas sintéticas bem estabelecidas. A inserção de diferentes substituintes nessas posições permite explorar interações nos subsítios S1, S2 e S3 de cisteíno proteases.

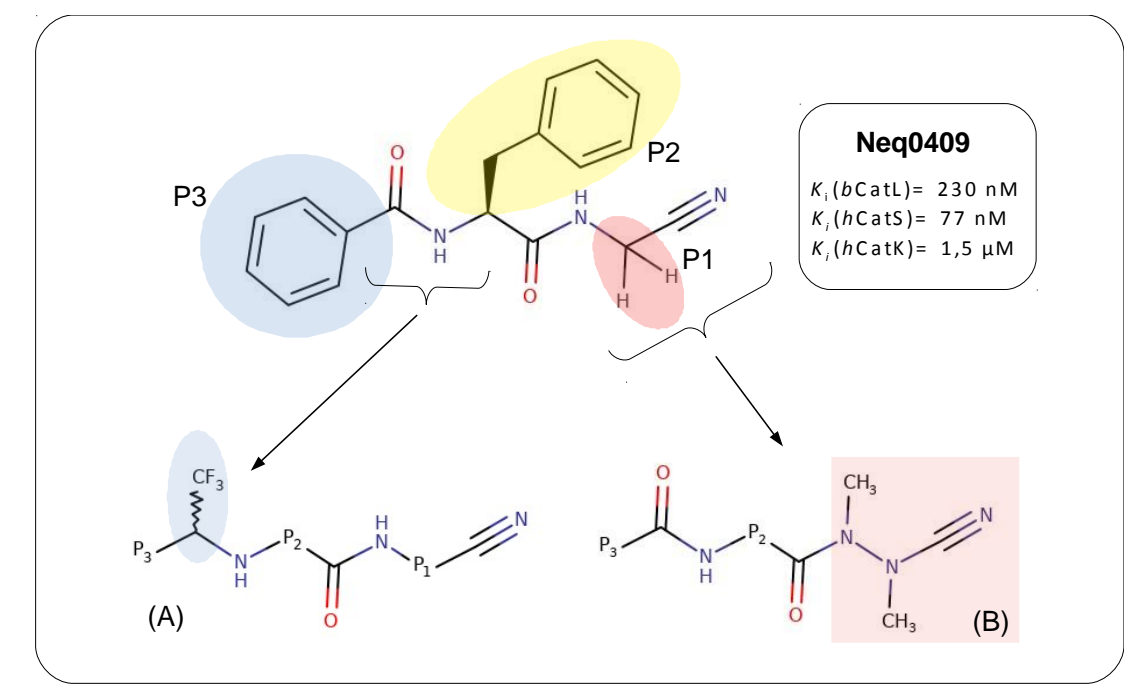

Figura 9 - Estrutura molecular do composto prototípico Neq0409 e os esqueletos base de seus análogos estruturais $(A) \mathrm{CF}_{3^{-}}$ substituídos e (B) dipeptidil-azanitrilas estudados nesse trabalho.

Além disso, para diminuir o caráter peptídico desses inibidores, a substituição bioisostérica da ligação amida (entre as posições P2 e P3 do esqueleto base) pelo grupo trifluoroetilamina também foi avaliada. Esses derivados $\mathrm{CF}_{3^{-}}$substituídos têm demonstrado uma maior estabilidade metabólica em estudos in vivo e são análogos estruturais dos compostos 2, 3 e 4 (figura 3). ${ }^{39}$ Por fim, a substituição da aminonitrila pelo grupo azanitrila foi usada para síntese de três inibidores, sendo que um deles, o Neq0690, foi co-cristalizado 
com a enzima $L m C P B 2.8 \Delta C$ TE e sua estrutura tridimensional foi determinada através da técnica de cristalografia de raios-X durante o estágio de doutorado sanduíche realizado no Grupo de Biologia Estrutural da Universidade de Nottingham, Reino Unido, sob a supervisão dos Professores Dr. Jonas Emsley e Dr. Charles A. Laughton.

\subsection{Cristalização e determinação estrutural das estruturas cristalográficas dos complexos $L m$ CPB-Neq0690 e $L m$ CPB-MMTS}

A cristalografia de raios- $X$ de proteínas desempenha um papel fundamental dentro do contexto da química medicinal, haja vista sua capacidade de fornecer informações detalhadas sobre os processos de reconhecimento molecular. ${ }^{40-41}$ A principal vantagem dessa técnica envolve a obtenção das coordenadas tridimensionais (x, y, z) do complexo proteína-ligante, fornecendo imagens de alta resolução do mesmo que podem ser analisadas através de uma estação gráfica. Dessa maneira, a interação entre a macromolécula e o ligante testado pode ser estudada a nível atômico, produzindo informações úteis para guiar a síntese de compostos mais potentes e seletivos. Dentre várias informações fornecidas destacam-se: i) a composição, forma e natureza do sítio ativo, sendo possível observar as conformações das cadeias laterais de resíduos de aminoácidos presentes no sítio de interação e próximo a ele; ii) alterações conformacionais na estrutura da enzima induzidas pela interação com o ligante; iii) o modo de interação do ligante e os resíduos de aminoácidos envolvidos nessa interação; iv) informações sobre a alocação de moléculas de águas que são frequentemente exploradas na otimização estrutural de ligantes; v) informações detalhadas como posição, estereoquímica, conformação, estado tautomérico e protonação do ligante complexado, entre outros. ${ }^{42-43}$

O principal parâmetro relacionado a qualidade dos dados obtidos através da cristalografia de macromoléculas é o limite de difração, comumente conhecido como resolução. Tipicamente, estruturas cristalográficas com resoluções de até $2,5 \AA$ fornecem dados com qualidade aceitável para os propósitos de planejamento de fármacos. De forma geral, quanto maior a resolução (ou seja, menor as distâncias entre os planos cristalinos de um cristal, medida em Angstroms), maior é o grau de detalhamento dos mapas de densidade eletrônica e, portanto, mais precisamente se pode definir a posição dos átomos individuais no

modelo. A resolução depende, basicamente, de dois fatores: o primeiro refere-se à organização interna do cristal e o segundo à estratégia de coleta dos dados (dose de exposição, 
distância entre o cristal e o detector, comprimento de onda), sendo que este último, em alguns equipamentos, pode ser controlado pelo cristalógrafo. ${ }^{44}$

Embora a cristalografia de macromoléculas seja uma técnica extensivamente estudada, cuja as bases teóricas já estão bem consolidadas, a cristalização de proteínas ainda é uma ciência empírica que exige experiência, capacidade de observação e muita persistência. Não obstante, o grande gargalo dos estudos cristalográficos envolve obter cristais de qualidade e com alto poder de difração. Geralmente, essa etapa exige o uso de grandes quantidades de proteína, livre de impurezas e com alto grau de homogeneidade. ${ }^{45-46}$

Para se obter um cristal de proteína é necessário que uma condição de supersaturação seja atingida. Nessa condição, milhares de moléculas de proteínas desordenadas na solução interagem umas com as outras para formar pequenos agregados moleculares, um fenômeno conhecido como nucleação. Segue-se, então, uma fase de crescimento de cristais que geralmente requer uma condição diferente da anterior.

Uma das formas mais comuns de descrever o caminho pelo qual uma proteína cristaliza é através do diagrama de fases. Esses diagramas são utilizados para guiar a estratégia de obtenção de cristais. Uma amostra proteica pura e em elevada concentração (7$12 \mathrm{mg} / \mathrm{ml}$ ) é comumente misturada a uma solução de cristalização para gerar uma condição de supersaturação. As condições do meio são alteradas adicionando-se agentes precipitantes, modificando-se o pH, a temperatura, a concentração proteica, a força iônica, entre outros parâmetros. O objetivo aqui é alcançar pontos de nucleação, evitando, no entanto, a agregação desordenada que pode levar a precipitação da proteína na forma não cristalina. Uma vez na zona de nucleação, a proteína deve ser levada, gradualmente, à zona metaestável, onde a fase de crescimento de cristais ocorre. Vários métodos são utilizados para promover uma alteração gradativa das condições de cristalização, entre eles destacam-se: o método da gota suspensa, gota sentada, micro diálise e capilares. A alteração lenta e gradual das condições de cristalização, facilita um contato ordenado das moléculas de proteína, promovendo um crescimento cristalino uniforme, fundamental para obtenção de cristais de alta qualidade. ${ }^{47-46}$

Um cristal de proteína pode ser entendido como um arranjo ordenado e periódico de seus elementos constituintes. A rede cristalina é formada pela repetição infinita de um elemento básico nas três dimensões. Esse elemento básico é conhecido como célula unitária que é caracterizada por três vetores unitários não coplanares $\mathbf{a}, \mathbf{b}, \mathbf{c}$, e pelos ângulos entre eles $\alpha, \beta$ e y. A partir da célula unitária é possível reconstruir o cristal por operações de translação 
ao longo dos eixos cristalográficos. A maneira como os elementos de um cristal se repetem regularmente ao longo da estrutura cristalina é chamada de simetria. Dessa forma, podemos reduzir o problema ao nível da unidade assimétrica que é, em outras palavras, a menor parte de uma estrutura tridimensional da qual toda a estrutura pode ser reproduzida a partir das aplicações das operações de simetria (translacional e pontual). Assim, de acordo com suas características geométricas, todos os cristais são classificados em um dos sete sistemas cristalinos (cúbico, tetragonal, ortorrômbico, hexagonal, trigonal, monoclínico e triclínico). Entende-se por sistema cristalino o conjunto de cristais cujos eixos cristalográficos são iguais nas suas dimensões relativas, apresentando relações angulares gerais constantes. Sendo assim, os eixos cristalográficos servem como referência na descrição da estrutura e simetria dos cristais. Medindo-se suas dimensões relativas e os valores dos ângulos, pode-se determinar a qual sistema cristalino pertence um dado cristal. A combinação dos sete sistemas cristalográficos com as diferentes possibilidades de disposição espacial das partículas nas faces e no interior das células unitárias (centragens) fornece 14 configurações básicas, denominadas redes de Bravais. ${ }^{48}$ Qualquer operação de simetria na rede de Bravais é composta por uma translação e/ou uma operação de simetria que deixa pelo menos um ponto fixo (operações pontuais). As operações pontuais podem ser do tipo reflexão em um plano, inversão, rotações em torno de um eixo ou uma combinação de uma rotação com uma inversão, fornecendo um total de 10 operações. Todo o cristal pode ser descrito por uma combinação particular dos elementos de simetria pontuais e essa combinação é chamada de grupo pontual. As simetrias pontuais são classificadas em rotações próprias (rotações de frações de $360^{\circ}$ em torno de um eixo) e rotações impróprias (combinação simultânea de uma rotação e um centro de inversão). De forma geral, reflexões e inversões são classificadas como operações de simetria impróprias e envolvem a mudança de quiralidade da molécula, o que não ocorre nas operações de simetria próprias. Além disso, devido a restrições impostas pela simetria translacional, algumas rotações são incompatíveis com a repetição na rede cristalina. Dessa forma, as rotações possíveis são aquelas de ordem 1, 2, 3, 4 e 6. Assim, combinando-se todas as operações de simetria possíveis envolvendo os elementos de rotação própria e imprópria podemos obter um total de 32 grupos pontuais. Desses 32 grupos pontuais, 11 possuem centro de simetria e são conhecidos como grupos de Laue. Dos 21 grupos pontuais restantes não-centrossimétricos, 11 são enantiomorfos e podem conter uma mistura não-racêmica de espécies quirais. Os outros 10 são não-centrossimétricos, mas possuem um eixo de rotação impróprio. Da combinação das operações de simetria pontuais 
com os elementos de simetria translacional surgem os eixos helicoidais e os planos de deslizamento. Combinando-se os 32 grupos pontuais com os elementos de simetria translacional, obtêm-se os 230 grupos espaciais descritos na International Tables for Crystallography (ITC). Contudo, elementos de simetria impróprios não são possíveis para proteínas por serem moléculas quirais (formadas por L-aminoácidos) e, por isso, o número de grupos espaciais permitidos se restringi aos 65 grupos espaciais enantiomorfos. ${ }^{49-50}$

Uma vez que bons cristais são obtidos, os experimentos de difração de raios-X podem ser conduzidos. A difração de raios-X usa a repetição do arranjo regular de objetos na rede cristalina (simetria) para produzir o padrão de difração. Os raios-X são radiações eletromagnéticas com comprimento de onda que varia de $10-10^{-3} \mathrm{~nm}$, ideais para o estudo de objetos a nível atômico como pequenas moléculas, proteínas e ácidos nucleicos. O comprimento de onda dos feixes de raios-X monocromático geralmente usados em cristalografia de macromoléculas varia de 0,8-1,6̊ dependendo da fonte e estratégia de coleta empregada. ${ }^{49-51}$

Quando um cristal é submetido a um feixe de raios-X, os elétrons de seus átomos vibram e emitem radiação em todas as direções como uma nova fonte espalhadora. Devido a simetria típica de materiais cristalinos e aos fenômenos de interferência, um padrão regular de ondas difratadas representativo da distribuição dos átomos no espaço é obtido. A difração de raios-X e as condições de interferência construtivas podem ser matematicamente entendidas através da lei de Bragg (10). Segundo essa lei, a difração é o resultado da reflexão dos raios-X por um conjunto de planos reticulares que passam através de pontos da rede cristalina. Esses planos são caracterizados por três números inteiros $h k l$, denominados índices de Miller. Quando a diferença de caminho ótico $\left(2 \mathrm{~d}_{h k l} \operatorname{sen} \theta\right)$ entre dois feixes de raios-X é igual a um número inteiro de comprimentos de onda, isto significa que as ondas estão em fase, ou dito de outra forma, os máximos e mínimos de uma onda coincidem com os máximos e mínimos da outra. Quando a lei de Bragg não é satisfeita, isto é, quando a diferença de caminho ótico não é um número inteiro de comprimentos de onda, os máximos e mínimos de uma onda aparecem deslocados em relação aos máximos e mínimos da outra e uma interferência do tipo destrutiva é observada. ${ }^{49-52}$ 


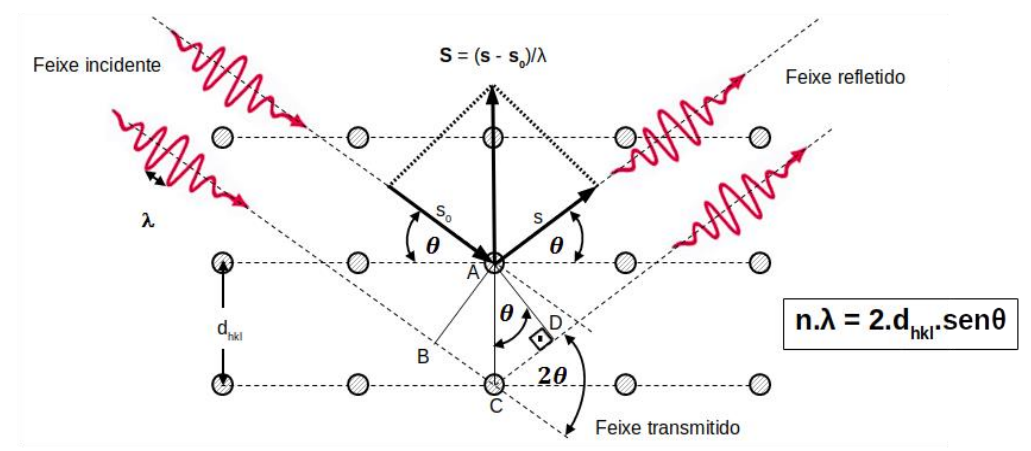

Figura 10 - Representação esquemática da lei de Bragg. ${ }^{51-52}$

Cada feixe de raios- $\mathrm{X}$ espalhado possui o mesmo comprimento de onda do feixe incidente, mas difere quanto a sua fase e amplitude. $\mathrm{O}$ espalhamento da radiação pode ser vetorialmente representado pelo vetor espalhamento atômico $(\mathbf{S})$ que depende da direção da radiação incidente $\left(\mathbf{s}_{\mathbf{0}}\right)$ e refletida $(\mathbf{s})$, bem como o seu comprimento de onda. O vetor espalhamento atômico $\mathbf{S}$ é uma função do ângulo de espalhamento e o seu módulo pode variar de 0 a $2 / \lambda$. Por isso, esse vetor está descrito num espaço onde cada eixo de seu sistema de coordenadas tem dimensão do recíproco da distância $\left(\AA^{-1}\right)$. Esse espaço de coordenadas é chamado de espaço recíproco. ${ }^{48}$

No espaço recíproco, os planos (hkl) são representados por vetores perpendiculares a eles com módulo igual a $\mathrm{d}_{\mathrm{hkl}}{ }^{*}=1 / \mathrm{d}_{\mathrm{hkl}}$ (onde $\mathrm{d}_{\mathrm{hlk}}$ representa a distância inter planar). Assim, temos uma correspondência entre os potenciais planos refletores e pontos do espaço recíproco. Para cada rede cristalina pode-se construir uma rede recíproca que também possui uma célula unitária recíproca caracterizada pelos eixos $\mathbf{a}^{*}, \mathbf{b}^{*}, \mathbf{c}^{*}$ e ângulos $\alpha^{*}, \beta^{*}$ e $\gamma^{*}$. A célula unitária recíproca se relaciona matematicamente com a célula unitária do espaço direto através das seguintes equações abaixo, onde V é o volume da célula unitária: ${ }^{49-48}$

$$
\mathbf{a}^{*}=\frac{1}{V}(b x c) \quad \mathbf{b}^{*}=\frac{1}{V}(c x a) \quad \mathbf{c}^{*}=\frac{1}{V}(a x b)
$$

Dessa forma podemos descrever o vetor espalhamento atômico $\mathbf{S}$ e a diferença de fase $\varphi$ no espaço recíproco conforme as equações abaixo:

$$
\begin{aligned}
& \mathbf{S}=\frac{s-s_{\mathbf{0}}}{\lambda}=\mathrm{ha}^{*}+\mathrm{k} \mathbf{b}^{*}+\mathrm{l} \mathbf{c}^{*} \\
& \varphi=2 \pi(\mathrm{xa}+\mathrm{yb}+\mathrm{zc}) .\left(\mathrm{h} \mathbf{a}^{*}+\mathrm{k} \mathbf{b}^{*}+\mathrm{lc} \mathbf{c}^{*}\right)
\end{aligned}
$$


Para que a difração ocorra, o vetor espalhamento atômico deve estar sobre um ponto do retículo recíproco, satisfazendo, assim, as equações de Laue que são obtidas através do produto escalar da equação 8 pelos vetores $\mathbf{a}, \mathbf{b}$ e $\mathbf{c}$ do retículo cristalino. ${ }^{49}$
S. $\mathbf{a}=\mathrm{h}$
$\mathbf{S} . \mathbf{b}=\mathrm{k}$
S.c $=1$

As condições de difração expressas pela equação 8 podem ser representadas graficamente pela construção de Ewald (uma esfera centrada no cristal, de raio $1 / \lambda$, sendo o vetor $\mathbf{s}_{\mathbf{0}} / \lambda$ paralelo ao feixe incidente). Assim a condição para ocorrer a difração a partir dos planos (hkl) é que o ponto $\mathrm{P}(\mathrm{hkl})$ toque a superfície da esfera de Ewald (figura 11). A direção do feixe difratado (s/ $\lambda$ ) é obtida unindo-se a origem (000) ao ponto $\mathrm{P}(101) .{ }^{48-53}$
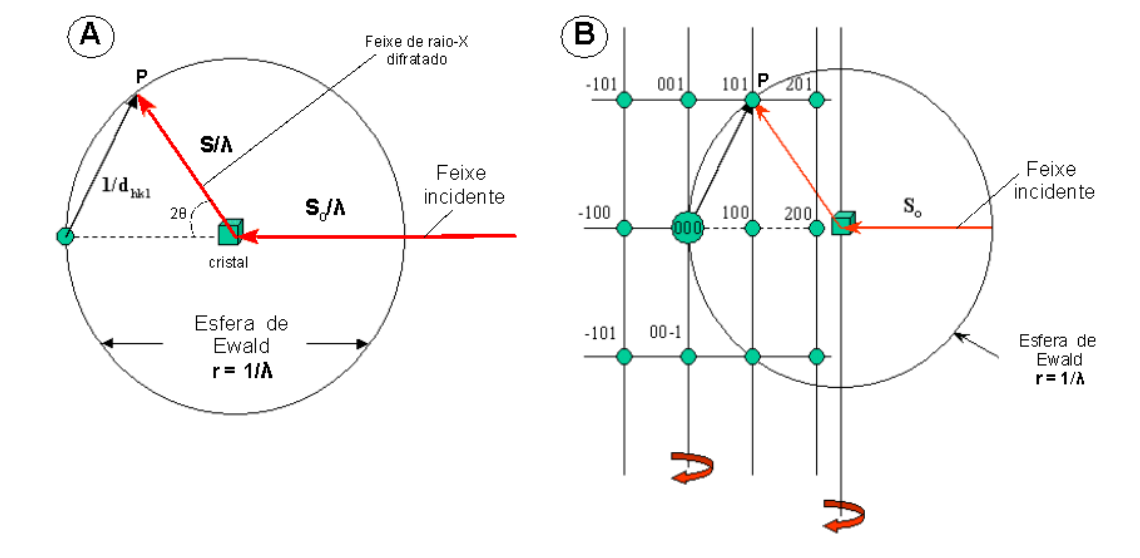

Figura 11 - A) Nessa representação geométrica da esfera de Ewald, o ponto P que toca a superfície da esfera produz um feixe difratado de módulo $\mathbf{s} / \lambda$. O vetor espalhamento de módulo $1 / \mathrm{d}_{\mathrm{hkl}}$ está relacionado ao vetor de onda incidente, ao vetor de onda refletido e ao comprimento de onda do feixe incidente. B) A direção do vetor espalhamento de módulo $1 / \mathrm{d}_{\mathrm{hkl}}$ é dada pela união da origem $(0,0,0)$ ao ponto $\mathrm{P}(1,0,1)$. A intersecção do ponto $\mathrm{P}(101)$ com a superfície da esfera satisfaz as condições de Bragg e Laue para a difração. ${ }^{53}$

Cada reflexão hkl pode ser descrita por um fator estrutura $\mathbf{F}_{\mathbf{h k l}}$ (equação 5) que representa a resultante de $\mathrm{N}$ ondas espalhadas em uma dada direção para os $\mathrm{N}$ átomos que estão presentes em uma célula unitária. A magnitude desse fator depende da posição relativa dos átomos na célula unitária e de seus respectivos fatores de espalhamento atômico f. Esse fator indica o poder de espalhamento de raios-X que um determinado átomo possui. De forma geral, quanto maior o número de elétrons de um átomo, maior o seu poder de espalhamento de raios-X. $\mathbf{F}_{\mathbf{h k l}}$ fornece uma medida da amplitude de reflexão para um conjunto de planos hkl e, se a posição dos átomos na célula unitária é conhecida, o correspondente padrão de difração pode ser calculado. ${ }^{48-51}$ 


$$
F_{h k l}=\sum_{j=1}^{n} f_{j} e^{2 \pi i \cdot(h x j+k y j+l z j)}
$$

Todo padrão de difração registrado é centrossimétrico, mesmo que a estrutura não possua um centro de simetria. Essa característica é consequência da lei de Friedel que define que os módulos para os fatores estrutura das reflexões de índices $(h, k, 1)$ e $(-h,-k,-1)$ são iguais. A exceção ocorre no caso do espalhamento anômalo em que pequenas distorções geradas pela presença de elementos pesados podem ser usadas para fornecer informações sobre a fase.

O fator estrutura pode ser expresso em função da contribuição de cada elemento de volume de densidade eletrônica $\rho$ na célula unitária através da equação $12 .^{48}$

$$
F_{h k l}=\int_{v} \rho(x, y, z) e^{2 \pi i(h x+k y+l z)} d V
$$

Podemos descrever matematicamente o padrão de difração como a transformada de Fourier da densidade eletrônica da estrutura. Da mesma forma, a densidade eletrônica da estrutura é a transformada de Fourier do padrão de difração. Assim, se os fatores de estrutura, $\mathbf{F}_{\mathbf{h k l}}$, são conhecidos para todas as reflexões, h,k,l, então a densidade eletrônica, $\rho(\mathrm{x}, \mathrm{y}, \mathrm{z})$, pode ser calculada para cada ponto x,y,z na cela unitária através da equação 7. A densidade eletrônica representa a estrutura do cristal. ${ }^{48}$

$$
\rho(x y z)=\frac{1}{V} \sum_{h=-\infty}^{\infty} \sum_{k=-\infty}^{\infty} \sum_{=-\infty}^{\infty} F(h k l) e^{-2 \pi i(h x+k y+l z)}
$$

Durante um experimento de difração de raios-X somente as intensidades hkl são registradas. Essas intensidades são, então, convertidas em módulo do fator estrutura através da relação I $\sim\left(\left|\mathbf{F}_{\mathbf{h k l}}\right|\right)^{2}$. No entanto, pode-se observar pela equação 8 que $\mathbf{F}_{\mathbf{h k l}}$ é um número complexo com módulo e fase $\varphi .^{49}$

$$
F_{h k l}=\left|F_{h k l}\right| e^{i \varphi_{h k l}}
$$

Uma vez que a informação sobre a fase é sistematicamente perdida durante a coleta de dados, se torna impossível determinar a estrutura diretamente das medidas do padrão de difração. Essa importante limitação dos experimentos de difração de raios-X ficou conhecida como o problema da fase. Existem quatro principais métodos para resolução do problema da fase: substituição molecular, substituição isomórfica múltipla, dispersão anômala e métodos diretos. Neste trabalho foi utilizado o método de faseamento de substituição molecular que faz 
uso das fases de estruturas cristalográficas de proteínas homólogas já resolvidas (com identidade de sequência primária > 30\%) para o cálculo dos primeiros mapas de densidade eletrônica da estrutura de interesse. ${ }^{54-55}$ Contudo, esta estimativa inicial de densidade eletrônica é ruidosa devido à má qualidade das fases iniciais. Por este motivo, vários ciclos de refinamentos das fases são necessários. ${ }^{48-53}$

Uma vez que o mapa de densidade eletrônica é constituído a partir da função $\rho(x y z)$ que depende das amplitudes observadas no experimento $\left(\mathrm{F}_{\mathrm{obs}}\right)$ e as fases calculadas $\left(\varphi_{\text {calc }}\right)$ através da solução da estrutura, o modelo obtido $\left(\mathrm{F}_{\mathrm{obs}} \varphi_{\text {calc }}\right)$ será uma aproximação da estrutura verdadeira, dependendo de quão acurada é a $\varphi_{\text {calc. }}$ O refinamento do modelo atômico envolve o uso de restrições geométricas e pesos adequados para melhoramento das fases, diminuindo assim as diferenças entre o modelo e a estrutura verdadeira. ${ }^{48-56}$

O mapa de diferença é um tipo de mapa de densidade eletrônica que utiliza as diferenças entre as amplitudes observadas e calculadas $\left(F_{o b s}-F_{\text {calc }}, \varphi_{\text {calc }}\right)$. Nesse mapa, as partes presentes na estrutura, porém não incluídas no modelo são apresentadas como contornos positivos. Por outro lado, as partes adicionadas no modelo, mas ausentes na estrutura verdadeira são representados como contornos negativos. A superposição dos dois mapas (positivo e negativo) nos fornece os mapas $\left(2 F_{F o b s}-F_{\text {calc }}, \varphi_{\text {cal }}\right)$ que evidencia os aspectos que ainda requerem alguma correção a partir do modelo de densidade eletrônica. ${ }^{57-56}$

Os parâmetros estatísticos $\mathrm{R}_{\text {work }}$ e $\mathrm{R}_{\text {free }}$ também são utilizados para guiar o refinamento do modelo estrutural. $\mathrm{O} \mathrm{R}_{\text {work }}$ é definido como $\left.\sum|| \mathrm{F}\right|_{\text {obs }}-\left.|\mathrm{F}|_{\text {calc }}\left|/ \sum\right| \mathrm{F}\right|_{\text {obs }}$ e fornece um indicativo da similaridade do modelo em relação à realidade. $\mathrm{O} \mathrm{R}_{\text {work }}$ leva em consideração $\sim 95 \%$ dos $\mid \mathbf{F}_{\mathrm{hkl}}$, contudo este parâmetro pode ser influenciado por fatores que convergem para mínimos. Em cristalografia de proteínas valores $\mathrm{R}_{\mathrm{work}}$ de até $20 \%$ são típicos de proteínas bem resolvidas. $O$ fator $R_{\text {free }}$ usa $\sim 5 \%$ dos $\left|F_{\text {hkl }}\right|$ medidos que são aleatoriamente escolhidos e não são utilizados no processo de refinamento, formando, assim, um conjunto teste. $O R_{\text {free }}$ é calculado de maneira análoga ao $\mathrm{R}_{\text {work }} \mathrm{e}$ é mais utilizado para a validação cruzada do refinamento. A diferença $R_{\text {free }}-R_{\text {work }}$ não deve ser superior que $7 \%$. Valores superiores indicam problemas com o ajuste do modelo aos dados experimentais. ${ }^{57-58}$ 


\section{Objetivos}

Este trabalho tem como objetivo principal avaliar o potencial inibitório de análogos nitrílicos sintetizados no grupo NEQUIMED/IQSC/USP contra três cisteíno proteases da família da papaína: catepsina L, $L m C P B 2.8 \Delta C T E$ e cruzaína.

Os objetivos específicos deste trabalho são:

- Avaliação da inibição in vitro dos compostos sintetizados no grupo NEQUIMED/IQSC/USP, determinando suas constantes de inibição (Ki) contra as enzimas cruzaína, LmCPB2.8 $\Delta \mathrm{CTE}$ e catepsina L;

- Proposição do mecanismo de inibição, bem como a análise das relações entre a estrutura-atividade (SAR) dos compostos estudados neste trabalho;

- Desenvolvimento da uma nova construção da pró-LmCPB2.8 $\Delta$ CTE clonada no vetor pET21a com cauda de histidina na porção N-terminal com o intuito de expressá-la na fração solúvel do lisado. 


\section{Material e métodos}

\subsection{Construção da enzima cruzaína e $L m C P B 2.8 \Delta C T E$ usadas nesse trabalho}

A cruzaína é uma glicoproteína expressa como uma pró-enzima com três domínios distintos: o pró-domínio N-terminal, o domínio catalítico e uma extensão C-terminal com 130, 215 e 104 resíduos de aminoácidos, respectivamente. Três potenciais sítios de glicosilação estão presentes, sendo um na porção C-terminal e os outros dois no domínio catalítico da enzima. Estudos tem indicado que a glicosilação na porção C-terminal está relacionada ao mecanismo de ligação da cruzaína à superfície da forma amastigota do T.cruzi. A remoção dessa extremidade não afeta sua atividade catalítica e tem fornecido uma abordagem eficaz para a obtenção dessa enzima a partir de sistemas bacterianos de expressão.

O gene sintético da cruzaína truncada na extremidade C-terminal comercialmente adquirido a partir da Epoch Biolabs foi clonado entre os sítios NdeI e HindIII do vetor pET21a. A figura 12 mostra a sequência proteica codificada pelo gene da pró-cruzaína (wild type-W.T) com uma cauda de seis histidinas na extremidade $\mathrm{N}$-terminal usada nos estudos de inibição enzimática. ${ }^{59}$

\begin{tabular}{|c|c|}
\hline $\mathrm{His}_{6}$ + Pró-domínio & Cruzaína \\
\hline-112 & HH HHHHGSCLVP \\
\hline -100 AATASLHAEE TLTSQFAEFK & QKHGRVYESA AEEAFRLSVF RENLFLARLH \\
\hline -50 AAANPHATFG VTPFSDLTRE & EFRSRYHNGA AHFAAAQERA RVPVKVEVVG \\
\hline 1 APAAVDWRAR GAVTAVKDQG & QCGSCWAFSA IGNVECQWEL AGHPLTNLSE \\
\hline 51 QMLVSCDKTD SGCSGGLMNN & AFEWIVQENN GAVYTEDSYP YASGEGISPP \\
\hline 101 CTTSGHTVGA TITGHVELPQ & DEAQIAAWLA VNGPVAVAVD ASSWMTYTGG \\
\hline 151 VMTSCVSEQL DHGVLLVGYN & DSAAVPYWII KNSWTTQWGE EGYIRIAKGS \\
\hline 201 NQCLVKEEAS SAVVG & \\
\hline
\end{tabular}

Figura 12- Sequência proteica codificada pelo gene da pró-cruzaína nativa. O domínio catalítico é formado pelos resíduos 1 a 215 e os resíduos da cauda de histidina N-terminal e o pró-domínio estão numerados de -112 até -1 .

Similarmente, a CPB2.8 de L. mexicana é expressa como uma pró-forma inativa, contendo um pró-domínio N-terminal, o domínio catalítico e um domínio C-terminal compostos por 106, 219 e 100 resíduos de aminoácidos, respectivamente. O processamento do pró-domínio e parte do domínio C-terminal é requerido para obtenção da forma madura de aproximadamente $23300 \mathrm{kDa}$. A deleção do domínio C-terminal não bloqueia a atividade catalítica nem previne o auto processamento in vitro da pró-região, sendo essa estratégia comumente usada para expressão dessa enzima em células bacterianas. 
Neste trabalho, o gene sintético da pró-CPB2.8 (GenBank: Z14061.1) de Leishmania mexicana truncada na extremidade C-terminal foi clonado entre os sítios NdeI e HindIII do vetor pET21a. Esse gene foi adquirido comercialmente a partir da Epoch Biolabs. Similarmente a cruzaína, uma sequência de seis histidinas foi adicionada na porção $\mathrm{N}$ terminal com o intuito de facilitar a purificação por meio de cromatografia por afinidade ao níquel (Figura 13). Essa construção foi utilizada nos estudos de inibição enzimática e cristalografia.

\begin{tabular}{|c|c|}
\hline $\mathrm{His}_{6}$ + Pró-domínio & CPB2.8 \\
\hline-113 & HHH HHHGSACAPA \\
\hline -100 RAIHVGTPAA ALFEEFKRTY & GRAYETLAEE QQRLANFERN LELMREHQAR \\
\hline -50 NPHAQFGITK FFDLSEAEFA & ARYLNGAAYF AAAKRHAAQH YRKARADLSA \\
\hline 1 VPDAVDWREK GAVTPVKDQG & ACGSCWAFSA VGNIEGQWYL AGHELVSLSE \\
\hline 51 QQLVSCDDMD NGCSGGLMLQ & AFDWLLQNTN GHLHTEDSYP YVSGNGYVPE \\
\hline 101 CSNSSELVVG AQIDGHVLIG & SSEKAMAAWL AKNGPIAIAL DASSFMSYKS \\
\hline 151 GVLTACIGKQ LNHGVLLVGY & DMTGEVPYWV IKNSWGGDWG EQGYVRVVMG \\
\hline 201 VNACLLSEYP VSAHVR & \\
\hline
\end{tabular}

Figura 13 - Sequência proteica codificada pelo gene $L m C P B 2.8 \Delta C T E$ com o pró-domínio e os resíduos da cauda de histidina N-terminal (-113 a -1) e o domínio catalítico (1 a 201).

\subsection{Protocolo de expressão das enzimas estudadas nesse trabalho}

O protocolo usado para a expressão das enzimas cruzaína e $L m C P B 2.8 \Delta C T E$ se baseia do método de autoindução publicado por Studier com algumas modificações. ${ }^{60}$

Células de E. coli do tipo ArcticExpress (DE3)Ril foram transformadas e crescidas em $5 \mathrm{ml}$ de meio Lysogen Broth contendo carbenecilina $(100 \mu \mathrm{g} / \mathrm{ml})$ e gentamicina $(20 \mu \mathrm{g} / \mathrm{ml})$. Após um período de crescimento de aproximadamente $15 \mathrm{~h}$ à $37^{\circ} \mathrm{C}$, a cultura foi adicionada diretamente a $1 \mathrm{~L}$ de meio de autoindução. Esse meio foi preparado a partir de $10 \mathrm{~g}$ de $\mathrm{N}-\mathrm{Z}$ amina, $5 \mathrm{~g}$ de extrato de levedura, $5 \mathrm{ml}$ de glicerol, $900 \mathrm{ml}$ de água, $25 \mathrm{ml}$ de uma solução a $1 \mathrm{M}$ de $\mathrm{Na}_{2} \mathrm{HPO}_{4}, 25 \mathrm{ml}$ de uma solução a $1 \mathrm{M}$ de $\mathrm{KH}_{2} \mathrm{PO}_{4}, 50 \mathrm{ml}$ de uma solução a $1 \mathrm{M}$ de $\mathrm{NH}_{4} \mathrm{Cl}, 5 \mathrm{ml}$ de uma solução a $1 \mathrm{M}$ de $\mathrm{Na}_{2} \mathrm{SO}_{4}$ e $2 \mathrm{ml}$ de uma solução a $1 \mathrm{M}$ de $\mathrm{MgSO}_{4}$. O meio foi auto clavado e misturado a $10 \mathrm{ml}$ de uma solução de D-glicose 5\%, $40 \mathrm{ml}$ de $\alpha$ lactose $5 \%$ e o volume necessário para os antibióticos (carbenicilina e gentamicina) alcançarem a concentração final igual $100 \mu \mathrm{g} \mathrm{mL}^{-1}$ e $20 \mu \mathrm{g} \mathrm{mL}^{-1}$, respectivamente. Após um período de agitação de 5 horas à $37^{\circ} \mathrm{C}\left(\right.$ até $\left.\mathrm{DO}_{600}>0.5\right)$, a temperatura foi reduzida a $12{ }^{\circ} \mathrm{C}$ e a cultura foi mantida sob agitação por um período de $72 \mathrm{~h}$. A amostra foi, então, centrifugada a $4^{\circ} \mathrm{C}$ e $5000 \mathrm{rpm}$ por 30 minutos e o pellet armazenado à $-80^{\circ} \mathrm{C}$ até a etapa de lise. 
O Pellet obtido foi ressuspenso em $50 \mathrm{ml}$ do tampão de lise. Após duas horas, as células foram submetidas à sonicação através de pulsos ultrassônicos de 20 s intercalados a períodos de 40s de interrupção, durante um tempo total de 10 minutos. O tampão de lise era composto por Tris $50 \mathrm{mM}\left(\mathrm{pH}\right.$ ), $\mathrm{NaCl} 300 \mathrm{mM}$, imidazol $10 \mathrm{mM}, \mathrm{CaCl}_{2} 1 \mathrm{mM}$ e $\mathrm{MgSO}_{4} 1$ mM. O lisado foi centrifugado a $18.000 \mathrm{rpm}$ e o sobrenadante filtrado antes da purificação pelo FPLC. A purificação inicial foi realizada à $4^{\circ} \mathrm{C}$ usando uma coluna de níquel HisTrapFF de $5 \mathrm{ml}$ (GE Healthcare LifeSciences). O tampão de lavagem/ligação era composto por TrisHCl 50 mM (pH 8), NaCl 300 mM e 10 mM de imidazol. Já o tampão de eluição era composto por tris $50 \mathrm{mM}$ (pH 8), $\mathrm{NaCl} 300 \mathrm{mM}$ e $500 \mathrm{mM}$ de imidazol. Um gradiente de 0$100 \%$ foi usado para purificar a proteína sob um fluxo de $1 \mathrm{ml} / \mathrm{min}$. As principais frações foram combinadas e dialisada à $4{ }^{\circ} \mathrm{C}$ para o tampão de ativação (acetato de sódio $50 \mathrm{mM}$ - pH 5.5, $\mathrm{NaCl} 300 \mathrm{mM}$ e EDTA $0.1 \mathrm{mM})$.

\subsection{Ativação das enzimas cruzaína (W.T) e $\operatorname{LmCPB2.8\Delta CTE}$}

Para a enzima cruzaína, logo após a diálise de $12 \mathrm{~h}$ para o tampão de ativação, a solução de aspecto turvo foi ativada pela adição de DTT $1 \mathrm{mM}$ seguida de incubação à $37{ }^{\circ} \mathrm{C}$ por um período de 2-3 horas. Amostras de $20 \mu \mathrm{l}$ foram retiradas durante o processo de ativação e analisadas por eletroforese em gel de poliacrilamida sob condições desnaturantes, com o intuito de acompanhar a degradação da pró-região do zimogênio. Ao final da ativação a solução se tornou límpida e a reação foi levada ao gelo depois de suprimida pela adição de MMTS 1 mM. A solução da enzima inibida com MMTS foi dialisada para o tampão Tris-HCl 50 mM (pH 8.0) e $\mathrm{NaCl} 10 \mathrm{mM}$ e, em seguida, submetida a uma segunda etapa de purificação, utilizando-se a coluna Hiload 16/60 superdex 200 acoplada ao FPLC. A cruzaína eluiu com um tempo de retenção de $55 \mathrm{~min}$. Ao término do processo, a enzima foi concentrada e sua atividade medida. Por fim, a enzima foi congelada em nitrogênio líquido e estocada em freezer a $-80^{\circ} \mathrm{C}$.

A concentração da cruzaína foi determinada usando um NanoDrop (Denovix Ds-11+ spectrophotometer) com os seguintes coeficientes de extinção: para a forma His6-prodomíniocruzaína, $\varepsilon_{280}=68.910 \mathrm{M}^{-1} \mathrm{~cm}^{-1}$ (cisteína oxidada) e $\varepsilon_{280}=68410 \mathrm{M}^{-1} \mathrm{~cm}^{-1}$ (cisteína reduzida). Para a forma madura da cruzaína, os coeficientes de extinção usados foram $\varepsilon_{280}=$ $60430 \mathrm{M}^{-1} \mathrm{~cm}^{-1}$ (Cisteína oxidada) e $\varepsilon_{280}=59930 \mathrm{M}^{-1} \mathrm{~cm}^{-1}$ (Cisteína reduzida).

Para a $L m C P B 2.8 \Delta C$ TE, após a diálise de 12h para o tampão de ativação (acetato de sódio $50 \mathrm{mM}$ pH 5.0, $\mathrm{NaCl} 500 \mathrm{mM}$ e EDTA $0.1 \mathrm{mM}$ ), a solução de aspecto turvo foi ativada 
pela adição de DTT $10 \mathrm{mM}$ seguida de incubação à $37^{\circ} \mathrm{C}$ por um período de 5-6 horas sob agitação a $180 \mathrm{rpm}$. Amostras de $20 \mu \mathrm{l}$ foram retiradas antes e após o processo de ativação e analisadas por eletroforese em gel de poliacrilamida sob condições desnaturantes, com o intuito de se observar a perda da pró-região do zimogênio. Ao final da ativação a solução se tornou límpida e a reação foi levada ao gelo depois de suprimida pela adição de MMTS 5 mM. A solução da enzima inibida com MMTS foi dialisada para o tampão Tris-HCl $50 \mathrm{mM}$ (pH 8.0) e $\mathrm{NaCl} 10 \mathrm{mM}$ e, em seguida, submetida a uma segunda etapa de purificação, utilizando-se a coluna Hiload 16/60 superdex 200 acoplada ao FPLC. A LmCPB2.8 $\Delta$ CTE eluiu com um tempo de retenção de aproximadamente 55 minutos. Ao término do processo, a enzima foi concentrada e sua atividade medida. Por fim, a enzima foi congelada em nitrogênio líquido e estocada em freezer a $-80{ }^{\circ} \mathrm{C}$.

A concentração de enzima foi determinada usando um NanoDrop (Denovix Ds-11+ spectrophotometer) com os seguintes coeficientes de extinção: para a forma His6-prodomínioLmCPB2.8 $\Delta$ CTE, $\varepsilon_{280}=65.360 \mathrm{M}^{-1} \mathrm{~cm}^{-1}$ (cisteína oxidada) e $\varepsilon_{280}=64860 \mathrm{M}^{-1} \mathrm{~cm}^{-1}$ (cisteína reduzida). Para a forma madura da $L m \mathrm{CPB} 2.8 \Delta \mathrm{CTE}$, os coeficientes de extinção usados foram $\varepsilon_{280}=57785 \mathrm{M}^{-1} \mathrm{~cm}^{-1}$ (Cisteína oxidada) e $\varepsilon_{280}=57410 \mathrm{M}^{-1} \mathrm{~cm}^{-1}$ (Cisteína reduzida).

\subsection{Ensaios de determinação da constante de inibição $\left(K_{i}\right)$}

Os ensaios fluorimétricos foram realizados em $200 \mu \mathrm{L}$ de solução contendo tampão acetato de sódio $100 \mathrm{mM}$ (pH 5.5), $300 \mathrm{mM}$ de $\mathrm{NaCl}, 5 \mathrm{mM}$ de DTT, DMSO 2,5\% V/V e a analisada em uma microplaca preta de 96 poços de fundo plano. A velocidade da reação foi monitorada em um leitor de placas fluorimétrico (Biotek® SynergyTM HT plate reader) através da emissão de fluorescência em 460 nm (excitação em $355 \mathrm{~nm}$ ) gerada pela hidrólise do substrato N-benzóxcarbonil-L-fenilalanina-L-arginina-amido-metil-cumarina (Z-FR-AMC, Sigma Aldrich). A enzima foi descongelada rapidamente a $37{ }^{\circ} \mathrm{C}$ e incubada com o tampão de ensaio (acetato de sódio $100 \mathrm{mM}, \mathrm{NaCl} 300 \mathrm{mM}$, DTT $5 \mathrm{mM}$ em pH 5,5) por 20 minutos. A reação foi iniciada pela adição do substrato após 2 minutos de incubação com os inibidores.

Os compostos foram testados em concentrações determinadas previamente através dos ensaios de percentual de inibição e foram dispensados nos poços dissolvidos em DMSO. Foi realizada a inspeção visual e uma pré-leitura da placa com o intuito de verificar possível precipitação dos inibidores e fluorescência de fundo. Além disso, o espectro de emissão de fluorescência foi obtido para todos os inibidores no mesmo comprimento de onda de 
excitação (355 nm) usado no ensaio fluorimétrico. Nenhum dos compostos apresentou sinal de emissão próximo a $460 \mathrm{~nm}$, comprimento de onda usado no ensaio enzimático.

A velocidade inicial da reação foi monitorada durante um período de 10 minutos para inibidores de ligação rápida e 30 minutos para inibidores de ligação lenta. Os experimentos foram realizados no mínimo em triplicatas para cada composto testado e a constante de inibição $\left(K_{\mathrm{i}}\right)$ foi determinada através da análise da curva progresso, segundo os métodos descritos nas sessões 3.5.

$\mathrm{O} K_{\mathrm{M}}$ das enzimas foram calculados usando oito diferentes concentrações do substrato que variaram de 18-1.4 $\mu \mathrm{M}$ para $L m C P B 2.8 \Delta \mathrm{CTE}$ e 25-0,69 $\mu \mathrm{M}$ para cruzaína W.T e catepsina L.

Para a determinação do mecanismo de inibição, alguns ligantes foram avaliados em até três diferentes concentrações, usando o método de Michaelis-Menten. O software SigmaPlot (v. 10.0) foi empregado para o ajuste não linear dos dados e determinação dos parâmetros cinéticos.

A concentração de cruzaína usada no ensaio foi de $0,15 \mathrm{nM}$ e o $\mathrm{K}_{\mathrm{M}}$ variou entre 0,92 2,3 $\mu \mathrm{M}$ durante as análises. Para enzima $\operatorname{LmCPB} 2.8 \Delta \mathrm{CTE}$, a concentração enzimática foi de 7,0 $\mathrm{nM}$ e os valores de $\mathrm{K}_{\mathrm{M}}$ obtidos variaram entre 4,0-6,0 $\mu \mathrm{M}$. A catepsina $\mathrm{L}$ de humanos foi comercialmente adquirida da Sigma-Aldrich. A concentração de enzima usada no ensaio foi 2 nM e o $\mathrm{K}_{\mathrm{M}}$ variou de 3,0-5,0 $\mu \mathrm{M}$.

\subsection{Caracterização cinética de inibidores através da análise da curva progresso}

A análise da curva progresso (do inglês, PCA - progress curve analysis) é um método usado para avaliar o efeito de inibidores e ativadores em reações enzimaticamente catalisadas. ${ }^{61}$ Esse método pode ser empregado na análise de inibidores tempo- e dose dependentes e sua configuração pode ser facilmente adaptada para ensaios em larga escala.

$\mathrm{Na}$ configuração desse experimento, concentrações variadas do composto teste são pré-incubadas com uma concentração fixa de enzima. O substrato é adicionado com o mínimo volume de diluição possível e a reação é monitorada por um longo período de tempo através do qual a condição de equilíbrio do estado estacionário deve ser mantida. Para essa finalidade, um controle sem inibidor é usado para garantir a linearidade do ensaio durante todo o tempo de análise. Mudanças lineares da curva progresso da reação (RFU x tempo) são tipicamente produzidas por inibidores de ligação rápida. Por outro lado, mudanças assintóticas da curva 
progresso são produzidas por inibidores de ligação lenta. A partir da análise da curva progresso pode-se determinar a constante de afinidade $K_{\mathrm{i}}$ do composto estudados, assim como os parâmetros cinéticos da interação $\left(\mathrm{k}_{\text {on }}\right.$ e $\left.\mathrm{k}_{\text {off }}\right)$ para os inibidores de ligação lenta. Isso será matematicamente descrito nas próximas sessões.

\subsubsection{Caracterização cinética de inibidores de ligação rápida}

A constante de inibição aparente $K_{\mathrm{i}}^{\prime}$ para inibidores de ligação rápida foi determinada através do ajuste não-linear dos dados na equação 9:

$$
v_{s}=\frac{v_{0}}{1+[I] / K_{i}^{\prime}}
$$

Onde $\mathrm{v}_{\mathrm{s}}$ é a velocidade no estado estacionário, $\mathrm{v}_{0}$ é a velocidade na ausência de inibidor e [I] é a concentração do inibidor. A constante de inibição verdadeira $K_{\mathrm{i}}$ foi calculada pela correção de $K_{\mathrm{i}}^{\prime}$ de acordo com a equação $K_{i}=K_{\mathrm{i}}^{\prime} /\left(1+[\mathrm{S}] / K_{\mathrm{M}}\right)$, onde [S] é a concentração de substrato e $K_{\mathrm{M}}$ é a constante de Michaelis-Menten. A concentração de substrato usado no experimento foi igual ao valor de $\mathrm{K}_{\mathrm{M}}$ obtido separadamente para cada uma das enzimas estudadas.

\subsubsection{Determinação dos parâmetros cinéticos de inibidores de ligação lenta}

A caracterização dos inibidores de ligação lenta foi realizada através da análise da curva progresso, seguindo o tratamento matemático proposto por Morrison e Walsh. Assim a reação foi iniciada pela adição da enzima em uma solução contendo concentrações variadas do inibidor e uma concentração fixa do substrato fluorogênico Z-Phe-Arg-AMC no tampão de reação (tampão acetato de sódio $100 \mathrm{mM}, \mathrm{NaCl} 300 \mathrm{mM}, \mathrm{pH} 5,5$, DTT $1 \mathrm{mM}$ a $37{ }^{\circ} \mathrm{C}$ ). A característica não-linear da curva progresso típica de inibidores de ligação lenta foi obtida para todas as dipeptidil azanitrilas testadas nesse trabalho, o que reflete o estabelecimento do equilíbrio entre a enzima e o inibidor. Um exemplo está ilustrado na figura 13, onde o controle do ensaio (sem inibidor) fornece uma linha reta para a curva progresso.

Cada curva progresso foi analisada por regressão não-linear utilizando a equação 10 descrita por Morrison e Walsh: ${ }^{62}$ 


$$
[P]=v_{s} t+\frac{\left(v_{i}-v_{s}\right)\left(1-e^{-k_{o b s}}\right)}{k_{o b s}}+d
$$

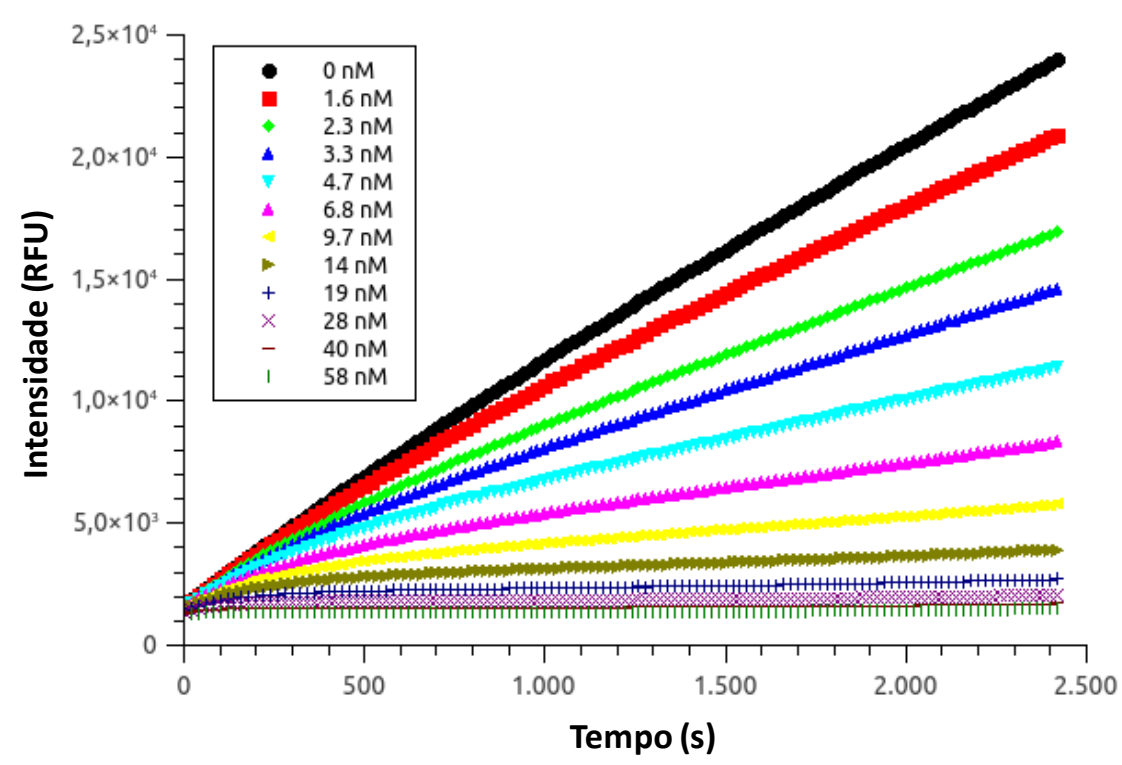

Figura 14- Curvas progresso para enzima $L m C P B 2.8 \Delta \mathrm{CTE}$ inibida por diferentes concentrações do Neq0687. [Z-Phe-Arg-AMC $]=25 \mu \mathrm{M},[\operatorname{LmCPB} 2.8 \Delta \mathrm{CTE}]=7 \mathrm{nM}$.

Onde $[\mathrm{P}]$ é a concentração do produto, $\mathrm{v}_{\mathrm{s}}$ é a velocidade no estado estacionário, $\mathrm{v}_{\mathrm{i}}$ é a velocidade inicial, $\mathrm{k}_{\mathrm{obs}}$ é a constante de velocidade de pseudo-primeira ordem observada e d é o deslocamento.

De forma geral, os inibidores de ligação lenta apresentam dois mecanismos básicos de ação (Figura 16): 

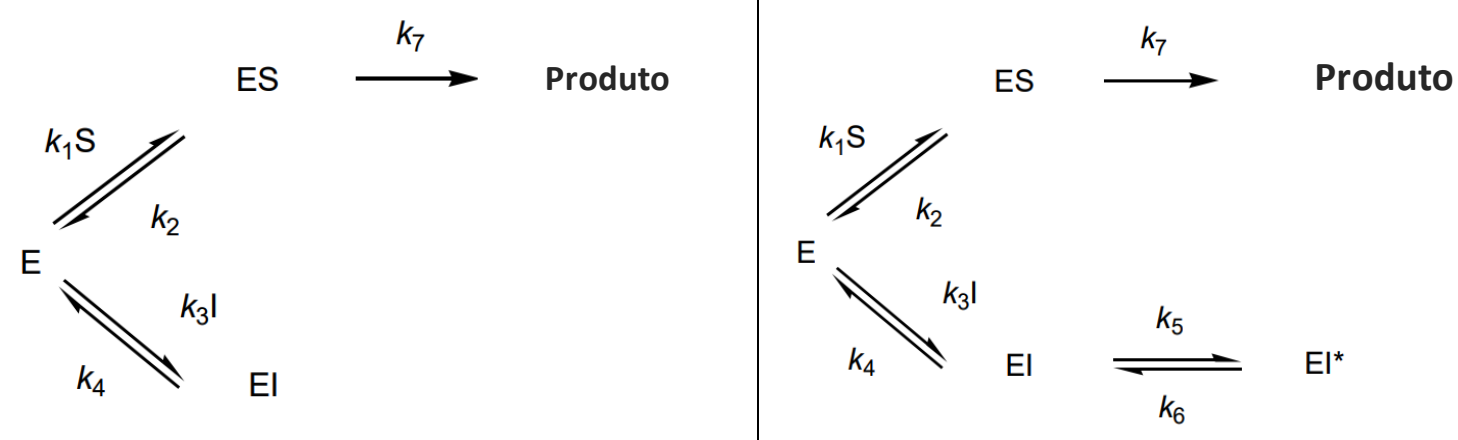

Figura 15- Mecanismo geral de inibição lentamente reversível para reações catalisadas por enzimas (E para a enzima livre, I para o inibidor e S para o substrato)

O mecanismo A assume que a formação do complexo EI ocorre em uma única etapa, simples e lenta, sem qualquer isomerização envolvida e pode ser representado pela seguinte expressão a baixo (figura 16):

$$
\mathrm{E}+\mathrm{I} \underset{k_{\text {off }}}{\stackrel{k_{\text {on }}}{\rightleftarrows}} \mathrm{E} \mathrm{I}
$$

Figura 16- Mecanismo A de um inibidor de ligação lenta.

Onde $\mathrm{k}_{\mathrm{on}}$ é equivalente ao $\mathrm{k}_{3}$ que corresponde a constante de velocidade de segunda ordem para formação do complexo EI e o $\mathrm{k}_{\text {off }}$ equivale ao $\mathrm{k}_{4}$ e corresponde a constante de velocidade de primeira ordem para o decaimento do complexo EI.

Para o mecanismo A, os gráficos de pseudo-primeira ordem para a inibição da enzima, $\mathrm{k}_{\mathrm{obs}}$ versus [I], foram lineares (figura 11) e um valor aparente da constante de associação, $\mathrm{k}_{\mathrm{on}}$, foi determinado pela inclinação da reta de acordo com a equação 11.

$$
k_{o b s}=k_{o n}^{\prime}[I]+k_{o f f}
$$

Dessa forma, o valor obtido foi corrigido considerando a interação entre a enzima e o substrato. Essa interação reduz parcialmente a concentração de enzima susceptível a inativação. A verdadeira constante de velocidade $\mathrm{k}_{\text {on }}$ foi calculada pela correção de $\mathrm{k}_{\text {on }}$ ' de acordo com a equação 12 :

$$
k_{o n}=\frac{k_{o n}^{\prime}}{1+[S] / K_{M}}
$$

Sendo [S] a concentração de substrato usada e $\mathrm{K}_{\mathrm{M}}$ a constante de Michaelis para o substrato Z-Phe-Arg-AMC determinada previamente em um ensaio separado. 
O $K_{\mathrm{i}}$ foi calculado pela regressão linear das velocidades medidas no estado estacionário, $\mathrm{v}_{\mathrm{s}}$ e $\mathrm{v}_{0}$ (onde $\mathrm{v}_{0}$ é a velocidade para a formação do produto na ausência do inibidor), através da equação 13 (figura 18). Um valor aparente de $K_{\mathrm{i}}$ ' foi, então, obtido e corrigido através da equação 14.

$$
\begin{gathered}
v_{s}=\frac{v_{0}}{1+[I] / K_{i}^{\prime}} \\
K_{i}=\frac{K_{i}^{\prime}}{1+[S] / K_{M}}
\end{gathered}
$$

A constante de velocidade de primeira ordem $k_{\text {off }}$ para a dissociação do complexo enzima-inibidor foi calculada de acordo com a equação 15:

$$
k_{\text {off }}=k_{\text {on }} K_{i}
$$

O mecanismo B é fundamentalmente caracterizado por duas etapas: a primeira envolve o choque entre as espécies e uma rápida formação do complexo EI. Subsequentemente a formação do complexo EI, a enzima sofre um processo de isomerização $\left(\mathrm{k}_{5}\right)$ que é mais lenta do que a etapa relacionada a formação do complexo inicial. Essa isomerização envolve uma mudança conformacional na enzima, $\mathrm{E}^{*}$, que resulta em uma afinidade consideravelmente maior pelo inibidor. A liberação da enzima a partir do complexo $\mathrm{E}^{*} \mathrm{I}$ é governada pela constante de primeira ordem $\mathrm{k}_{6}$. ). Esse mecanismo está descrito na figura 17:

$$
\mathrm{E}+\mathrm{I} \underset{K_{\mathrm{i}}}{\rightleftarrows} \mathrm{EI} \underset{k_{\text {off }}}{\stackrel{k_{\text {inact }}}{\rightleftarrows}} \mathrm{EI}^{*}
$$

Figura 17- Mecanismo B de um inibidor de ligação lenta, envolvendo uma etapa de isomerização.

Onde o $\mathrm{k}_{\text {inact }}$ é equivalente a $\mathrm{k}_{5}$, sendo a constante de primeira ordem da etapa de inativação química e $\mathrm{k}_{\text {off }}$ equivalente $a \mathrm{k}_{6}$. Quando o $\mathrm{k}_{\text {off }}$ tende a zero, o composto se torna um inibidor irreversível de ligação lenta e forte (do inglês, slow tigh-biding irreversible inhibitor), conduzindo a formação de um complexo enzima-inibidor altamente estável que é, para todos os fins práticos, irreversível. 
Para o mecanismo B, os gráficos de pseudo-primeira ordem para a inibição da enzima, $\mathrm{k}_{\mathrm{obs}}$ versus [I], produz curvas no formato de uma hipérbole retangular e essa característica pode ser utilizada para diferenciar os mecanismos A e B.

Todos os aza análogos testados produziram gráficos lineares para a relação $\mathrm{K}_{\mathrm{obs}}$ versus [I], indicando que a possível isomerização das enzimas estudadas não ocorreu. Por esse motivo uma descrição matemática detalhada do mecanismo B foge do escopo desse trabalho e não será discutida aqui.

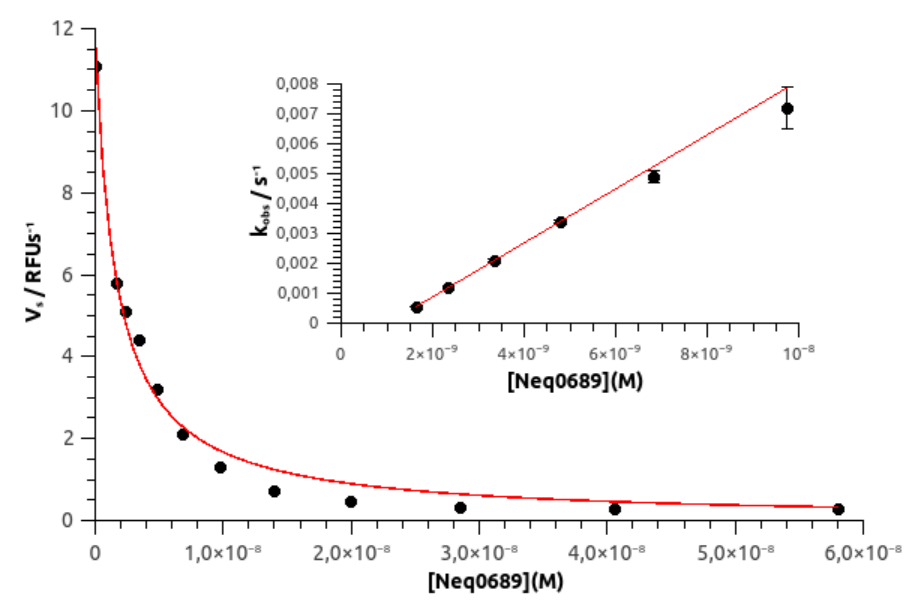

Figura 18- gráfico das taxas de velocidade obtidas no equilíbrio do estado estacionário, $\mathrm{v}_{0}$ e $\mathrm{v}_{\mathrm{i}}$, versus a [Neq0689] para a reação catalisada pela LmCPB2.8 $\triangle$ CTE. O inserto é um gráfico da constante de pseudoprimeira ordem $\mathrm{k}_{\mathrm{obs}}$ versus [Neq0689]. A relação linear obtida indica que esse inibidor através do mecanismo A de inibição lenta.

\subsection{Ensaios de cristalização}

Todos os experimentos de cristalização foram realizados no Grupo de Biologia Estrutural localizado no Centro de Biologia Molecular da Universidade de Nottingham Inglaterra (CBS), sob a supervisão do Prof. Dr. Jonas Emsley, durante o estágio sanduíche realizado no período de 11 de setembro de 2016 a 7 de setembro de 2017.

Experimentos de difusão a vapor de gota sentada foram usados para a pesquisa de condições de cristalização da enzima $\operatorname{LmCPB} 2.8 \Delta \mathrm{CTE}$ complexada com inibidores nitrílicos a partir de diferentes kits de cristalização, tais como: Crystal PiPEG, Index, PACT, Morpheus, JCSG, Proplex, SaltRx, MIDAS, MemGold I e MemGold II entre outros. As placas foram então incubadas em câmaras de cristalização à $20^{\circ} \mathrm{C}$. 
As triagens iniciais foram realizadas com o auxílio do robô mosquito. Cada gota montada na placa de cristalização era composta por $0.150 \mu l$ da enzima LmCPB2.8 $\Delta$ CTE/inibidor entre $5-10 \mathrm{mg} / \mathrm{ml}$ e $0.150 \mu \mathrm{l}$ da solução de cristalização. As gotas foram então equilibradas contra $80 \mu \mathrm{l}$ da solução de cristalização no reservatório. As amostras de enzima utilizadas nos ensaios de triagem apresentavam elevada pureza (avaliada pela ausência de bandas de proteínas contaminantes no gel SDS-PAGE) e foram sempre preparadas em tampão TRIS $50 \mathrm{mM}(\mathrm{pH}$ 8,0) e $\mathrm{NaCl} 20 \mathrm{mM}$.

Nos experimentos de co-cristalização, os inibidores foram inicialmente solubilizados em DMSO e então utilizados na preparação das amostras com concentração molar 10 vezes superior à concentração de enzima (razão estequiométrica 1:10 proteína/inibidor) de forma que a concentração de DMSO final não excedesse 3\%. Nos casos de baixa solubilidade, uma concentração de inibidor dez vezes superior ao valor de $K_{\mathrm{i}}$ (constante de inibição) foi utilizada.

As condições iniciais de cristalização identificadas no experimento de triagem produziram, na maioria dos casos, cristais pequenos e com baixo poder de difração ( $\sim$ A $)$. A tabela 1 sumariza cada condição de cristalização onde pontos de nucleação foram identificados com o respectivo inibidor co-cristalizado. A otimização dessas condições foi realizada utilizando-se uma placa de cristalização de 24 poços com gotas de $2 \mu 1(1 \mu 1$ proteína/inibidor: $1 \mu 1$ solução de cristalização) equilibradas contra $500 \mu 1$ da solução de cristalização no reservatório. Pequenas e incrementais mudanças na concentração de precipitante, concentração de proteína e $\mathrm{pH}$ foram realizadas e cristais de tamanho adequado surgiram entre 10-20 dias de incubação.

Todos os cristais obtidos foram congelados em nitrogênio líquido com o auxílio de solução crio protetora (20-30\% de glicerol adicionado à solução de cristalização). A exceção refere-se aos cristais obtidos da condição D, uma vez que o MPD na concentração utilizada já possui ação crio-protetora. Os cristais pescados em loops de diversos tamanhos foram armazenados em pucks e transportados em deware contendo nitrogênio líquido até o local de coleta. 


\begin{tabular}{|c|c|c|c|c|c|c|}
\hline Condição & Kit screen & Ligante & Sal & Tampão & Precipitante & Temp \\
\hline $\mathbf{A}$ & $\begin{array}{l}\text { PACT } \\
\text { (D11) }\end{array}$ & Neq0409 & $\begin{array}{c}\text { Cloreto de cálcio } 0.2 \\
\text { M }\end{array}$ & $\begin{array}{l}\text { Tampão tris } \\
0.1 \mathrm{M}, \mathrm{pH} 8\end{array}$ & $\begin{array}{c}\text { PEG } 600020 \% \\
(\mathrm{w} / \mathrm{v})\end{array}$ & $20^{\circ} \mathrm{C}$ \\
\hline B & PACT (H5) & Neq0409 & Nitrato de sódio $0.2 \mathrm{M}$ & $\begin{array}{c}\text { Bis tris propano } \\
0.1 \mathrm{M}, \mathrm{pH} 8.5\end{array}$ & $\begin{array}{c}\text { PEG } 335020 \% \\
(w / v)\end{array}$ & $20^{\circ} \mathrm{C}$ \\
\hline $\mathbf{C}$ & SaltRX & MMTS & & $\begin{array}{c}\text { Tampão acetato } \\
0.1 \mathrm{M}, \mathrm{pH} 4.6\end{array}$ & $\begin{array}{c}\text { Sulfato de lítio } \\
\text { monohidratado } \\
0.8 \mathrm{M}\end{array}$ & $20^{\circ} \mathrm{C}$ \\
\hline D & Memgold2 & Neq0690 & & $\begin{array}{l}\text { Tampão tris } \\
0.1 \text { M, pH } 8\end{array}$ & MPD $65 \%$ & $20^{\circ} \mathrm{C}$ \\
\hline
\end{tabular}

Tabela 1- Condições de cristalização identificadas nos experimentos de triagens com Kits comercialmente disponíveis.

Os cristais obtidos a partir da otimização das condições A e B se mostraram extremamente sensíveis a radiação e com baixo poder de difração (resolução maior que $3 \AA ̊$ ). Além disso, pouca densidade eletrônica estava disponível para a construção do inibidor no sítio ativo e uma severa geminação dos cristais impossibilitava o processamento dos dados assim como o refinamento da estrutura. A figura 20 mostra a morfologia dos cristais obtidos a partir dos experimentos de co-cristalização da $L m \mathrm{CPB} 2.8 \Delta \mathrm{CTE}$ com o composto prototípico Neq0409.

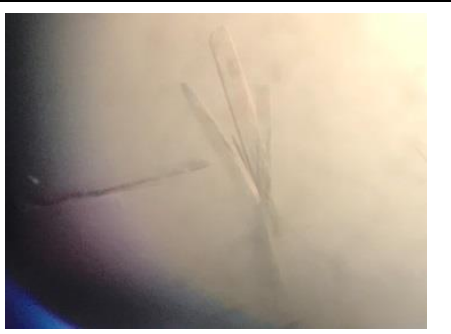

A

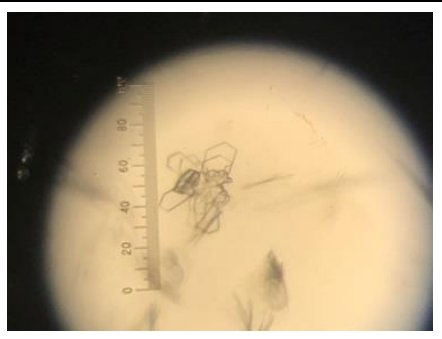

B

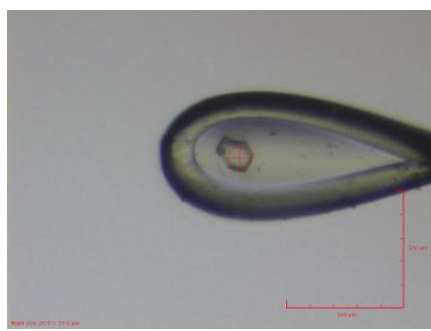

$\mathrm{D}$

$\mathrm{C}$

Figura 19 - Cristais obtidos a partir dos ensaios de co-cristalização da enzima LmCPB2.8 $\Delta$ CTE com o composto prototípico Neq0409. A e B corresponde aos cristais provindos da otimização da condição A (tabela 1, PACT D11). C e D corresponde aos cristais obtidos a partir da otimização da condição B (tabela 1, PACT H5). 
Por outro lado, os cristais obtidos a partir da otimização das condições C e D difrataram com alta resolução e forneceram excelentes densidades eletrônicas para os inibidores co-cristalizados (figura 21).

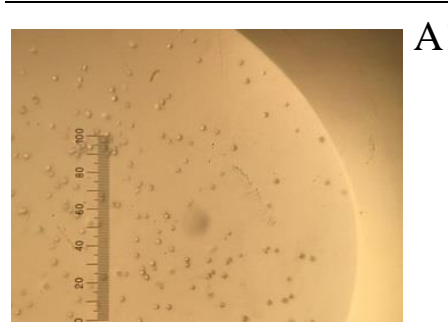

B1

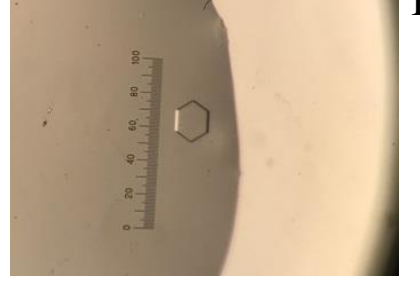

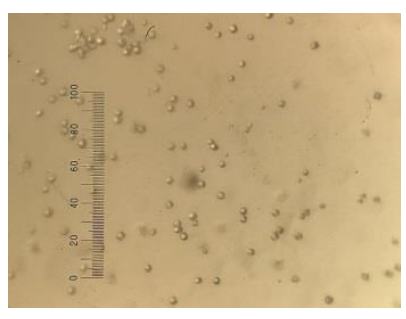

A2
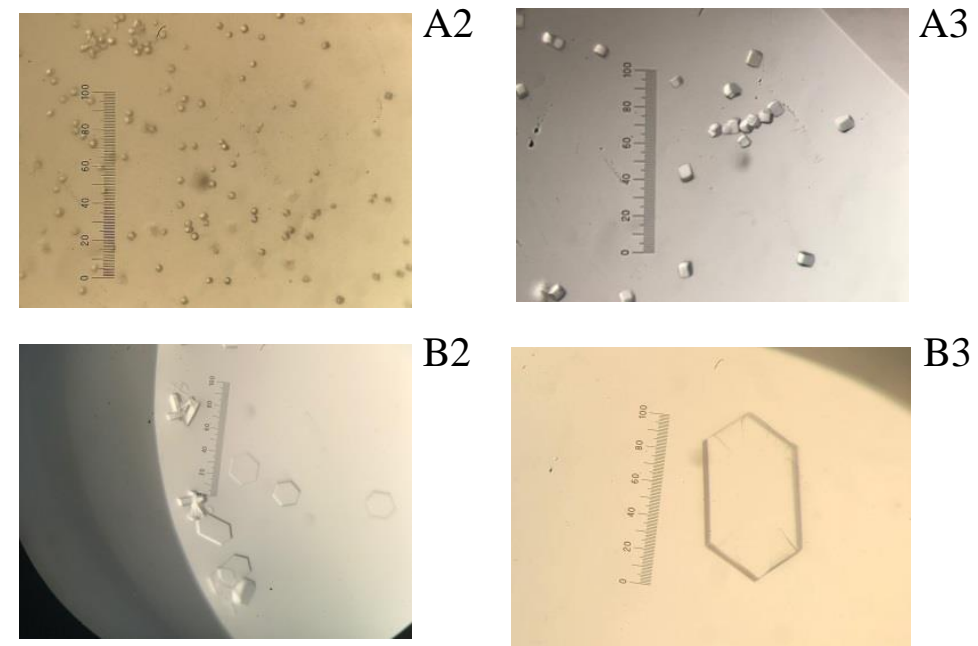

B2

B3

Figura 20 - Em A1, cristais de morfologia cúbica referentes a LmCPB2.8 $\Delta$ CTE co-cristaliza com o inibidor MMTS obtidos a partir dos ensaios de triagem (condição C, tabela 1). Em A2 e A3 estão os cristais produzidos a partir da otimização desta condição. Em B1, é apresentado o cristal de morfologia hexagonal referente a enzima LmCPB2.8 $\triangle$ CTE co-cristalizada com o Neq0690 obtido a partir da condição D (tabela 1). B2 e B3 correspondem a otimização dessa condição para a produção de cristais gigantes.

A dipeptidil azanitrila, Neq0690, apresentou elevada afinidade contra a enzima LmCPB2.8 $\Delta$ CTE associado a um mecanismo covalente-reversível de inibição dependente do tempo. Compostos dessa classe têm sido extensivamente estudados como inibidores de ligação lenta de cisteíno proteases, porém não há, até o presente momento, qualquer informação estrutural disponível de aza análogos complexados com enzimas da família da papaína. Nesse sentido, a elucidação da estrutura tridimensional do co-complexo Neq0690$L m \mathrm{CPB}$ se torna especialmente relevante dentro do contexto da química medicinal, tanto pela novidade relacionada a estrutura da enzima envolvida quanto pelas informações relacionadas ao modo de interação desse inibidor. Essas informações poderão orientar os esforços despendidos no desenvolvimento de novos inibidores enzimáticos mais potentes e eficazes para essa enzima.

Uma segunda estratégia adotada nesse trabalho envolveu a obtenção de cristais da LmCPB2.8 $\Delta$ CTE complexada com MMTS, um inibidor covalente-reversível cisteíno proteases. ${ }^{63}$ Considerando que essa ligação covalente possa ser facilmente revertida com o uso de agentes redutores, como o DTT, o crescimento de cristais desse co-complexo poderá fornecer uma valiosa via para estudos de "soaking" com outros ligantes de interesse. 


\subsection{Coleta e processamento de dados de difração de raios-X}

Os cristais foram submetidos a experimento de difração de raios-X na Fonte de Luz Diamond (Diamond Light Source) localizada no Campus de Inovação e Ciências de Harwell em Oxfordshire - Reino Unido, na linha de luz I24 equipada com o detector Pilatus3 6M.

Inicialmente, foi realizada uma triagem dos cristais usando a opção Grid Scan que permite, tanto a visualização de pequenos cristais no loop (algumas vezes escondidos por soluções opacas), quanto a identificação de regiões ótimas para difração (pontos quentes - do inglês, hot spots) em grandes cristais. Uma vez escolhida a melhor região a ser difratada, o sistema automaticamente alinha o cristal ao feixe de raios-X para iniciar a coleta dos dados. Essa opção só é possível graças a implementação do microfoco. Esse sistema permite alcançar um tamanho de feixe de aproximadamente $5 \times 5$ micrometros, possibilitando a difração de regiões específicas de grandes cristais e, principalmente, a difração de pequenos cristais (até 1,5 micrometros).

Uma vez identificada a melhor região do cristal para difração, seguia-se os testes iniciais de dose/tempo de exposição à radiação e determinação preliminar da resolução da difração. A indexação, integração e escalonamento dos dados foram realizadas no programa

iMosfilm e o grupo espacial foi confirmado usando o programa Pointless. ${ }^{64-65}$

Os dados coletados foram avaliados quanto a sua qualidade, considerando-se, principalmente, a resolução (melhor que 2.5Å), formas das reflexões, mosaicidade, dano causado pelo tempo de exposição à radiação e presença de patologias cristalográficas. Quando necessário, ajustes dos parâmetros de coleta e o realinhamento do cristal no feixe eram realizados.

Uma vez que a estrutura cristalográfica de raios-X da enzima $L m C P B 2.8 \Delta \mathrm{CTE}$ ainda não havia sido determinada, a recuperação das fases foi realizada por substituição molecular usando a estrutura da enzima homóloga cruzaína complexada com um inibidor não-covalente (código PDB 3KKU). O modelo inicialmente construído foi então refinado no programa Coot com ciclos de refinamento por máxima verossimilhança, com restrição de geometria, realizados pelo programa Refmac5. ${ }^{66-67}$ 


\section{Resultados e discussão:}

\subsection{Expressão, ativação e purificação da enzima cruzaína W.T.}

A tentativa de obter altos níveis de expressão de uma proteína heteróloga em E. coli pode resultar na produção de grandes quantidades de proteína enovelada incorretamente, produzindo agregados proteicos conhecidos como corpos de inclusão. O renovelamento e purificação dessas proteínas são geralmente custosos e resultam em uma baixa recuperação de enzima bioativa. As células competentes de E. coli do tipo ArcticExpress (DE3)RIL fornecem uma abordagem in vivo para aumentar o rendimento de proteínas heterólogas na fração solúvel, utilizando para isso baixas temperaturas de expressão. Estas células expressam as chaperoninas Cpn10 e Cpn60 (provenientes da bactéria Oleispira antárctica) que retêm grande parte de sua atividade catalítica mesmo em baixas temperaturas $\left(4-12{ }^{\circ} \mathrm{C}\right)$. O plasmídeo bacteriano pET-21a possui o gene lacI que codifica a proteína repressora de lac, um promotor T7 que é específico somente para a T7 RNA polimerase e um operador lac que pode bloquear a transcrição. Quando lactose ou uma molécula similar está presente na célula, a transcrição da T7 RNA polimerase é ativada. Um método que é bastante empregado atualmente para a expressão de grandes quantidades de proteínas de fusão é o de autoindução mínima, onde lactose é utilizado como agente indutor em um meio balanceado de sais e açúcares que fornecem a quantidade de nutrientes necessária para o crescimento celular e a expressão gradual da proteína de interesse. Essa expressão lenta e contínua da proteína alvo é responsável por um aumento na sua quantidade na fração solúvel. O meio de autoindução mínima foi usado nesse trabalho para o cultivo de células do tipo ArcticExpress (DE3)RIL com a finalidade expressar as enzimas $L m C$ PB2.8 $\Delta$ CTE e cruzaína na fração solúvel do lisado.

A cruzaína foi expressada na forma zimogênica que possui massa molecular de aproximadamente $36 \mathrm{kDa}$. O pró-domínio contribui com $14 \mathrm{kDa}$ e a porção madura com, aproximadamente, $22 \mathrm{kDa}$ restantes. Pode-se observar nos trilhos 2 e 3 do gel da figura 22A, referente as amostras retiradas após a lise das células, uma banda espessa na região de 37 $\mathrm{kDa}$, indicando que a enzima foi eficientemente expressada durante o período de $48 \mathrm{~h}$ e $60 \mathrm{~h}$. Pode-se observar, também, a presença da forma madura da enzima (próxima ao marcador de $25 \mathrm{kDa}$ ), o que indica que o processo de ativação ocorreu no interior da célula bacteriana, já na fase de expressão proteica. Os trilhos 7 e 8 do gel referem-se à fração citosólica, obtidas 
após a centrifugação do lisado e, também, indicam a presença da forma zimogênica e madura da cruzaína. Essa fração foi submetida à purificação por meio de cromatografia de afinidade ao níquel, permitindo a obtenção da enzima na forma zimogênica com alto grau de pureza. Após o processo de ativação, uma segunda etapa de purificação por gel filtração foi realizada com a finalidade de remover os fragmentos peptídicos provenientes da auto proteólise do pródomínio. A presença da forma madura da cruzaína foi confirmada por gel nas principais frações coletadas (figura 22B). Após esse processo, a enzima foi concentrada, congelada e estocada a $-80^{\circ} \mathrm{C}$ até o uso nos ensaios de determinação da constante de inibição $\left(K_{i}\right)$.
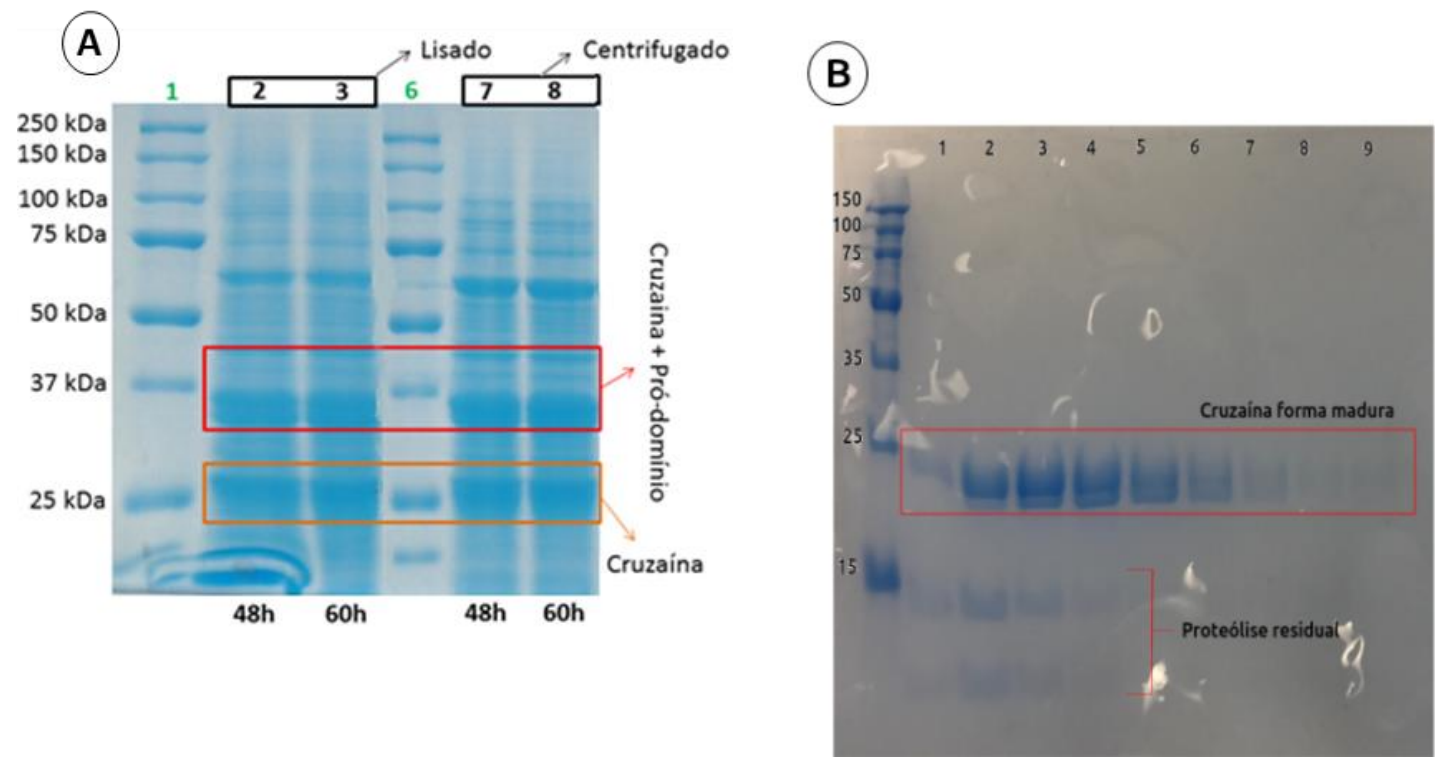

Figura 21 - A: Teste de expressão da enzima cruzaína W.T. Trilhas 2 e 3 referem-se a amostras do lisado coletadas após $48 \mathrm{~h}$ e $60 \mathrm{~h}$ de expressão, respectivamente. As trilhas 7 e 8 referem-se à fração citosólica de amostras coletadas em 48h e 60h de expressão; B: Principais frações coletadas a partir da coluna de gel filtração. Destaca-se a cruzaína madura com aproximadamente $23 \mathrm{kDa}$ e fragmentos peptídicos provenientes da auto proteólise enzimática em aproximadamente $13 \mathrm{kDa}$ e $10 \mathrm{kDa}$.

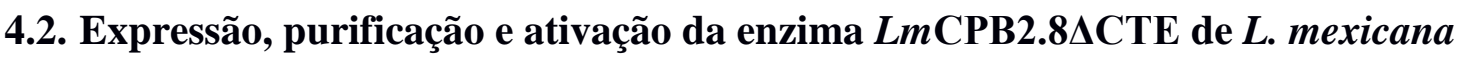

Uma extensa modificação do protocolo de expressão e purificação da enzima LmCPB2.8 $\Delta$ CTE foi necessária para a obtenção da enzima solúvel, ativa e em quantidade e pureza adequadas para a realização dos estudos bioquímicos e estruturais.

No protocolo original, aproximadamente $90 \%$ da proteína era expressa associada a corpos de inclusão e sua purificação envolvia o uso de agentes desnaturantes, além de várias etapas de renovelamento e diálises. Os rendimentos reportados estavam na ordem de 3,5 mg 
de enzima ativa após a auto ativação e purificação. ${ }^{68}$ No atual protocolo, a enzima LmCPB2.8 $\triangle \mathrm{CTE}$ foi totalmente expressa na fração solúvel do lisado com rendimentos de aproximadamente $10 \mathrm{mg}$ por litro de cultura, utilizando o método de autoindução publicado por Studier. ${ }^{60}$

A expressão do gene $L m \mathrm{CPB} 2.8 \Delta \mathrm{CTE}$ clonado no vetor pET-21a resultou na produção abundante de uma proteína de massa molecular próxima a $36 \mathrm{kDa}$ (figura 23A). Esse valor corresponde a massa predita da forma zimogênica da $L m C P B 2.8 \Delta C T E$ (35028 Da) acrescida de 930 Da provindos da cauda de seis histidinas adicionada na porção N-terminal. Embora a pró-enzima $(\sim 36 \mathrm{kDa})$ foi a forma predominante, duas outras formas de maior mobilidade $(\sim 27 \mathrm{kDa}$ e $\sim 23 \mathrm{kDa})$ foram detectadas no gel SDS/PAGE nesse estágio da purificação. Isso se deve a atividade proteolítica residual da enzima que iniciou o processamento da pró-região do zimogênio antes mesmo da etapa de auto ativação. A figura 23B confirma a eficácia do processo de auto ativação em converter a forma zimogênica (2) na forma completamente madura da $L m C$ PB2.8 $\Delta$ CTE de aproximadamente $23 \mathrm{kDa}$ (3), prevista, mas ainda não descrita na literatura.

Após a coluna de níquel, as frações principais foram coletadas e dialisadas para o tampão de ativação. A precipitação de parte da proteína era frequentemente observada durante a acidificação por diálise contra o tampão de ativação (tampão acetato $0.1 \mathrm{M}, \mathrm{pH} 5.5, \mathrm{NaCl}$ $300 \mathrm{mM})$. A baixa solubilidade da forma zimogênica $\left(\mathrm{pI}_{\text {(teórico) }}=5.1\right)$ no tampão de ativação, a presença de grupos -SH livres notoriamente conhecidos como indutores de agregação pela formação de ligações -S-S- intermoleculares, além da repentina mudança de $\mathrm{pH}$ durante a diálise foram considerados os mais significativos desencadeadores de precipitação. O ajuste do $\mathrm{pH}$ do tampão de lise ( $\mathrm{pH} 10$ para $\mathrm{pH}$ 8), assim como um procedimento de diálise em duas etapas reduziram dramaticamente a formação de precipitado. Além disso, a combinação de baixa concentração de proteína $(0.1-0.3 \mathrm{mg} / \mathrm{ml}$ ), alta força iônica (concentração de $\mathrm{NaCl}$ de 0.9M no tampão de ativação) na presença de altas concentrações de DTT 10mM contribuíram para maximizar o rendimento da forma madura após a ativação. A conversão da espécie de 36 $\mathrm{kDa}$ e $27 \mathrm{kDa}$ na forma madura de $23 \mathrm{kDa}$ foi confirmada por SDS/PAGE e a ativação foi monitorada através de ensaio fluorimétrico usando o substrato Z-FR-AMC. 

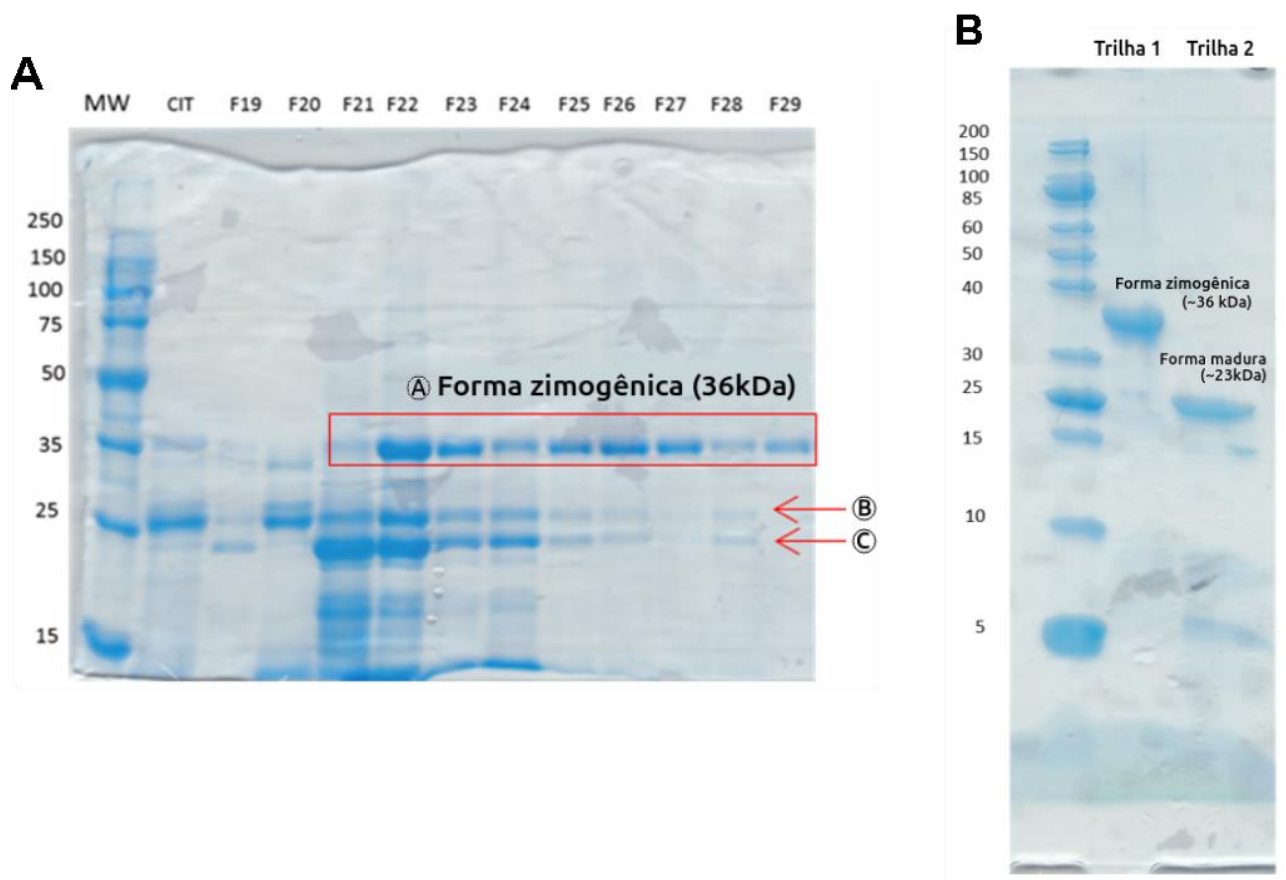

Figura 22 - A) Teste de expressão da CPB2.8DCTE de L. mexicana. CIT: fração solúvel do lisado; F19-F29: correspondem as frações coletadas a partir da coluna de Níquel; A: forma zimogênica da $L m C P B 2.8 \Delta C T E(\sim 36$ $\mathrm{kDa}$; B: forma intermediária da enzima de $\sim 27 \mathrm{kDa}$; C: forma madura da enzima de $\sim 23 \mathrm{kDa}$. B) Processo de ativação da pró- $L m$ CPB2.8 $\Delta$ CTE. Trilhas 1 e 2 correspondem as amostras colhidas antes e depois do processo de ativação que correspondem, respectivamente, as formas zimogênica ( 36 kDa) e madura ( 23 kDa) da enzima.

Fragmentos peptídicos obtidos a partir das bandas de $36 \mathrm{kDa}$ e $23 \mathrm{kDa}$ foram identificados por análise de espectrometria de massas e pesquisados contra a sequência primária de aminoácidos da pró-LmCPB2.8 $\triangle$ CTE. A espécie de $36 \mathrm{kDa}$ apresentou nove fragmentos peptídicos dos quais seis foram oriundos da pró-região da enzima, o que sugere que essa espécie corresponde a forma zimogênica da $L m C P B 2.8 \Delta C T E$ (figura 24A). Embora a espécie de $23 \mathrm{kDa}$ tenha apresentado dois dos mesmos fragmentos peptídicos da extremidade C-terminal, também encontrados na espécie de $36 \mathrm{kDa}$, nenhum sinal dos fragmentos peptídicos característicos da região $\mathrm{N}$-terminal foi identificado(figura 24B). A ausência da pró-região sugere que a espécie de $23 \mathrm{kDa}$ observada no gel de SDS/PAGE corresponde a forma madura de $23300 \mathrm{Da}$ da enzima. Os fragmentos peptídicos liberados durante o processo de ativação foram removidos por cromatografia por exclusão de tamanho e as frações foram coletadas, congeladas em nitrogênio líquido e estocadas a $-80^{\circ} \mathrm{C}$. 

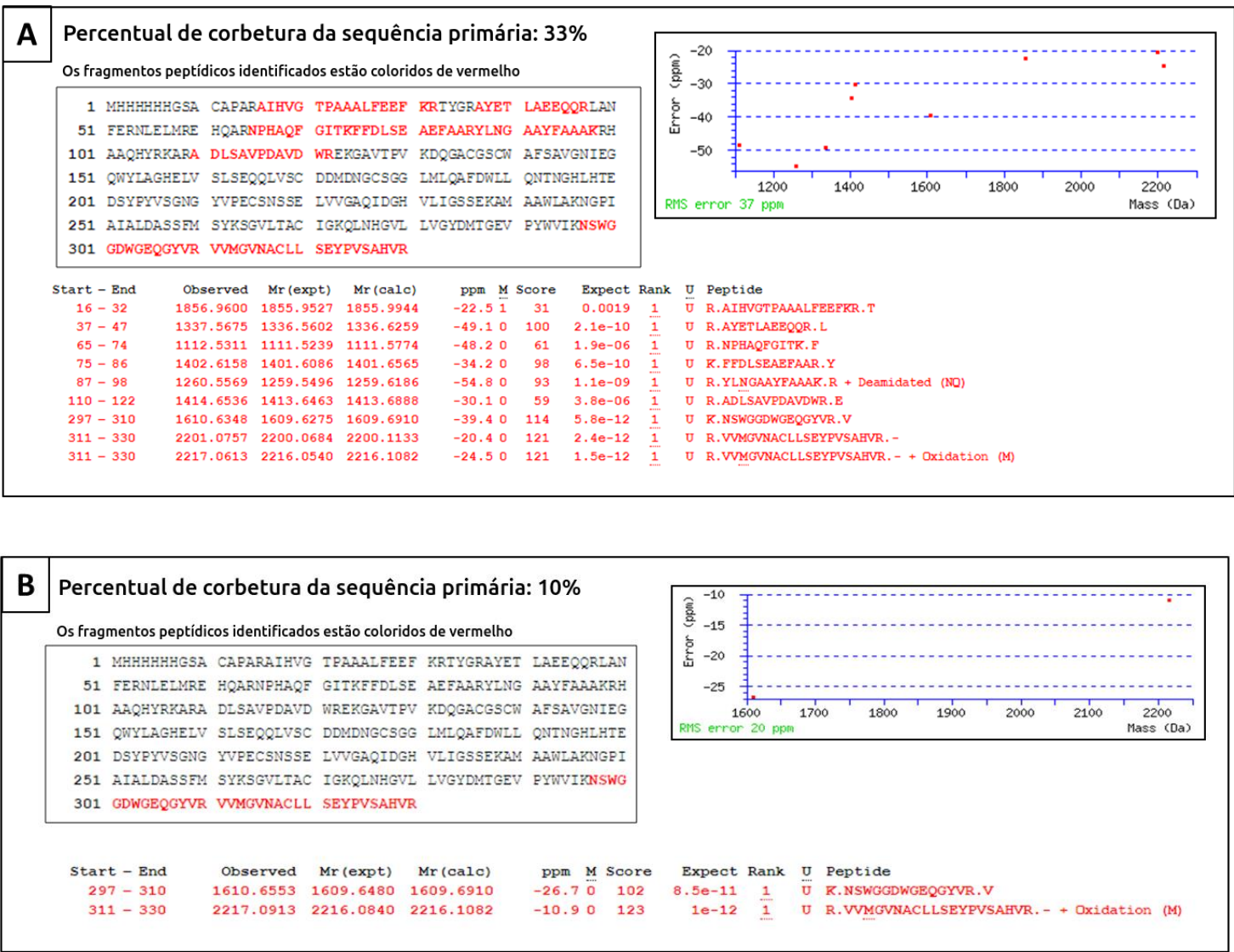

Figura 23 - Identificação das formas zimogênica (A) e madura (B) da enzima $L m C P B 2.8 \Delta C T E$, usando espectrometria de massas de alta resolução. Fragmentos peptídicos obtidos a partir do espectro de fragmentação MS/MS das bandas de $36 \mathrm{kDa}$ e $23 \mathrm{kDa}$ previamente tratadas com tripsina foram pesquisados contra a sequência primária da forma zimogênica da enzima. As regiões de correspondência são mostradas em vermelho.

\subsection{Estudos de inibição enzimática}

Modificações estruturais foram realizadas em diferentes regiões do composto prototípico incluindo as posições $\mathrm{P} 1, \mathrm{P} 2, \mathrm{P} 3$ e P1', sendo essa última correspondente ao warhead. Sendo assim, três classes de compostos nitrílicos sintetizados no grupo NEQUIMED foram exploradas nesse trabalho, são elas: dipeptidil nitrilas e seus derivados $\mathrm{CF}_{3}$ substituídos (obtidos pela substituição bioisostérica da ligação amida em $\mathrm{P} 2$ pelo grupo trifluoroetilamina), além das dipeptidil azanitrilas produzidas a partir da substituição do grupo aminonitrila em P1' pelo grupo azanitrila.

Em trabalhos anteriores realizados pelo nosso grupo, o Neq0409 foi co-crsitalizado com a enzima cruzaína e sua estrutura revelou que os substituintes das posições P1, P2 e P3 ocupavam três subsítios distintos da enzima S1, S2 e S3, respectivamente (Figura 25). ${ }^{69} \mathrm{~A}$ 
cadeia lateral do Glu208 estava exposta ao solvente e interações com os resíduos de aminoácidos Gln19, Asp61 e Gly66 foram observadas nos subsítios S1 e S3. ${ }^{69}$ Esse modo de interação é similar àqueles encontrados para análogos estruturais ligados catepsina L. ${ }^{70}$

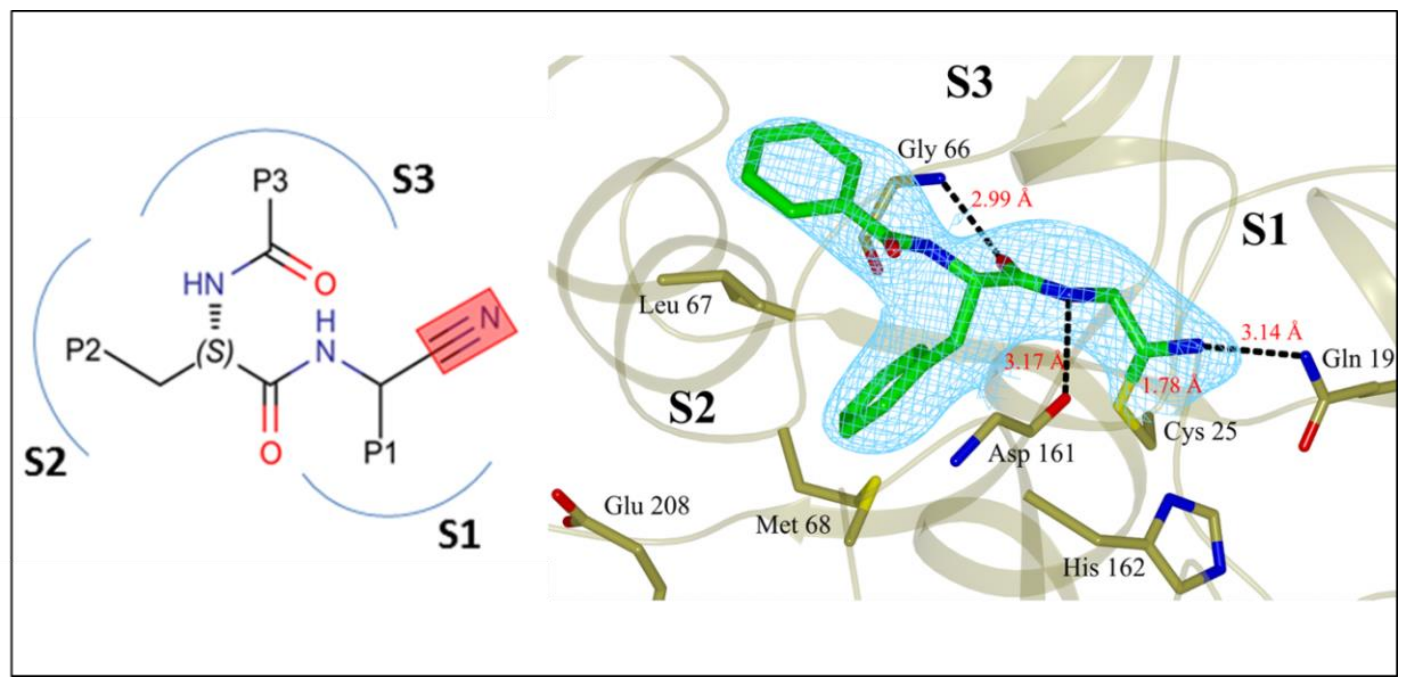

Figura 24- Na esquerda, uma visão esquemática do esqueleto molecular base da dipeptidil-nitrilas e as posições onde as modificações estruturais foram realizadas. Na direita, o modo de interação do Neq0409 com a enzima cruzaína, destacando o posicionamento dos grupos em P1, P2 e P3 ocupando os subsítios S1, S2 e S3. ${ }^{69}$

Uma lista detalhada de todos os compostos testados, bem como suas constantes de inibição contra as enzimas cruzaína, catepsina L e $L m C$ PB2.8 $\Delta$ CTE é apresentada ao final das sessões 4.3.1, 4.3.2 e 4.3.3.

\subsubsection{Avaliação das relações estrutura-atividade (SAR) para os derivados dipeptidil nitrílicos estudados nesse trabalho.}

A figura 26 mostra o ajuste dos dados para a curva de Michaelis-Menten e Lineweaver-Burk do composto Neq0409 testado contra a enzima cruzaína, evidenciando seu mecanismo de ação competitivo, bem como os valores das constantes cinéticas em três concentrações distintas do inibidor. Esse mesmo mecanismo de inibição também foi observado para as enzimas catepsina L e $L m \mathrm{CPB} 2.8 \Delta \mathrm{CTE}$. 


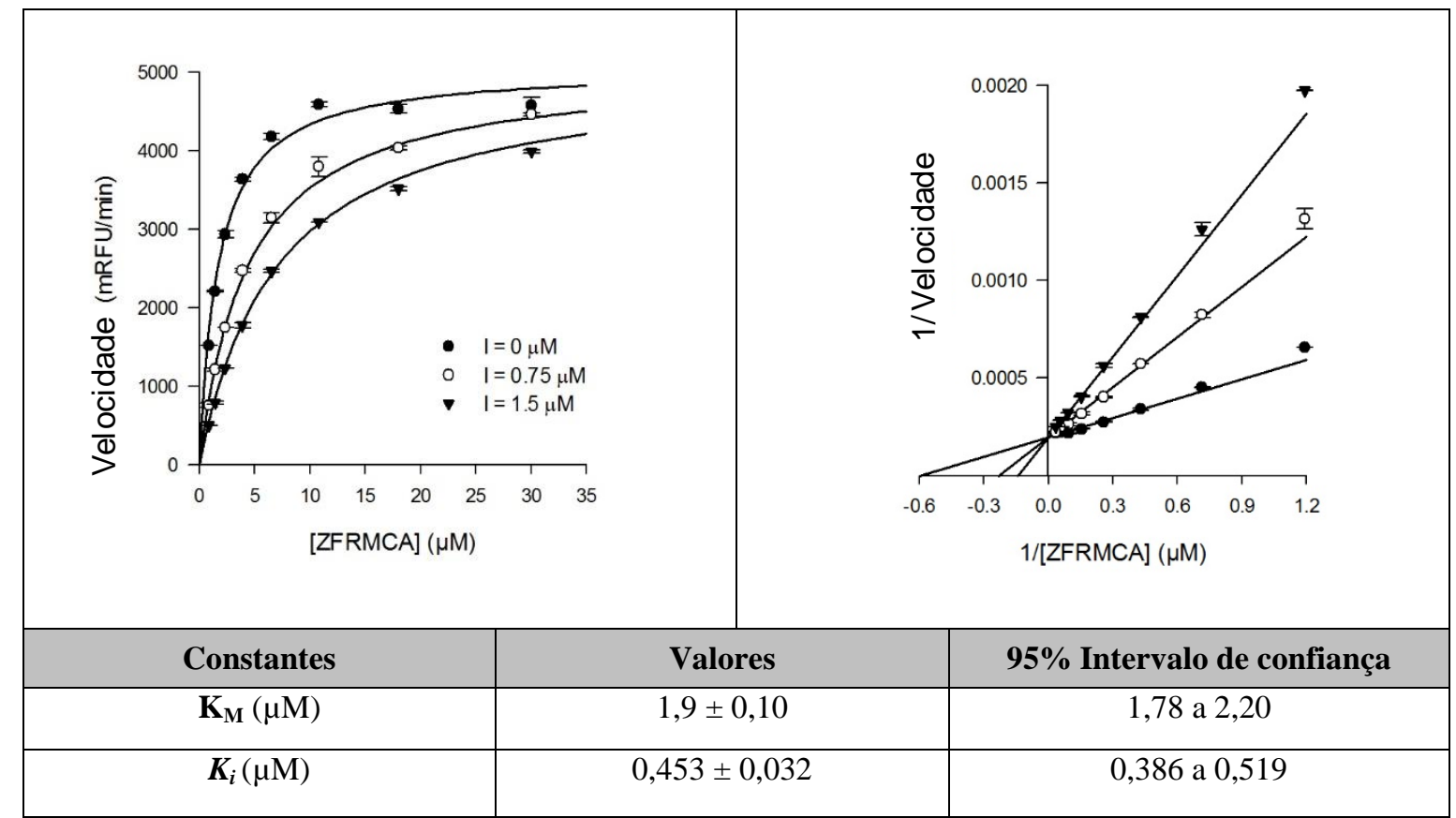

Figura 25 - Ajuste dos dados na curva de Michaelis-Meten e valor de Ki do composto prototípico Neq409 contra cruzaína. O gráfico de Lineweaver-Burk evidencia o mecanismo competitivo de inibição desse inibidor.

A atividade do Neq0409 contra várias cisteíno proteases da família da papaína já foi descrita na literatura. ${ }^{71}$ A substituição do grupo metileno pelo grupo ciclo propil na posição P1 do composto prototípico (Neq0570) conduziu a um aumento de 0,3 unidades logarítmicas em sua afinidade pela cruzaína. Um comportamento semelhante foi observado para a catepsina $\mathrm{L}$ e a $L m \mathrm{CPB} 2.8 \Delta \mathrm{CTE}$ com aumentos de afinidade de 0,4 e 0,2 unidades logarítmicas, respectivamente. Uma tendência de ganho de potência para todos os alvos (entre 0,2 - 0,4 unidades logarítmicas) foi observada para quatro pares de inibidores que possuíam a fenilalanina ou a leucina em P2. A adição do grupo ciclo propil em P1 é comum em um grande número de inibidores de cisteíno proteases e está relacionada a um aumento da estabilidade metabólica em virtude da elevada energia de dissociação da ligação C-H do ciclopropano. ${ }^{72}$ Além disso, foi reportado que essa modificação estrutural está associada a um aumento de quatro vezes na solubilidade aquosa de inibidores de catepsina $\mathrm{K}^{73}$

A substituição do grupo metileno em P1 do Neq0409 pelo grupo dimetil no Neq0410 resultou em perda de afinidade para todos os alvos analisados. Isso sugere que as restrições geométricas impostas pelo grupo dimetil comprometem a ocupação adequada do subsítio S1 dessas enzimas.

A substituição na posição P2 introduz um centro quiral no esqueleto dipeptídico. A preferência pela configuração (S) foi confirmada pela avaliação do Neq0579 que corresponde 
ao enantiômero $(R)$ do Neq0409. Esse composto apresentou valores de afinidade consideravelmente menores que o composto prototípico para todos os alvos avaliados.

A inserção do cloro na posição meta da fenilalanina do Neq0409 foi associada a um aumento de duas vezes na afinidade para a enzima cruzaína (Neq0413). Embora esse aumento foi expressivamente maior na catepsina L, um comportamento contrário foi observado para LmCPB2.8 $\Delta$ CTE com uma diminuição da afinidade em uma ordem de magnitude. Quando comparado ao Neq0570, a substituição da posição meta da fenilalanina pelo grupo ciano (Neq0578) em P2 conduziu a uma perda de afinidade para todos os alvos analisados. Essa substituição visou investigar possíveis interações com átomos doadores de ligação de hidrogênio na cadeia principal do subsítio S2. Uma estratégia semelhante já foi usada para explorar interações com os resíduos de aminoácidos Met70 e Asp71 nesse subsítio da catepsina L. ${ }^{74}$

Os análogos com tirosina (Neq0551) e triptofano (Neq0552) como substituintes da posição P2 do composto prototípico foram sintetizados com o intuito de se explorar uma possível interação com a cadeia lateral do Glu208 da cruzaína. Embora essa interação já tenha sido explorada em trabalhos prévios, ${ }^{75}$ os nossos resultados indicam apenas ganhos modestos de afinidade de até 0,4 unidades logarítmicas para cruzaína. Essas mesmas substituições produziram perdas de afinidade de até uma ordem de magnitude para $L m C P B 2.8 \triangle C T E$. Essa tendência pode ser estruturalmente justificada pela presença da Tyr210 que é equivalente ao Glu208 da cruzaína. Esse resíduo de aminoácido de natureza aromática polar altera significantemente o padrão de interação no fundo do subsítio S2 da $L m C P B 2.8 \Delta C T E$. Já o resíduo Ala214 da catepsina L (equivalente ao Glu208 na cruzaína) permite um melhor acomodamento de substituintes volumosos e hidrofóbicos no S2. Isso justifica os ganhos de afinidade de até 0.4 unidades logarítmicas para essas substituições.

A substituição da fenilalanina pela leucina na posição P2 do composto prototípico foi realizada com o intuito de explorar interações hidrofóbicas com os resíduos Leu67, Ala168 e Met68 no subsítio S2 da cruzaína. Apesar de não ter sido realizada diretamente no composto prototípico, essa substituição produziu um ganho de afinidade de 0,3 a 0,4 unidades logarítmicas para essa enzima. Em contraste, perdas de 0,2 a 0,6 unidades logarítmicas foram observadas para catepsina L e $L m$ CPB2.8 $\triangle$ CTE.

O Neq0571 e Neq0572 foram sintetizados a partir da substituição da fenilalanina pela ciclo leucina em P2 e suas afinidades para a cruzaína foram 1,2 e 1,7 unidades logarítmicas 
menores que seus respectivos análogos não substituídos. Essa mesma tendência foi observada para $L m C P B 2.8 \Delta C T E$ e catepsina L.

Várias modificações estruturais foram realizadas na posição P3 do composto prototípico. Os compostos sintetizados pela substituição do grupo fenila por anéis heteroaromáticos não resultaram em ganho de afinidade para qualquer um dos alvos avaliados. Os grupos pirazina (Neq0575) e pirimidina (Neq0574) se mostraram relativamente bem tolerados o que é consistente com um contato favorável entre as faces desses substituintes e a superfície hidrofóbica do subsítio S3. Intermediários sintéticos com grupos amino protetores (Neq0500 e Neq0400) foram, no máximo, equipotentes em comparação ao composto prototípico.

A adição em P3 do grupo 3-bromo-piridina (Neq0419) foi realizada com o intuito de se explorar a possível formação de uma ligação de halogênio com o grupo carbonil da cadeia principal do subsítio S3. Esse tipo de interação com o resíduo de aminoácido Gly61 já foi descrito para inibidores da catepsina $\mathrm{L}$, o que justifica o ganho de afinidade de uma ordem de magnitude observado para esse composto $\left(\mathrm{p} K_{\mathrm{i}(\mathrm{CATL})}=8.0\right)$. Em contraste, o modesto ganho de afinidade de 0,3 unidades logarítmicas nos fornece uma evidência circunstancial de que esse tipo de interação parece não ocorrer na cruzaína e na $L m C P B 2.8 \Delta C T E$.

A substituição em P3 do grupo fenil do Neq0409 pelo grupo 1-metil-3-terc-butilpirazol (Neq0414) resultou em um aumento de 0,9 e 0,8 unidades logarítmicas na afinidade pela cruzaína e LmCPB2.8 $\triangle \mathrm{CTE}$, respectivamente. Um ganho ainda maior de afinidade foi observado para catepsina L com 1,5 unidades logarítmicas a mais que o composto prototípico. Interessantemente, a dupla substituição envolvendo a adição do cloro na posição meta da fenilalanina em P2 e a adição do grupo 1-metil-3-terc-butil-pirazol em P3 (Neq0415; p $K_{\mathrm{i}(\mathrm{CRUZ})}$ $=7,8)$ conduziu a um aumento da afinidade para cruzaína de 1,5 unidades logarítmicas. Essa diferença no valor de $\mathrm{p} K_{\mathrm{i}}$ é superior àquelas produzidas pelas substituições em P2 (Neq0413; $\left.\Delta \mathrm{p} K_{\mathrm{i}}=0,3\right)$ e P3 (Neq0414; $\left.\Delta \mathrm{p} K_{\mathrm{i}}=0,9\right)$ tomadas isoladamente. Isso mostra que o efeito aditivo de um grupo pode ser influenciado pela presença do outro. Dessa forma o padrão de interação entre a enzima e o inibidor pode ser dependente do tipo de combinação de substituintes. Essa é uma característica da SAR que pode ser explorada e até mesmo melhorada em futuras otimizações. 


\begin{tabular}{|c|c|c|c|c|c|c|}
\hline $\begin{array}{c}\text { Neq } \\
\text { ID }\end{array}$ & P1 & $\mathrm{P} 2$ & P3 & $\begin{array}{c}\quad \mathrm{p} K_{\mathrm{i}}^{\mathrm{a}} \\
\text { (incert }^{\mathrm{b}} \text { ) } \\
\text { Cruzaina }\end{array}$ & $\begin{array}{c}\mathrm{p} K_{\mathrm{i}} \\
\text { (incert) } \\
\text { CatL } \\
\end{array}$ & $\begin{array}{c}\mathrm{p} K \mathrm{i} \\
\text { (incert.) } \\
\text { CPB2.8 } \\
\end{array}$ \\
\hline $\begin{array}{l}\text { Neq } \\
0400\end{array}$ & & & & $\begin{array}{c}5.6 \\
(0.03)\end{array}$ & $\begin{array}{c}5.9 \\
(0.04)\end{array}$ & $\begin{array}{c}5.8 \\
(0.05)\end{array}$ \\
\hline $\begin{array}{l}\text { Neq } \\
0409\end{array}$ & & & & $\begin{array}{c}6.3 \\
(0.03)\end{array}$ & $\begin{array}{c}6.9 \\
(0.06)\end{array}$ & $\begin{array}{c}6.6 \\
(0.03)\end{array}$ \\
\hline $\begin{array}{l}\mathrm{Neq} \\
0410\end{array}$ & & & & $\begin{array}{c}5.5 \\
(0.02)\end{array}$ & $\begin{array}{c}6.2 \\
(0.02)\end{array}$ & $\begin{array}{c}5.7 \\
(0.04)\end{array}$ \\
\hline $\begin{array}{l}\mathrm{Neq} \\
0413\end{array}$ & & & & $\begin{array}{c}6.6 \\
(0.02)\end{array}$ & $\begin{array}{c}7.7 \\
(0.02)\end{array}$ & $\begin{array}{c}5.2 \\
(0.06)\end{array}$ \\
\hline $\begin{array}{l}\mathrm{Neq} \\
0414\end{array}$ & & & & $\begin{array}{c}7.2 \\
(0.03)\end{array}$ & $\begin{array}{c}8.4 \\
(0.03)\end{array}$ & $\begin{array}{c}7.4 \\
(0.01)\end{array}$ \\
\hline $\begin{array}{l}\mathrm{Neq} \\
0415\end{array}$ & & & & $\begin{array}{c}7.8 \\
(0.03)\end{array}$ & $\begin{array}{c}8.9 \\
(0.02)\end{array}$ & $\begin{array}{c}6.6 \\
(0.02)\end{array}$ \\
\hline $\begin{array}{c}\text { Neq } \\
0419\end{array}$ & & & & $\begin{array}{c}6.8 \\
(0.02)\end{array}$ & $\begin{array}{c}8.0 \\
(0.03)\end{array}$ & $\begin{array}{c}6.9 \\
(0.03)\end{array}$ \\
\hline $\begin{array}{l}\mathrm{Neq} \\
0500\end{array}$ & & & & $\begin{array}{c}6.3 \\
(0.02)\end{array}$ & $\begin{array}{c}6.9 \\
(0.02)\end{array}$ & $\begin{array}{c}6.6 \\
(0.03)\end{array}$ \\
\hline $\begin{array}{l}\text { Neq } \\
0533\end{array}$ & & & & $\begin{array}{c}7.2 \\
(0.03)\end{array}$ & $\begin{array}{c}8.3 \\
(0.03)\end{array}$ & $\begin{array}{c}7.3 \\
(0.02)\end{array}$ \\
\hline
\end{tabular}




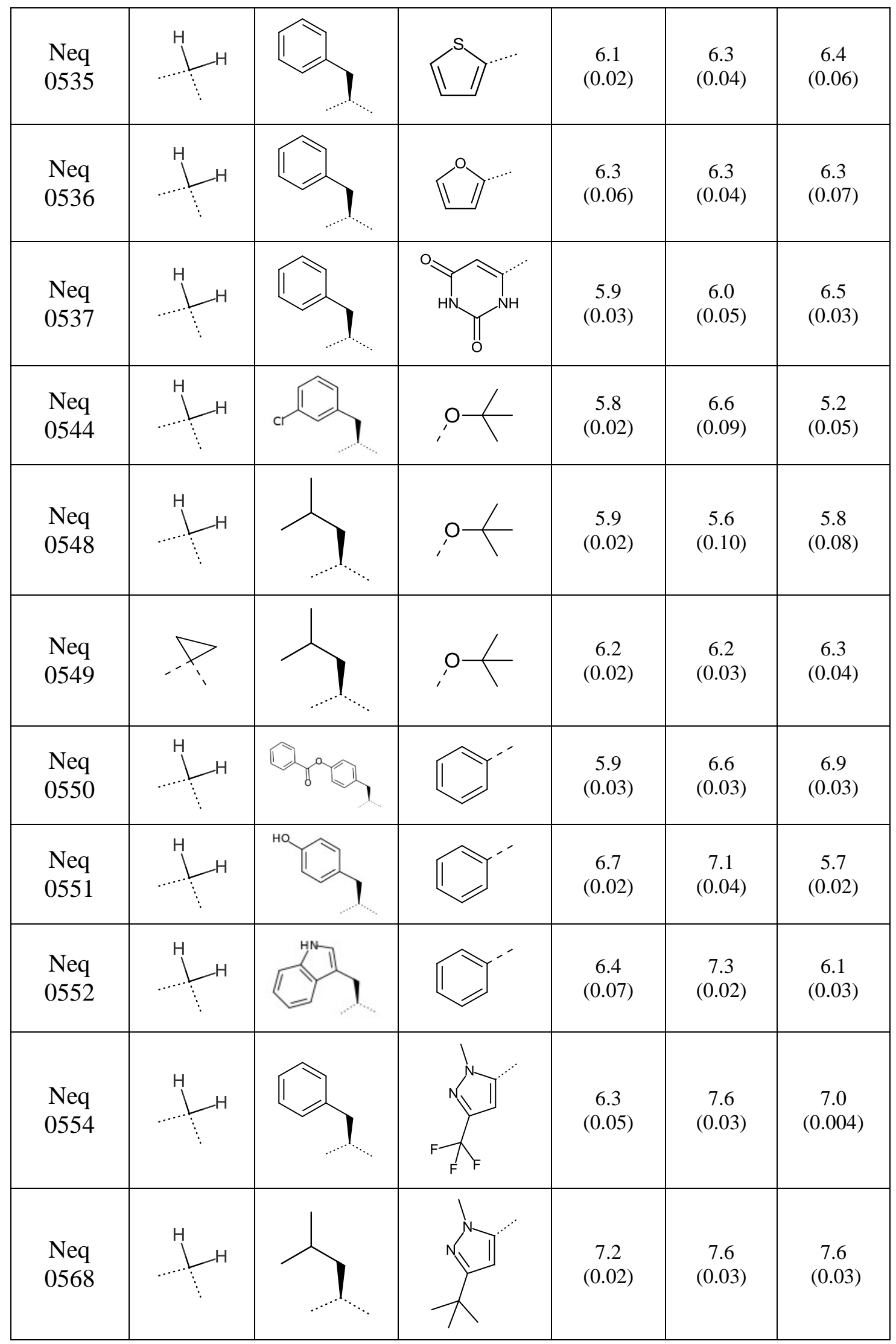




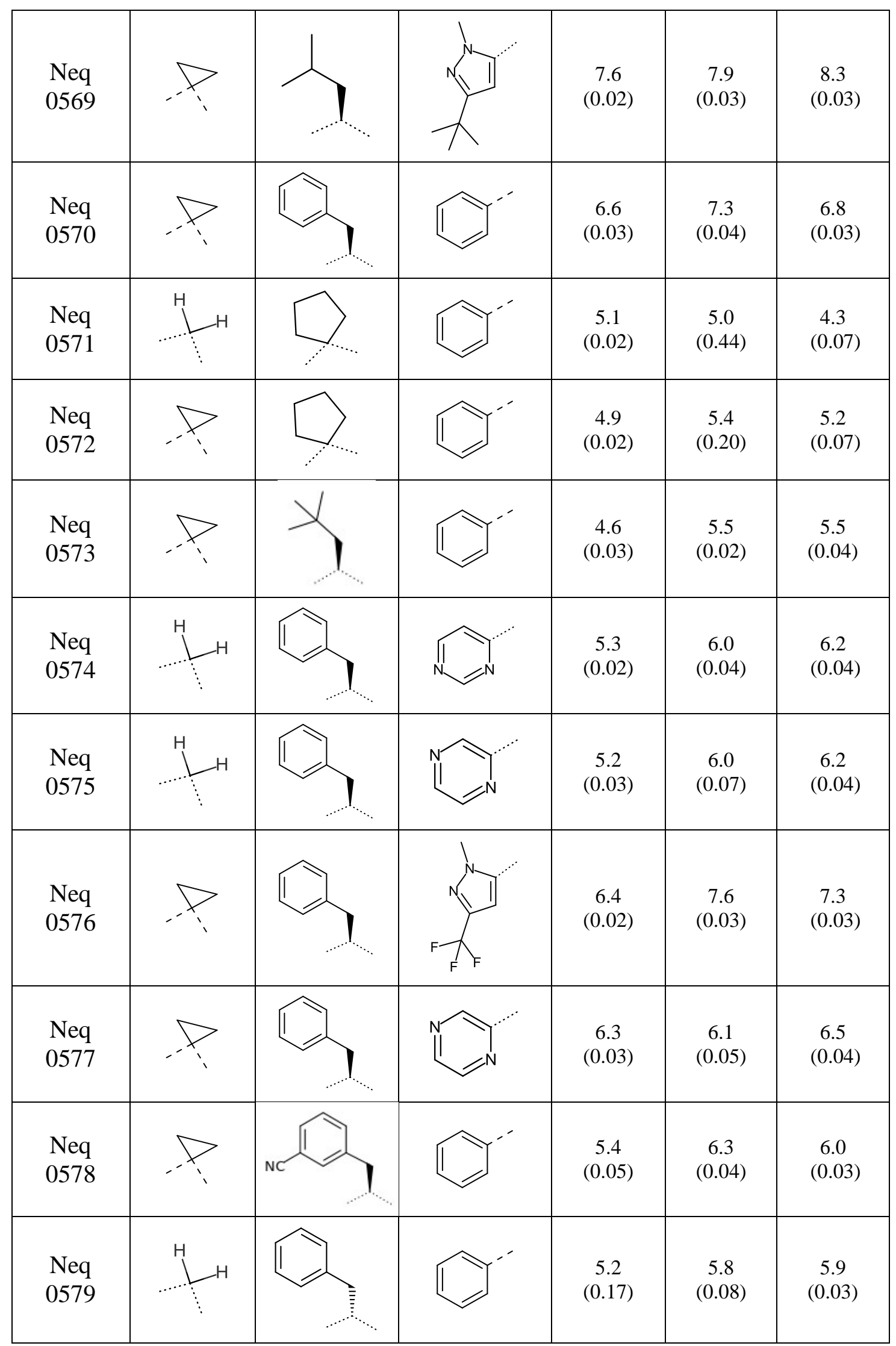

Tabela 2 - Valores de pKi para cruzaína, catepsina L e $\operatorname{lmCPB} 2.8 \Delta \mathrm{CTE} /{ }^{\mathrm{a}} \mathrm{pKi}=-\log (\mathrm{Ki} / \mathrm{M})$; ${ }^{\mathrm{b}}$ Incert. $=$ desvpad $/(\mathrm{Ki} * \ln (10))$ 


\subsubsection{Avaliação das relações estrutura-atividade (SAR) para os derivados $\mathrm{CF}_{3}$-substituídos}

Alguns estudos têm indicado que a ligação amida entre as posições P1 e P2 de dipeptidil nitrilas pode ser metabolicamente hidrolisada a ácido carboxílico. Esse efeito tem sido associado à baixa eficácia apresentada por essa classe de inibidores em estudos in vivo. Alguns grupos funcionais têm se mostrado capazes de mimetizar a geometria da ligação amida sem, contudo, comprometer sua propriedade de doadora de ligação de hidrogênio. Sulfonamidas, anilinas, álcoois secundários, hidrazinas e certos heterocíclicos constituem essa lista. Contudo, poucos grupos retém a capacidade de minimizar a basicidade do centro doador de ligação de hidrogênio de modo que o grupo $\mathrm{NH}_{2}{ }^{+}$não seja formado no meio biológico. Tal espécie carregada é pouco tolerada pelo sítio ativo de enzimas, onde as interações com os resíduos de aminoácidos não podem compensar o custo energético do processo de dessolvatação. Além disso, inibidores básicos geralmente são lisossomotrópicos o que acarreta perda de seletividade e maiores chances de eventos adversos in vivo. Dessa forma, o grupo trifluoroetilamina surge como uma interessante alternativa bioisostérica a amida de dipeptidil nitrilas, diminuindo a natureza peptídica desses compostos, ao passo que mantém um excelente padrão de ligação de hidrogênio e uma baixa basicidade. ${ }^{39}$

Uma avaliação da influência de diferentes substituintes na afinidade de compostos não-peptídicos contendo a nitrila como warhead e o grupo trifluoroetilamina como bioisóstero da ligação amida entre P2 e P3 do esqueleto dipeptídico foi realizada nessa sessão. Esses compostos apresentam dois centros quirais, sendo o primeiro ligado ao grupo $\mathrm{CF}_{3}$ e o segundo a posição P2. A configuração $(S)$ do último centro quiral foi mantida constante em todos os compostos da série, enquanto que as duas configurações possíveis para o primeiro centro quiral foram exaustivamente avaliadas. Sendo assim, apenas as configurações ópticas $R, S($ anti) e $S, S(s y n)$ foram estudadas nesse trabalho.

A Figura 27 mostra o ajuste dos dados para a curva de Michaelis-Menten e Lineweaver-Burk do composto Neq0633 testado contra a catepsina L humana, evidenciando seu mecanismo de ação competitivo. Esse mesmo mecanismo foi observado para as enzimas cruzaína e $L m C P B 2.8 \Delta$ CTE. 


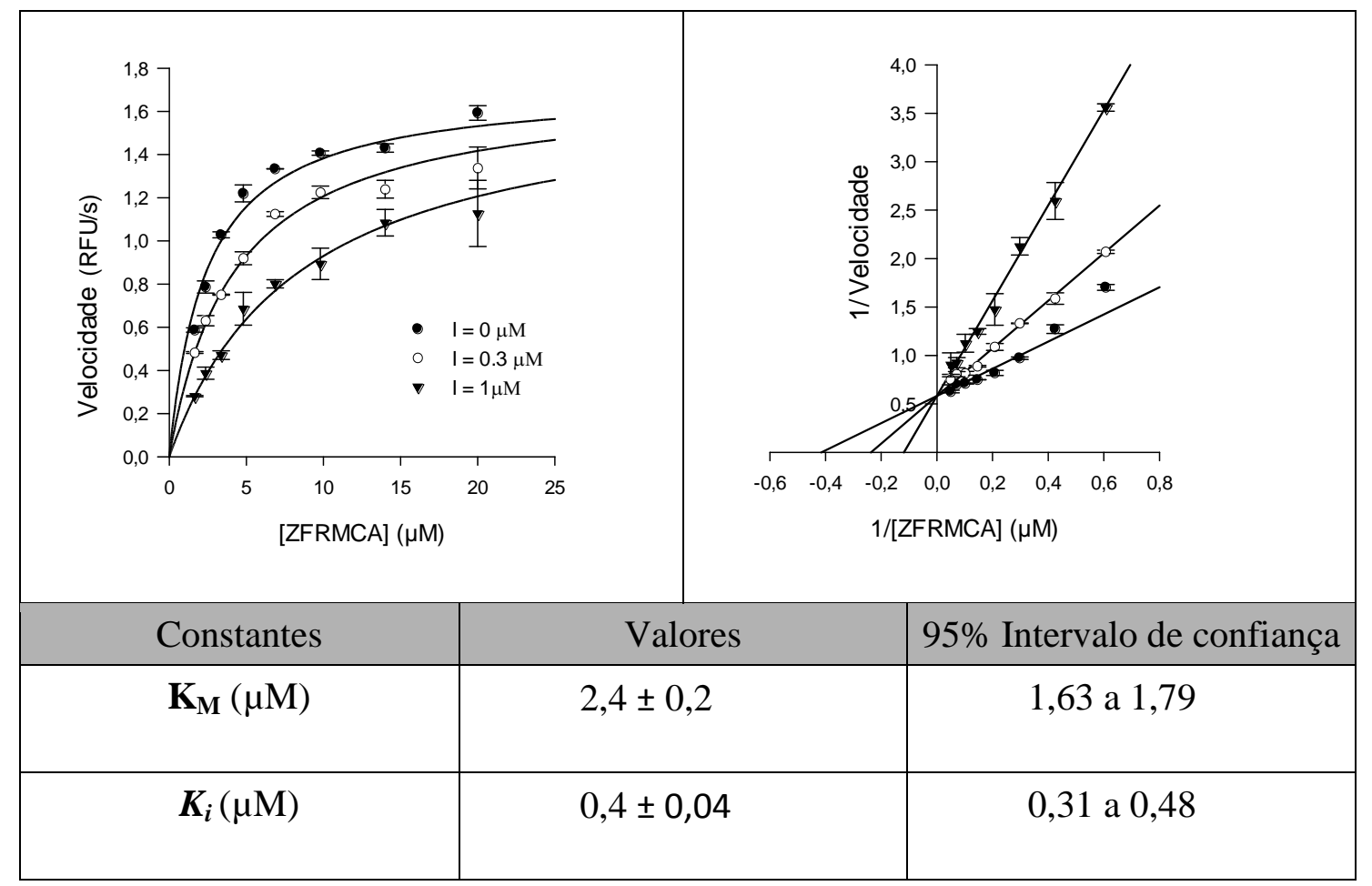

Figura 26 - Ajuste dos dados cinéticos na curva de Michaelis-Meten e o valor de $\mathrm{K}_{\mathrm{i}}$ para o composto Neq0633 contra a catepsina L humana. O gráfico de Lineweaver-Burk evidencia seu mecanismo competitivo de inibição.

$\mathrm{O}$ impacto da substituição bioisostérica da carbonila pelo grupo $\mathrm{CF}_{3}$ pode ser avaliado a partir da comparação direta do $\operatorname{Neq0631}(S, S)$ com a correspondente dipeptidil nitrila, Neq0570. Uma perda de afinidade de 0,6 e 0,2 unidades logarítmicas foi observado para cruzaína e catepsina $\mathrm{L}$, respectivamente. A enzima $L m \mathrm{CPB} 2.8 \Delta \mathrm{CTE}$ se mostrou ainda menos tolerável a essa modificação com perda de afinidade de 1 unidade logarítmica em comparação ao análogo dipeptídico.

Embora ambas configurações ópticas $(R, S)$ e $(S, S)$ foram reconhecidas, uma notável preferência pela configuração syn $(S, S)$ foi observada com aumentos de afinidade de 0,2 a 2,9 unidades logarítmicas para todos os alvos avaliados.

A substituição da posição P1 pelo grupo benzil foi responsável pela adição de um terceiro centro quiral a estrutura. Compostos com configuração óptica $(R, S, S)$ se mostraram relativamente bem tolerados, contudo um grande incremento na afinidade foi observado para compostos com configuração óptica $(S, S, S)$. O $(S, S, S)$-Neq0659 apresentou os maiores valores de pKi da série para as enzimas cruzaína (pKi 9,2) e LmCPB2.8 $\Delta$ CTE (pKi 9,1), além de uma considerável seletividade em relação a catepsina L (pKi 5,8).

A substituição do grupo benzil na posição P2 do Neq0631 pela leucina no Neq0635 promoveu um importante ganho de afinidade de 1,2 e 1,0 unidade logarítmica para cruzaína e $L m C$ PB2.8 $\Delta$ CTE, respectivamente. Um aumento de afinidade menos expressivo também foi 
observado para a catespsina L em 0,4 unidades logarítmicas. Por outro lado, a adição do grupo metoxibenzil em P2 foi associada a uma perda de afinidade para todos os alvos avaliados.

A substituição da fenila na posição P3 do Neq0644 pelos análogos 3-bromofenila (Neq0636) e 2-clorofenila (Neq0664) visou explorar possíveis ligações de halogênio no interior do subsítio S3. Essas substituições produziram ganhos de afinidade que variaram de 0,3 a 0,6 unidades logarítmicas para $L m \mathrm{CPB} 2.8 \Delta \mathrm{CTE}$ catepsina $\mathrm{L}$, respectivamente. Um efeito contrário foi observado para a cruzaína com perdas de afinidade de até 0,4 unidades logarítmicas. Já a adição da bifenila em P3 foi avaliada no par de inibidores Neq0635/Neq0642 e produziu um impacto negativo na afinidade das enzimas cruzaína e catepsina L em 0,2 e 0,9 unidades logarítmicas, respectivamente. Por outro lado, essa substituição foi responsável por um ganho de afinidade de 0,6 unidades logarítmicas para LmCPB2.8 $\Delta$ CTE o que revela uma maior capacidade do subsítio S3 dessa enzima em acomodar substituintes volumosos. Entretanto, a adição de grupos como bifenil piperazina (Neq0662) e fluoro bifenil (Neq0665) na posição P3 não produziram nenhum incremento de afinidade para as enzimas estudadas, sendo no máximo equipotentes ao análogo não substituído, Neq0641. 


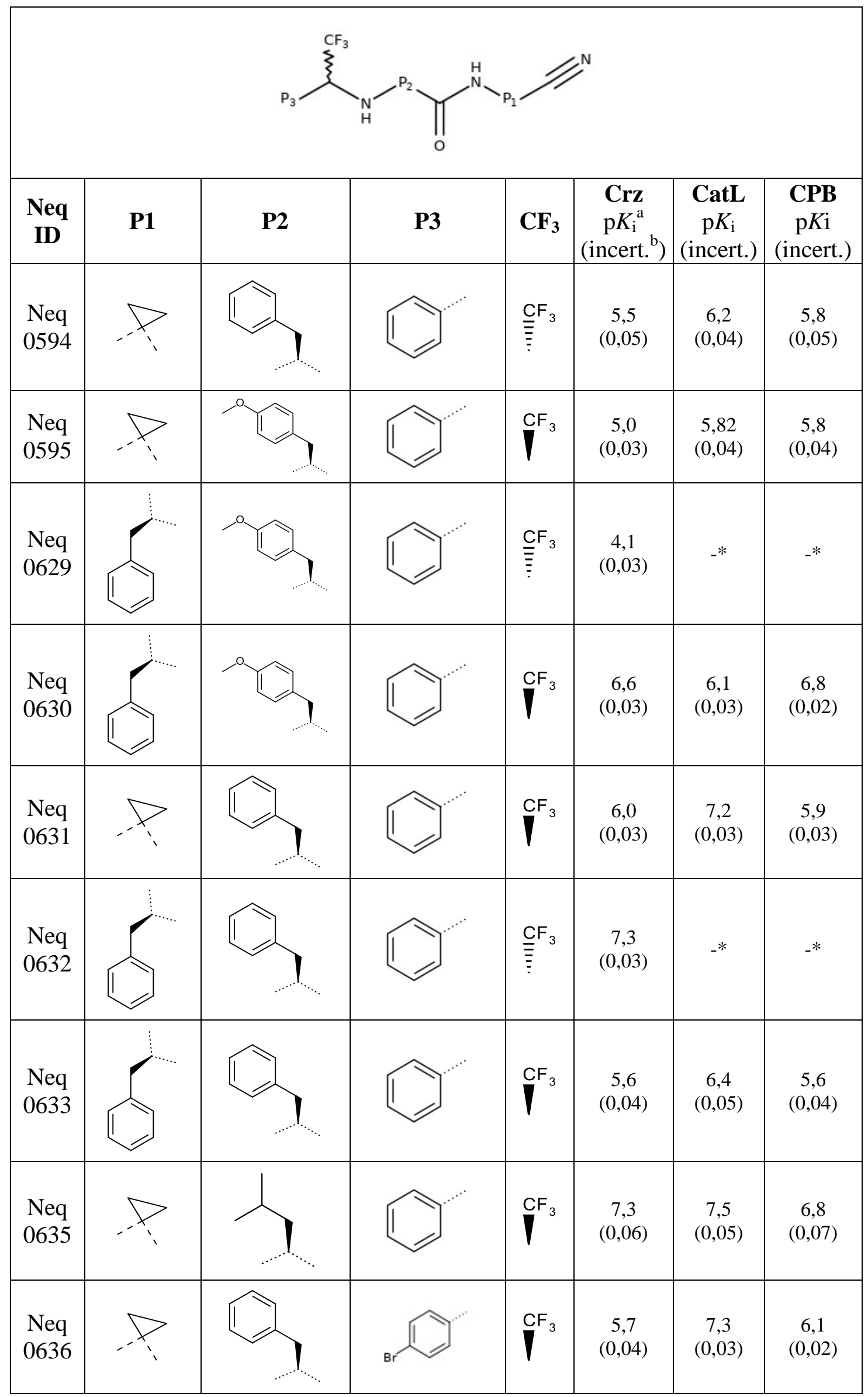




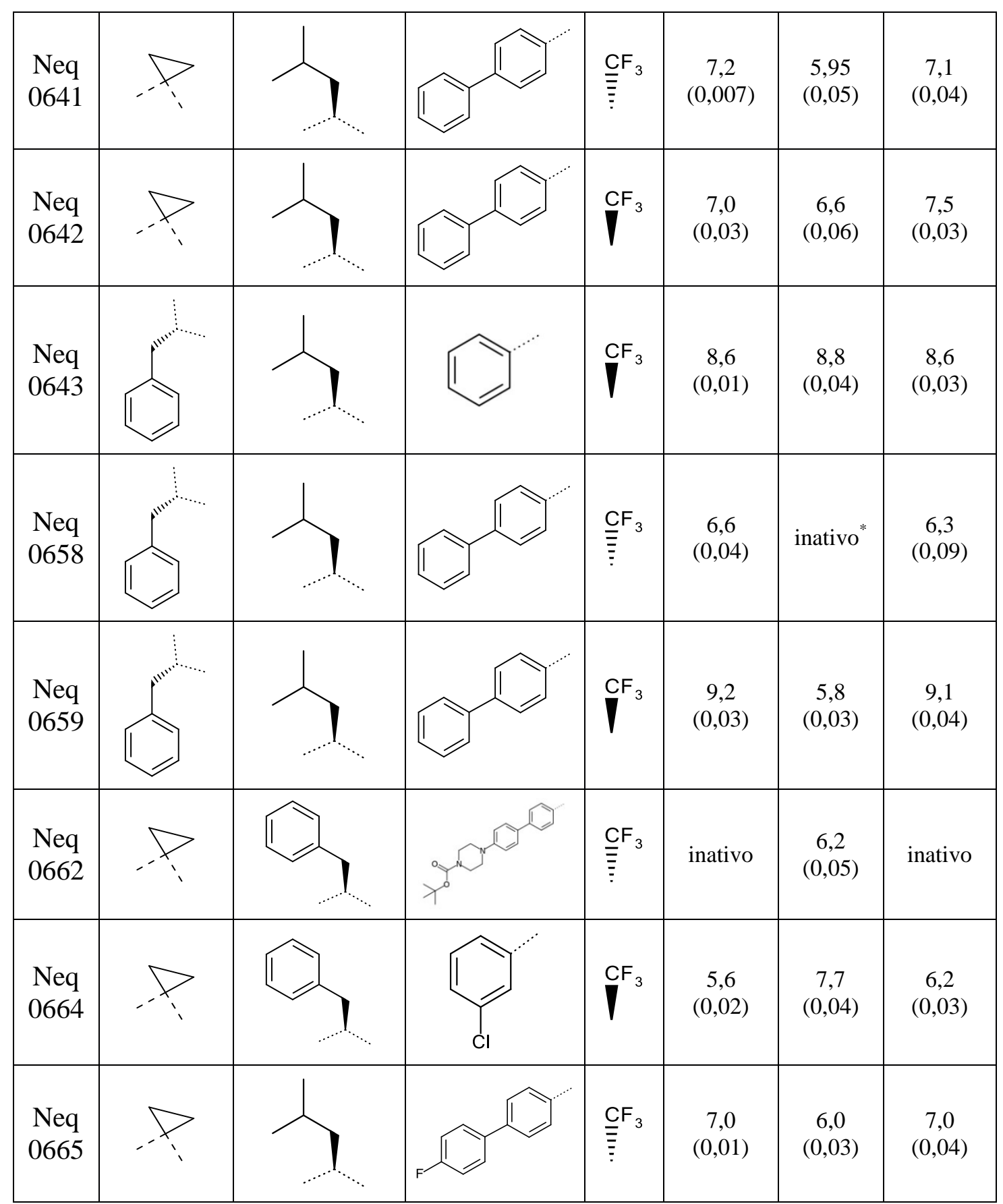

Tabela 3 - Valores de pKi para cruzaína, catepsina L e LmCPB2.8 $\Delta$ CTE / ${ }^{a} \mathrm{pKi}=-\log (\mathrm{Ki} / \mathrm{M})$; ${ }^{\mathrm{b}}$ Incert.=desvpad/(Ki*ln(10))

\subsubsection{Avaliação das relações estrutura-atividade (SAR) de derivados dipeptidil azanitrílicos.}

Enquanto que as dipeptidil nitrilas e seus isósteros $\mathrm{CF}_{3}$ substituídos apresentam tipicamente uma cinética de ligação rápida, um tipo de cinética de ligação lentamente 
reversível foi observado para três dipeptidil azanitrilas sintetizadas no grupo NEQUIMED. Esses compostos mostraram um perfil tempo-dependente de inibição com valores de afinidades maiores do que seus respectivos análogos aminonitrílicos. Além disso, esse tipo de inibição permite a determinação das constantes cinéticas $\mathrm{k}_{\text {on }}$ e $\mathrm{k}_{\text {off. }}$ A constante de velocidade de segunda ordem $\mathrm{k}_{\text {on }}$ governa a associação da enzima e do inibidor durante a formação do complexo enzima-inibidor. Já a constante de velocidade de primeira ordem $\mathrm{k}_{\text {off }}$ governa o decaimento desse complexo.

O Neq0677 $\left(\mathrm{pK}_{\mathrm{i}(\mathrm{crz})}=8.7\right)$ se mostrou duas ordens de magnitude mais potente contra a cruzaína do que seu derivado aminonitrílico Neq0500 (tabela 1, pK $\mathrm{i}_{\mathrm{i}(\mathrm{crz})}=6,3$ ). Valores similares de $\Delta \mathrm{pKi}$ foram obtidos, também, para outros compostos, onde a simples substituição $[\mathrm{NHCH} 2 \mathrm{CN} \rightarrow \mathrm{N}(\mathrm{Me}) \mathrm{N}(\mathrm{Me}) \mathrm{CN}]$ foi realizada, como por exemplo, para os pares de inibidores Neq0414lNeq0689 $(\Delta \mathrm{pKi}=1,6)$ e Neq0568 $\backslash \mathrm{Neq0690}(\Delta \mathrm{pKi}=1,6) . \mathrm{O}$ mesmo comportamento foi observado para a catepsina L com ganhos de afinidade de até 1,7 unidades logarítmicas. Contudo, a $L m C P B 2.8 \Delta C T E$ se mostrou a mais sensível entre todos alvos avaliados com ganhos de afinidade de 2,3 e 2,1 unidades logarítmicas para os compostos Neq0689 e Neq0690, respectivamente.

Embora resultados prévios indiquem que a presença do substituinte pirazol em P3 seja vantajosa para inibição de todos os alvos estudados, esse ganho de potência não foi completamente transferido para os compostos que apresentam o esqueleto dipeptidil azanitrílico na cruzaína. Esses resultados sugerem que o modo de ligação desses inibidores não favorece a interação ótima desse substituinte no subsítio S3 dessa enzima. Uma explicação mais detalhada desse efeito será dada na sessão 4.4.2.

Os valores da constante cinética de associação $\mathrm{k}_{\text {on }}$ variaram na ordem de $10^{3}-10^{6} \mathrm{M}^{-}$ ${ }^{1} \mathrm{~S}^{-1}$ condizente com resultados obtidos para outros aza análogos testados contra catepsina $\mathrm{S}$, catepsinas $\mathrm{K}$ e papaína na literatura. Os valores reduzidos da constante de primeira ordem $\mathrm{k}_{\text {off }}$ (entre $10^{-3}-10^{-6}$ ) refletem a alta estabilidade do complexo EI formado (tabela 5). Essa alta estabilidade é provavelmente decorrente da presença do grupo elétron-doador metil imina em P1 que diminui a eletrofilia do carbono nitrílico. Além disso, a presença desse grupo deixa o nitrogênio imínico da ligação covalentemente formada mais básico. ${ }^{34}$ A protonação desse nitrogênio poderia explicar a grande diferença de afinidade entre as dipeptidil nitrilas e seus aza análogos (figura 28). 


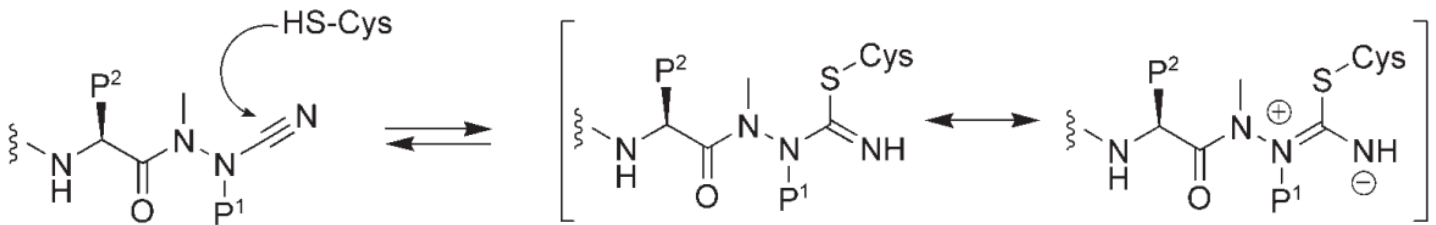

Figura 27- formação do complexo reversível isotiossemicarbazida a partir do ataque da cisteína ativada ao nitrogênio nitrílico. O carbono nitrílico está ligado a um nitrogênio que possui um par de elétrons livre. Após o ataque do grupo tiolato, um trigonal planar isotiossemicarbazida aduto é formado. A estabilização por ressonância do complexo deixa o nitrogênio imínico mais básico e sua protonação pode justificar a grande diferença de afinidade entre as dipeptidil nitrilas e seus aza análogos. ${ }^{34}$

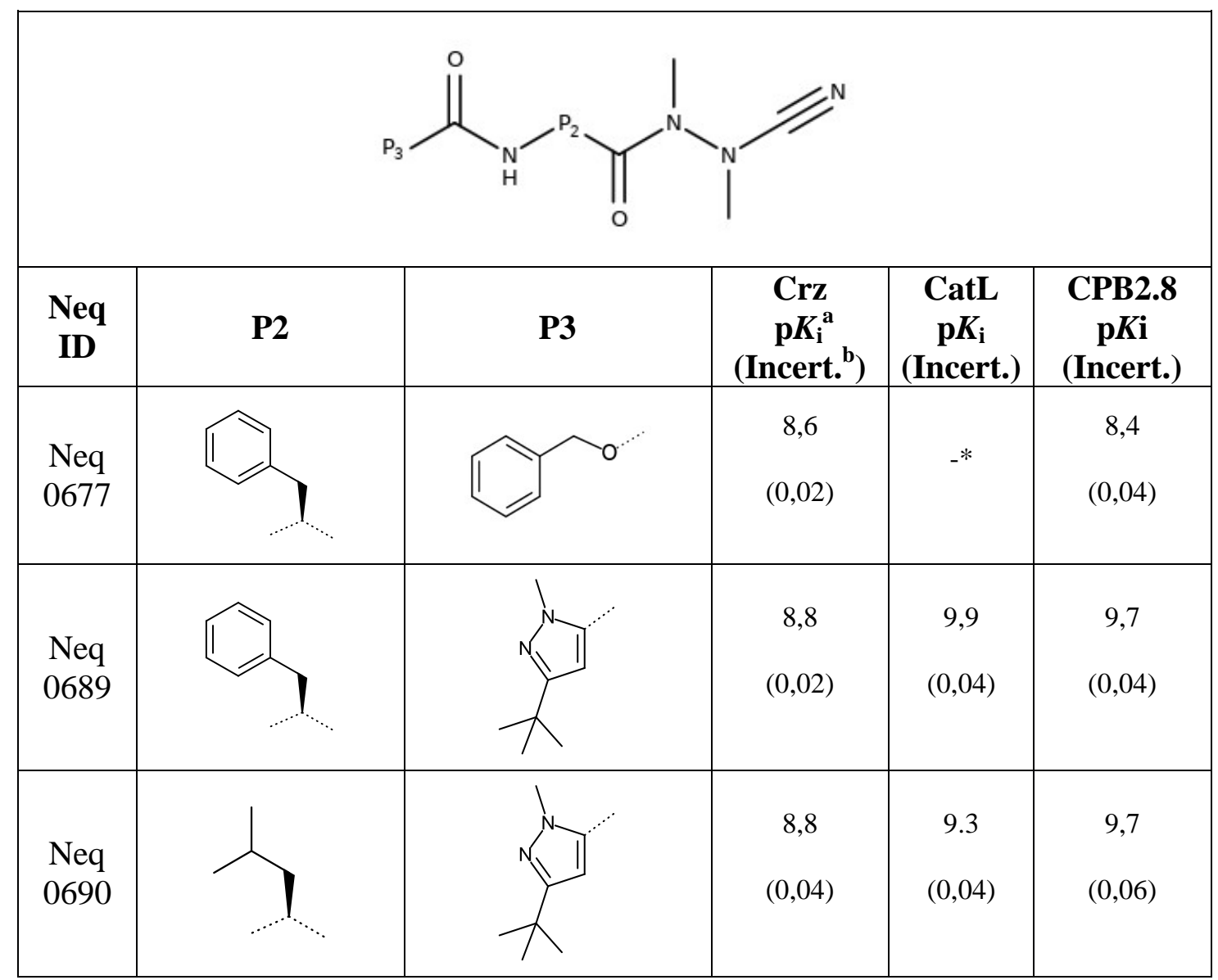

Tabela 4 - Valores de pKi para cruzaína, catepsina L e $L m \mathrm{CPB} 2.8 \Delta \mathrm{CTE} /{ }^{\mathrm{a}} \mathrm{pKi}=-\log (\mathrm{Ki} / \mathrm{M})$; ${ }^{\mathrm{b}}$ Incert.=desvpad/(Ki*ln(10)) 


\begin{tabular}{|c|c|c|c|c|c|c|}
\hline \multirow[b]{2}{*}{ NeqID } & \multicolumn{3}{|c|}{$\begin{array}{c}10^{-6} \times \mathrm{k}_{\mathrm{on}}\left(\mathrm{M}^{-1} \mathrm{~S}^{-1}\right) \\
(\mathrm{DP})\end{array}$} & \multicolumn{3}{|c|}{$\begin{array}{c}10^{3} \times k_{\text {off }}\left(s^{-1}\right) \\
(D P)\end{array}$} \\
\hline & Crz & $h$ CatL & CPB2.8 & Crz & $h$ CatL & LmCPB \\
\hline Neq0677 & $\begin{array}{c}5,0 \\
(0,2)\end{array}$ & - & $\begin{array}{c}0,03 \\
(0,002)\end{array}$ & $\begin{array}{c}11 \\
(0,8)\end{array}$ & - & $\begin{array}{c}0,1 \\
(0,01)\end{array}$ \\
\hline Neq0689 & $\begin{array}{c}7,7 \\
(0,3)\end{array}$ & $\begin{array}{c}0,7 \\
(0,04)\end{array}$ & $\begin{array}{c}1 \\
(0,1)\end{array}$ & $\begin{array}{c}12 \\
(0,8)\end{array}$ & $\begin{array}{c}0,08 \\
(0,008)\end{array}$ & $\begin{array}{c}0,2 \\
(0,03)\end{array}$ \\
\hline Neq0690 & $\begin{array}{c}11 \\
(0,7)\end{array}$ & $\begin{array}{c}0,1 \\
(0,007)\end{array}$ & $\begin{array}{c}0,22 \\
(0,001)\end{array}$ & $\begin{array}{c}15 \\
(1,8)\end{array}$ & $\begin{array}{c}0,05 \\
(0,005)\end{array}$ & $\begin{array}{c}0,04 \\
(0,005)\end{array}$ \\
\hline
\end{tabular}

Tabela 5 - Valores de $\mathrm{k}_{\text {on }}$ e $\mathrm{k}_{\text {off }}$ para todos os aza-análogos testados contra as enzimas cruzaína, catepsina $\mathrm{L}$ humana e $L m C P B 2.8 \Delta \mathrm{CTE}$.

\subsection{Elucidação estrutural e análise do modo de interação dos inibidores Neq0690 e MMTS.}

\subsubsection{Qualidade das estruturas cristalográficas e aspectos gerais}

Os mapas de densidade eletrônica $2 F_{\text {obs }}-F_{\text {calc }}$ finais calculados para ambos os modelos apresentaram boa qualidade ao ponto de ser possível observar detalhadamente a presença de variantes conformacionais na cadeia lateral de vários resíduos de aminoácidos. Os dados cristalográficos e as estatísticas dos refinamentos para os conjuntos de dados coletados estão apresentados na tabela 6.

As médias dos fatores temperatura (do inglês, B-factor) para todos os átomos dos modelos estudados estão descritas na Tabela 6. Os fatores de temperatura calculados para os átomos do modelo variaram de 3,77 a 79,45 $\AA^{2}$ para o complexo $L m$ CPB-Neq0690 (1.35 $\AA$ ) e de 11,8 a 98,61 $\AA^{2}$ para o complexo LmCPB-MMTS (1.5 $⿱$ ). As regiões de maior mobilidade em ambas as estruturas correspondem a alças que incluem os resíduos Glu101-Val109, Met173-Pro178 e Leu154-Cys157. Outros resíduos que apresentaram valores altos para o fator temperatura foram aqueles situados nas extremidades $\mathrm{N}$ e C-terminal (Ala1, Val2 e Arg217) e os resíduos Glu10, Asp59, Met60, Gln78, Ser122, Lys150, Gln161, Lys125 e Asp189. 


\begin{tabular}{|c|c|c|}
\hline Coleta de dados & Lm CPB-Neq0690 & LmCPB-MMTS \\
\hline Space group & P63 & P 41212 \\
\hline $\mathrm{a}, \mathrm{b}, \mathrm{c}(\stackrel{\mathrm{A}}{)})$ & $82.64,82.64,134.85$ & $64.95,64.95,122.44$ \\
\hline$\alpha, \beta, \gamma\left(^{\circ}\right)$ & $90,90,120$ & $90,90,90$ \\
\hline Wavelength $(\AA)$ & 0.9686 & 0.9686 \\
\hline Resolution $(\AA)$ & 1.35 & 1.50 \\
\hline Rmerge & $0.239(1.077)^{*}$ & $0.289(1.42)^{*}$ \\
\hline $\mathrm{I} / \sigma \mathrm{I}$ & $6.4(1.6)^{*}$ & $6.9(1.5)^{*}$ \\
\hline Completeness (\%) & $99(90.5)^{*}$ & $100(100)^{*}$ \\
\hline Multiplicity & $8.7(4.4)^{*}$ & $12.8(12.9)^{*}$ \\
\hline $\mathrm{CC} 1 / 2$ & $0.962(0.45)^{*}$ & $0.967(0.492)^{*}$ \\
\hline Unique reflections & 112897 & 42814 \\
\hline Refinamento & & \\
\hline $\mathrm{R}_{\text {work }}$ & $0.195(0.33)^{*}$ & $0.168(0.333)^{*}$ \\
\hline$R_{\text {free }}$ & $0.219(0.334)^{*}$ & $0.193(0.331)^{*}$ \\
\hline Overall B factor (A2) & 12.8 & 24.8 \\
\hline RMS deviations & & \\
\hline Bond length $(\AA)$ & 0.029 & 0.038 \\
\hline Bond Angel $\left({ }^{\circ}\right)$ & 2.69 & 2.247 \\
\hline
\end{tabular}

Tabela 6 - Estatísticas referentes à coleta de dados e ao refinamento dos modelos para a $L m C P B 2.8 \Delta C T E$ em complexo com os inibidores Neq0690 e MMTS. * valores para a camada de maior resolução.

A análise da estereoquímica dos modelos mostrou que mais de 99\% dos resíduos apresentaram ângulos torcionais dentro de regiões favorecidas e permitidas do diagrama de Ramachandran. As exceções envolvem o resíduo Gly159 para o complexo LmCPB-Neq0690 e os resíduos Glu107 e Met147 para o complexo LmCPB-MMTS (figura 29). 


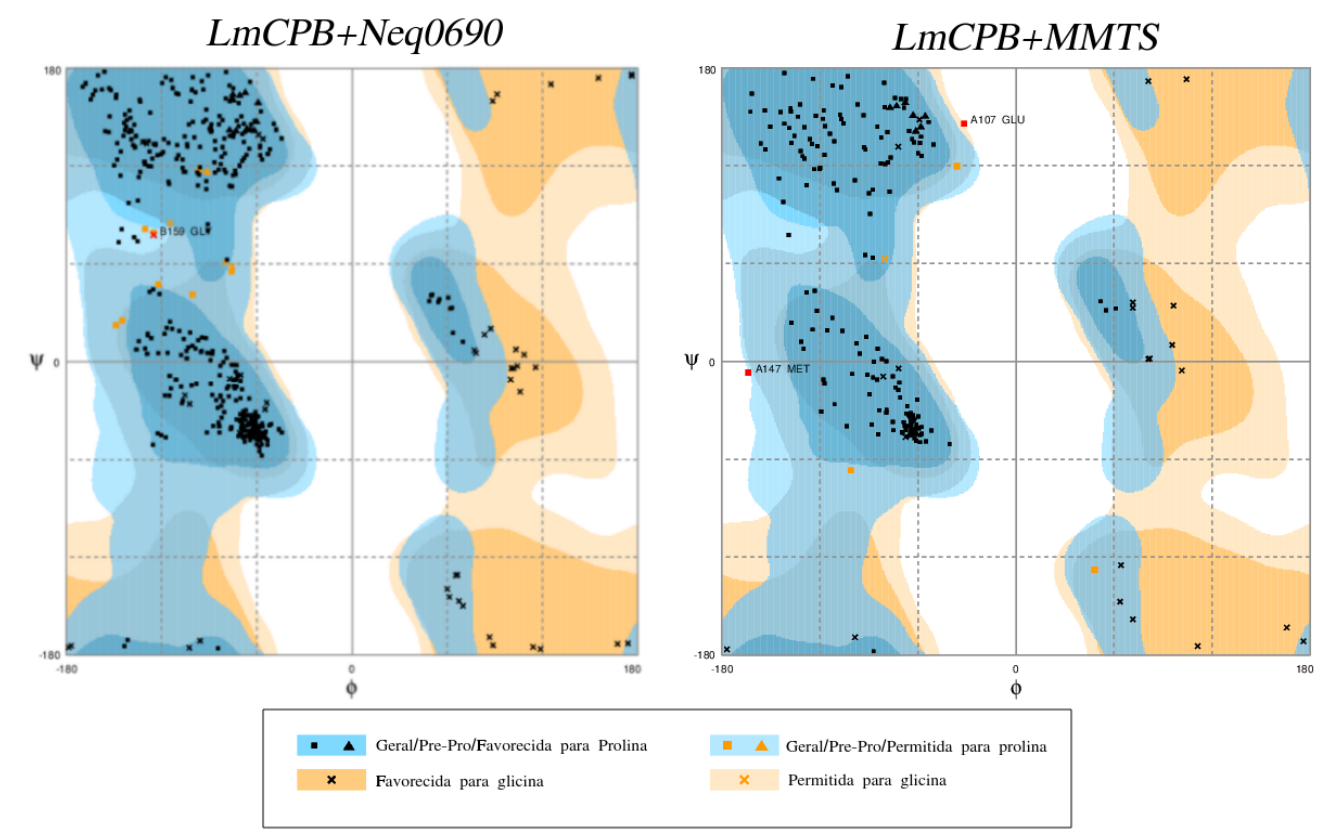

Figura 28 - Gráfico de Ramachandran para as estruturas do complexo LmCPB-Neq0690 e LmCPB-MMTS. Para o complexo LmCPB-MMTS - 97\% dos resíduos estão em regiões favorecidas do diagrama, $2 \%$ em regiões permitidas e 1\% em regiões desfavoráveis (Ala147 e Glu107). Para o complexo LmCPB-Neq0690 - $97 \%$ dos resíduos estão em regiões favorecidas do diagrama, 2,8\% em regiões permitidas e $0,2 \%$ em regiões desfavoráveis (Gly159).

A análise das estruturas cristalográficas obtidas revelou que a forma madura da enzima LmCPB2.8 $\Delta$ CTE é composta por uma cadeia polipeptídica de 217 resíduos de aminoácidos enovelada em dois principais domínios. Um domínio principalmente $\alpha$-helicoidal (domínio L) e o outro predominantemente formado por folhas- $\beta$ antiparalelas (domínio R), seguindo o padrão de enovelamento típico de cisteíno proteases da família da papaína. A tríade catalítica, altamente conservada entre membros dessa família, está situada em uma fenda formada entre os dois domínios da enzima e é composta pelos resíduos Cys26, His164 e Asn184 (figura 30).

O domínio L da LmCPB2.8 $\Delta$ CTE compreende os resíduos 13-113 e 209-217, sendo que as principais hélices são formadas pelos resíduos 26-41 (L2), 51-57 (L3), 69-79 (L4) e 87-90 (L5). Já o domínio R é composto pelos resíduos 1-12 e 114-208 com a presença das hélices constituídas pelos resíduos 8-11 (L1) e 124-134 (V). 


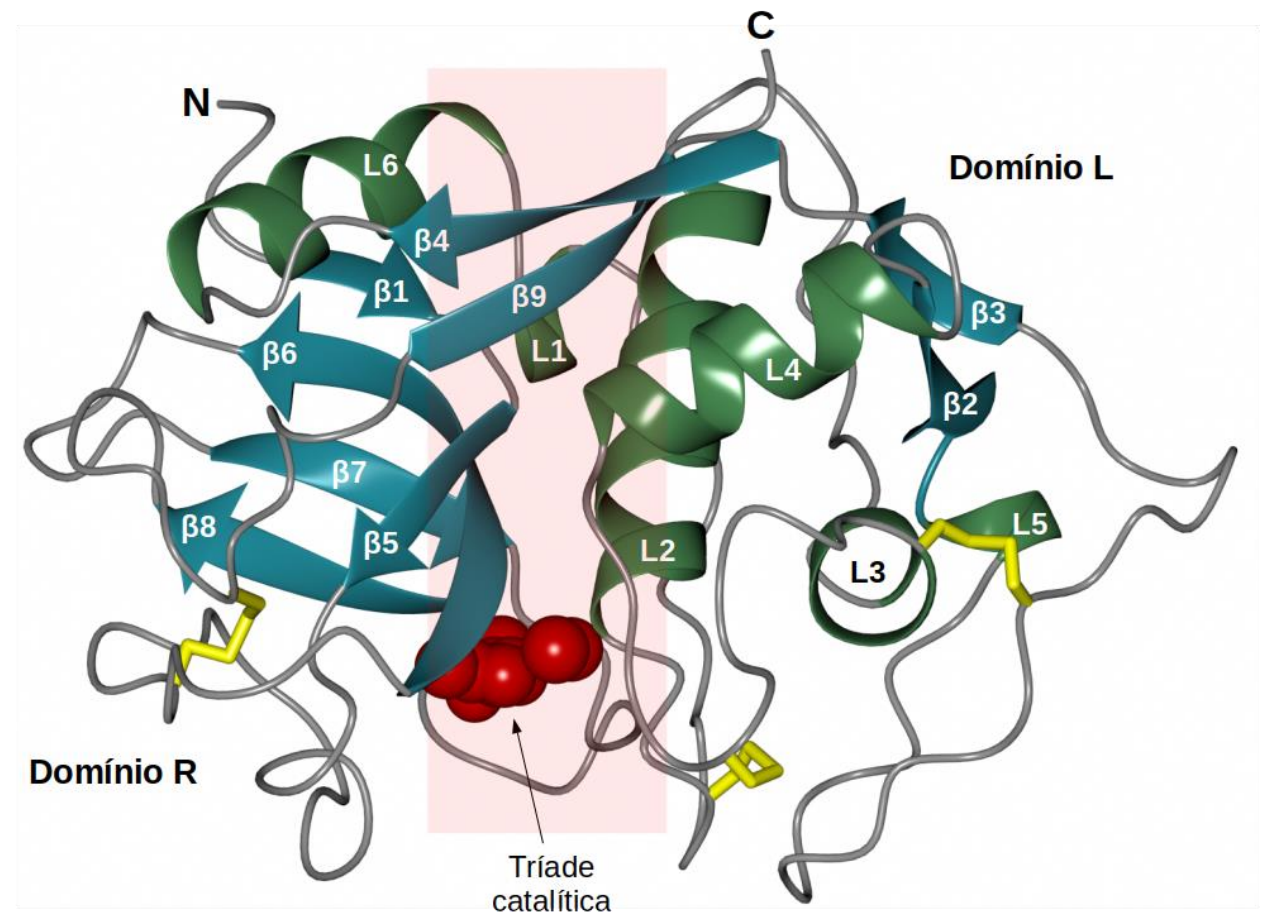

Figura 29 - Padrão de Enovelamento da enzima LmCPB2.8 $\Delta$ CTE com destaque para os elementos helicoidais (em verde) e folhas- $\beta$ (em azul). As pontes dissulfeto estão coloridas de amarelo e a tríade catalítica composta pelos resíduos Cys26, His164 e Asn184 (em vermelho) está localiza em uma fenda entre os domínios L e R da enzima.

O enovelamento do domínio $\mathrm{R}$ da $L m$ CPB2.8 $\Delta$ CTE é baseado em um motivo estrutural do tipo barril- $\beta$ formado por 7 fitas- $\beta$, além de duas $\alpha$-hélices. Os resíduos 164-172 formam uma longa fita- $\beta$ central ( $\beta 6$ ) que contribui para a formação de duas folhas- $\beta$ antiparalelas. Essa topologia se sobrepõe razoavelmente bem àquela encontrada na cruzaína com exceção dos resíduos 110-113 ( $\beta 3$ ) e 116-120 ( $\beta 4$ ) que são separados por um pequeno segmento não-estruturado formado pelos resíduos ILE114 e ASP115. Na cruzaína, esse segmento forma uma única e longa fita- $\beta$ que se estende dos resíduos 108 a 117. Interessantemente, as fitas- $\beta$ formadas pelos resíduos 83-85 ( $\beta 2)$ e 110-113 ( $\beta 3$ ) constituem a única folha- $\beta$ antiparalela encontrada no domínio $\mathrm{L}$ da $L m \mathrm{CPB} 2.8 \Delta \mathrm{CTE}$.

O modelo cristalográfico correspondente ao complexo $\operatorname{LmCPB}-\mathrm{Neq0690}$ foi estruturalmente alinhado com as enzimas cruzaína (PDB: 3KKU), catepsina L humana (PDB: 2XU1) e catepsina B humana (PDB: 3AI8). Apesar da alta identidade estrutural entre as enzimas, algumas importantes diferenças foram observadas principalmente ao nível do sítio ativo. A composição dos subsítios $\mathrm{S} 1, \mathrm{~S} 2, \mathrm{~S} 3$ e $\mathrm{S} 1$ ' das enzimas acima citadas pode ser encontrada na tabela 7 . 
Os resíduos de aminoácidos Asn69, Ser207 e Glu209 presentes no subsítio S2 da cruzaína são respectivamente substituídos pelos resíduos de aminoácidos Leu70, Val212 e Tyr210 na $L m C P B 2.8 \Delta C T E$. Essa composição torna o subsítio S2 consideravelmente mais hidrofóbico e restritivo do que aquele apresentado pela sua homóloga. ${ }^{76-77}$ De fato, sabe-se que proteases como a catepsina $\mathrm{L}$, catepsina $\mathrm{B}$, cruzaína e a LmCPB2.8 $\Delta \mathrm{CTE}$ apresentam uma alta especificidade para substituintes hidrofóbicos na posição P2 de substratos peptídicos. No caso da LmCPB2.8 $\Delta \mathrm{CTE}$, essa preferência abrange tanto substituintes aromáticos quanto alifáticos. Na cruzaína, contudo, substituintes básicos em P2 também são bem tolerados. Essa especificidade dual está diretamente relacionada a mobilidade do resíduo de aminoácido Glu205. ${ }^{76}$ Esse resíduo está localizado na base do subsítio S2 da cruzaína e pode ser direcionado tanto para substrato (quando um substituinte básico ocupa a posição P2), quanto para o solvente (quando o substituinte se trata de um grupo hidrofóbico). O mesmo comportamento é observado para catepsina B, uma vez que essa enzima possui o resíduo de aminoácido Glu245 (equivalente ao Glu205 na cruzaína). ${ }^{76}$ Além disso, a alta afinidade para substratos contendo substituintes volumosos em P2, sugere que o subsítio S2 da catepsina B seja maior do que aqueles encontrados na LmCPB2.8 $\Delta$ CTE e cruzaína. De fato, esse subsítio se encontra estendido na catepsina B devido o deslocamento de um loop formado pelos resíduos 196-199 (figura 26). O subsítio S2 da catepsina L, por sua vez, é mais profundo e delimitado do que o da LmCPB2.8 $\triangle \mathrm{CTE}$, sendo definido pelos resíduos de aminoácidos Asp163, Met161, Asp71 e Ala214 (sendo esse último estruturalmente equivalente a Tyr210 na LmCPB2.8 $\mathrm{CTTE}$ ). Essa composição determina uma estrita preferência para substituintes hidrofóbicos aromáticos na posição P2 de substratos peptídicos. ${ }^{78}$ Uma comparação estrutural detalhada entre essas enzimas pode ser encontrada nas figuras 31 e 32 . 


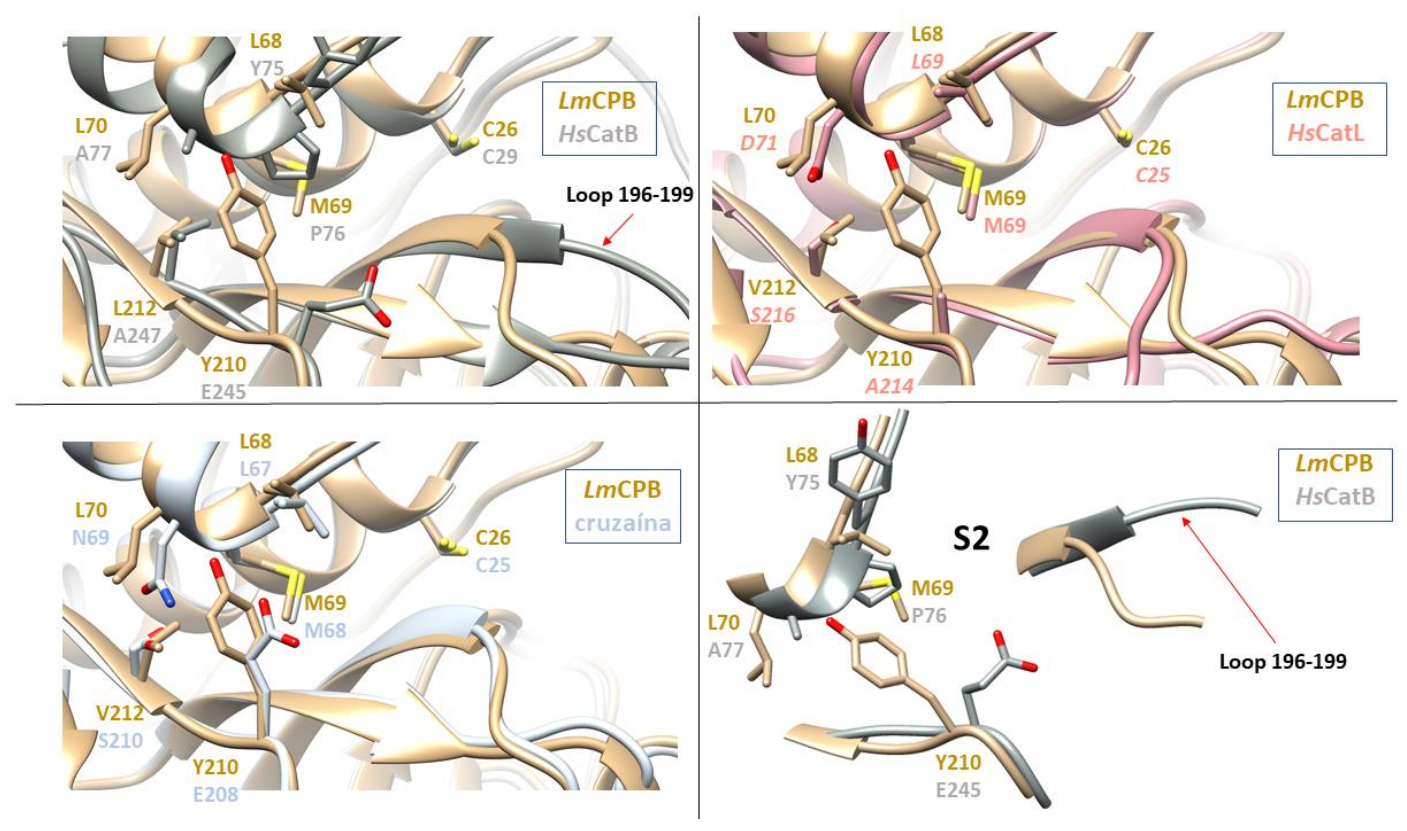

Figura 30- Alinhamento estrutural da $L m \mathrm{CPB} 2.8 \Delta \mathrm{CTE}$ com as enzimas cruzaína (PDB 3KKU), catepsina L (PDB 2XU1) e catepsina B (3AI8) com foco nos resíduos que compõe o subsítio S2. No quadrante inferior direito destaca-se o loop 196-199 da catepsina B, uma característica estrutural que estende o volume do subsítio S2 dessa enzima.
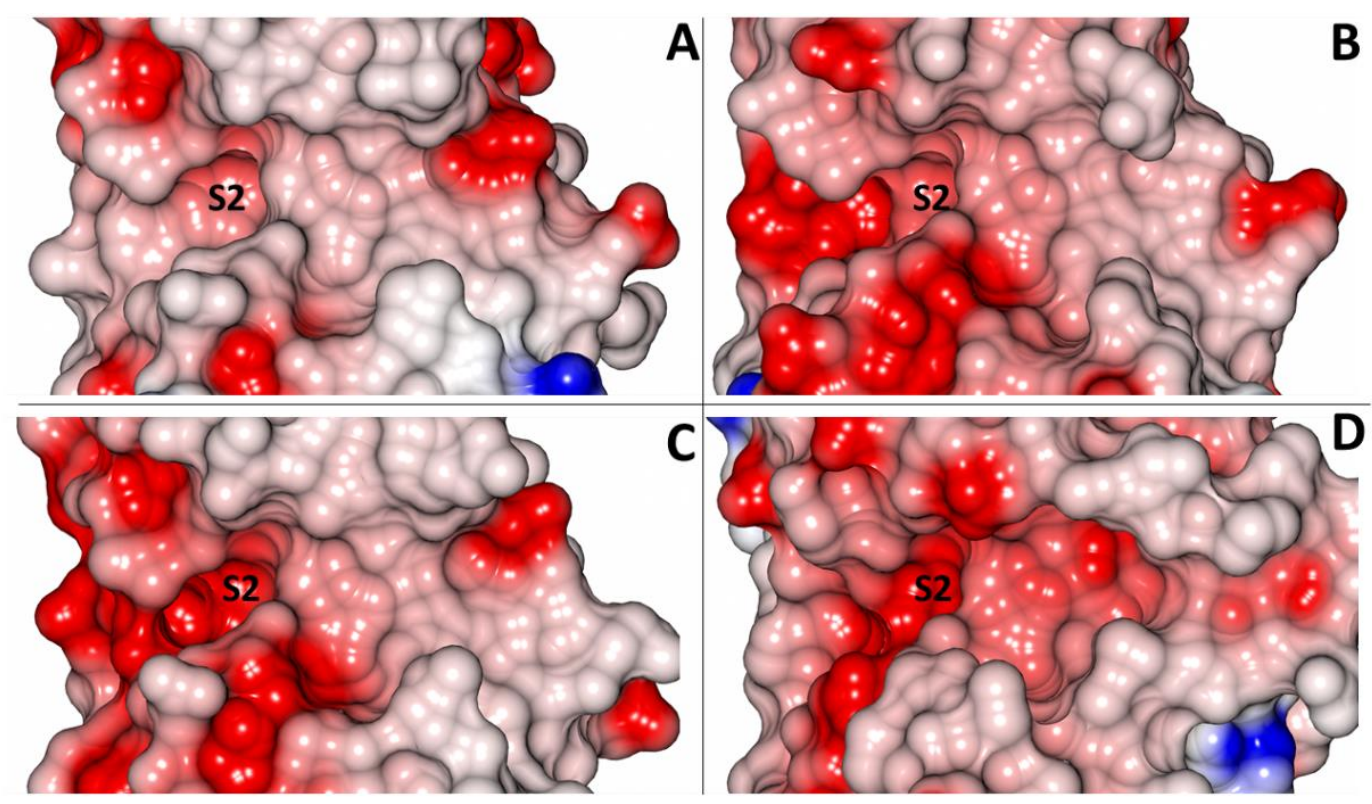

Figura 31-Representação das enzimas $\operatorname{LmCPB} 2.8 \Delta \mathrm{CTE}(\mathrm{A})$, catepsinas L humana (B), cruzaína (C), e catepsinas B humana (D) com base no potencial eletrostático de superfície. Em destaque o subsítio S2.

O subsítio $\mathrm{S} 1$ da LmCPB2.8 $\triangle \mathrm{CTE}$ repousa inteiramente no domínio $\mathrm{L}$ da enzima e é formado pelos resíduos Leu68, Met69, Ala140 e Gly165. Esse subsítio é capaz de interagir com substratos contendo arginina, lisina e outros aminoácidos de natureza combinada (aromática e básica) em P1, sendo que esses últimos se mostraram resistentes a hidrólise 
enzimática. $\mathrm{O}$ fato desses substratos serem reconhecidos, porém não hidrolisados sugere que a interação P1-S1 não ocorre de forma efetiva na $L m C$ PB2.8 $\Delta$ CTE. A análise da estrutura cristalográfica da catepsina B complexada com um inibidor contendo o grupo benzil em P1 revela que esse substituinte foi capaz de estabelecer interações com subsítio S1' da enzima. ${ }^{79}$ Essa característica pode também estar presente na $L m \mathrm{CPB} 2.8 \Delta \mathrm{CTE}$, já que o subsítio $\mathrm{S} 1$ se mostra pouco definido e interações com regiões vicinais parecem ser possíveis.

Embora a constituição do subsítio S1 da cruzaína seja idêntica ao da $L m \mathrm{CPB} 2.8 \Delta \mathrm{CTE}$ (Leu67, Met68, Ala138 e Gly163), pequenas diferenças em sua especificidade têm sido observadas. ${ }^{80}$ Essa enzima hidrolisa preferencialmente substratos com grupos hidrofóbicos (aromáticos ou alifáticos) e básicos em P1. Já a catepsina L difere no subsítio S1 pela presença do resíduo Ile136 (equivalente ao resíduo Ala140 na LmCPB2.8 $\Delta$ CTE). Essa diferença estrutural confere uma alta preferência para substituintes carregados positivamente nessa posição. ${ }^{81}$

Os resíduos de aminoácido Leu67 e Ser61 presentes no subsítio S3 da cruzaína são substituídos pelos resíduos Leu68 e Ans62 na estrutura da LmCPB2.8 $\Delta$ CTE. Diferentemente dos subsítios S1 e S2 que possuem uma cavidade bem delimitada, o subsítio S3 forma uma superfície plana e hidrofóbica que está completamente exposta ao solvente. Estudos têm demonstrado que substituintes básicos na posição P3 de substratos peptídicos são bem tolerados pelas enzimas $L m \mathrm{CPB} 2.8 \Delta \mathrm{CTE}$, cruzaína e catepsina L. A catepsina L, contudo, possui o resíduo de Glu63 (estruturalmente equivalente a Ser61 da cruzaína) no topo do S3. A presença de resíduos carregados negativamente ou polares não carregados parece ser uma característica estrutural fundamental para a interação de substituintes carregados positivamente no subsítio S3 dessas enzimas. Um padrão de especificidade mais complexo tem sido observado para a catepsina B e envolve os resíduos Try75 e Asp69 (que corresponde aos resíduos Leu68 e Asn62 na $L m$ CPB2.8 $\Delta$ CTE). A preferência por substratos tripeptídicos P3-substituídos tende a aumentar na ordem Glu $<$ Gly $<$ Arg $<$ Val $<$ Tyr. A maior preferência pela Tyr em P3 pode ser explicada pelo fato desse substituinte estabelecer interações hidrofóbicas com a Tyr75, além de uma potencial ligação de hidrogênio com o resíduo Asp69. ${ }^{82}$ 


\begin{tabular}{|l|c|c|c|c|}
\hline \multicolumn{1}{|c|}{ Protease } & Subsítio S3 & Subsítio S2 & Subsítio S1 & Subsítio S1 \\
\hline LmCPB2.8 $\Delta$ CTE & L68, N62 & L70, Y210, V212 & M69, A140, G165 & Q20, W186 \\
\hline Cruzaína & L67, S61 & N69, E208, S210 & M68, A138, G163 & Q19, W186 \\
\hline HsCatepsina L & L69, E63 & D71, A214, S216 & M69, I136, G164 & Q19, W189 \\
\hline HsCatepsina B & Y75, D69 & A77, E245, V247 & P76, A173, A200 & Q23, W221 \\
\hline
\end{tabular}

Tabela 7- Composição dos subsítios S3, S2, S1 e S1' das enzimas LmCPB2.8 $\Delta$ CTE, Cruzaína, HsCatepsina L e HsCatepsina B

\subsubsection{Análise estrutural do complexo $\operatorname{LmCPB-Neq0690}$}

O modo de interação do Neq0690 (figura 33) revela que este inibidor se ligou covalentemente a cisteína catalítica (Cys26) através do ataque nucleofílico do grupo tiolato ao carbono nitrílico. O nitrogênio imínico em P1' estabeleceu uma ligação de hidrogênio com o resíduo Gln20. Contatos hidrofóbicos com os resíduos Cys26 e Trp27 ajudaram a estabilizar a região do warhead no subsítio S1'. Além disso, a configuração oposta adotada pelos dois grupos metila substituídos nas posições $\mathrm{N}^{1}, \mathrm{~N}^{2}$ do warhead azanitrila possibilitou o estabelecimento de contatos favoráveis com os resíduos His164, Gly165 e Gly66. Os grupos situados na posição P2 e P3 do ligante ocuparam o interior das cavidades formadas pelos subsítios S2 e S3, respectivamente. A leucina em P2 estabeleceu interações hidrofóbicas no subsítio S2 com os resíduos Leu162, Ala140, Met69 e Tyr210. A interação por ligação de hidrogênio entre Asn62 e o nitrogênio pirazólico do ligante foi mediada por uma molécula de água. Além disso, contatos hidrofóbicos com os resíduos Leu68 e Met60 foram responsáveis pelo acomodamento desse grupo no interior do subsítio S3. Ligações de hidrogênio típicas do esqueleto dipeptídico com a cadeia principal da Gly 67 também foram observadas para o Neq0690. Essas interações ajudaram na estabilização da posição adotada pelo ligante no sítio ativo, já que formam um importante ponto de ancoragem na interface dos subsítios S2 e S3. 


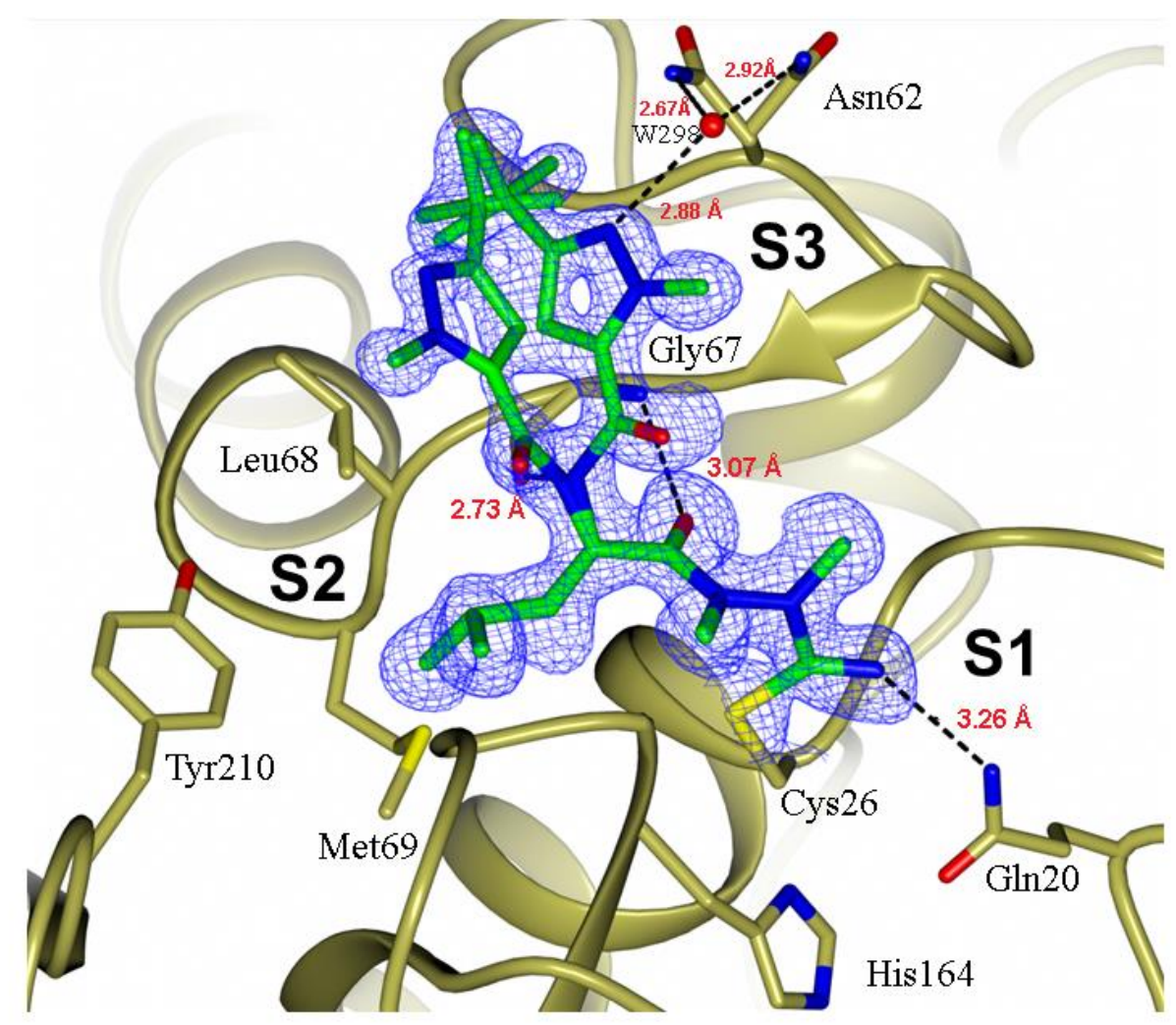

Figura 32 - MOB do Neq0690 em complexo com a $L m$ CPB2.8 $\Delta$ CTE com mapa de densidade eletrônica $2 \mathrm{~F}_{\text {obs }^{-}}$ $\mathrm{F}_{\text {calc }}$ contornados ao nível de $1 \sigma$. O inibidor se liga de forma covalente a cisteína catalítica (Cys26). As ligações de hidrogênio são representadas por pontilhados de cor preta.

Uma comparação com o inibidor aminonitrílico estruturalmente relacionado AZ12878478 cristalizado com a catepsina L (PDB: 3HHA) nos revela um modo de interação bastante similar (figura 34). Contudo, o anel heterocíclico situado na posição P3 do Neq0690 adota uma conformação notavelmente distinta daquela encontrada em seu análogo estrutural se posicionando quase que perpendicularmente a superfície do subsítio S3. Essa alteração conformacional pode ser explicada pela interação do nitrogênio pirazólico do ligante com o resíduo de aminoácido Asn62 que ocorreu através de uma rede de ligações de hidrogênio mediada por uma molécula de água (W298). Já o grupo pirazólico do análogo aminonitrílico se dobra sobre a superfície da cadeia lateral do resíduo Leu69 da catepsinas L (equivalente a Leu68 da $L m$ CPB2.8 $\Delta \mathrm{CTE}$ ), estabelecendo contatos hidrofóbicos com o mesmo. Embora seja difícil de ser modelada, uma conformação alternativa do Neq0690 parece indicar um posicionamento do anel heterocíclico semelhante aquele observado para o AZ12878478, sugerindo que a interação com a Leu68 pode também ser possível na $L m C P B 2.8 \Delta C$ TE, não sendo, contudo, a conformação preferencial desse substituinte. O baixo impacto na afinidade para a cruzaína referente a adição do grupo 1-metil-3-terc-butil-pirazol na poisção P3 do esqueleto dipeptidil azanitrílico indica que interação entre o nitrogênio pirazólico e a Ser61 
(equivalente ao resíduo Asn62 na LmCPB2.8 $\Delta \mathrm{CTE}$ ) possa não ocorrer de forma efetiva nessa enzima. A relativa rigidez observada pelo esqueleto dipeptidil azanitrílico quanto ao substiutinte em P3 parece não permitir uma compensação através de contatos hidrofóbicos mais efetivos com o resíduo Leu 67 da cruzaína (equivalente ao resíduo Leu68 na LmCPB2.8 $\Delta \mathrm{CTE})$.

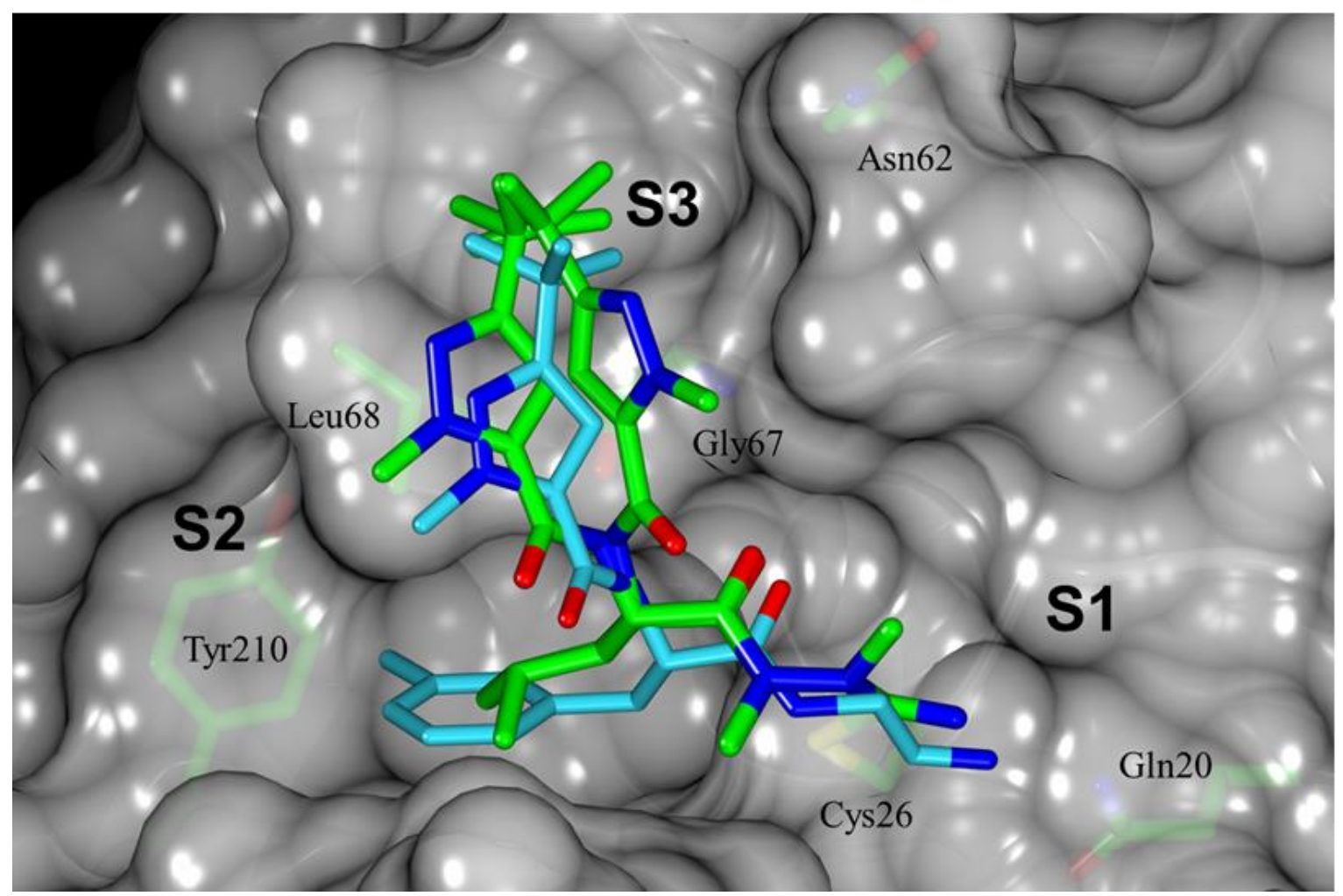

Figura 33 - Sobreposição do MOB do Neq0690 com o análogo estrutural ligado a catepsina L (código PDB 3HHA) em superfície de Van der Waals da $L m$ CPB2.8 $\Delta$ CTE. Átomos de carbono estão coloridos em verde para o composto Neq0690 e em azul claro para o análogo. Os principais aminoácidos da $L m C P B 2.8 \Delta C T E$ estão numerados.

Adicionalmente, o mapa de diferença $\mathrm{F}_{\mathrm{obs}}-\mathrm{F}_{\text {calc }}$ nos fornece contornos negativos (em vermelho) na região da ligação covalente, indicando que essa ligação seria proibitiva para uma ocupação de $100 \%$. Para investigar melhor esse resultado, a reversibilidade do Neq0690 para $L m C$ PB2.8 $\Delta$ CTE foi realizada medindo-se a recuperação da atividade enzimática após uma rápida e extensiva diluição do complexo enzima-inibidor (figura 36). Os resultados indicam que o Neq0690 se liga através de um mecanismo reversível de inibição o que valida ortogonalmente os resultados estruturais obtidos. Resultados semelhantes também foram observados para a cruzaína e catepsina L. ${ }^{83}$ 


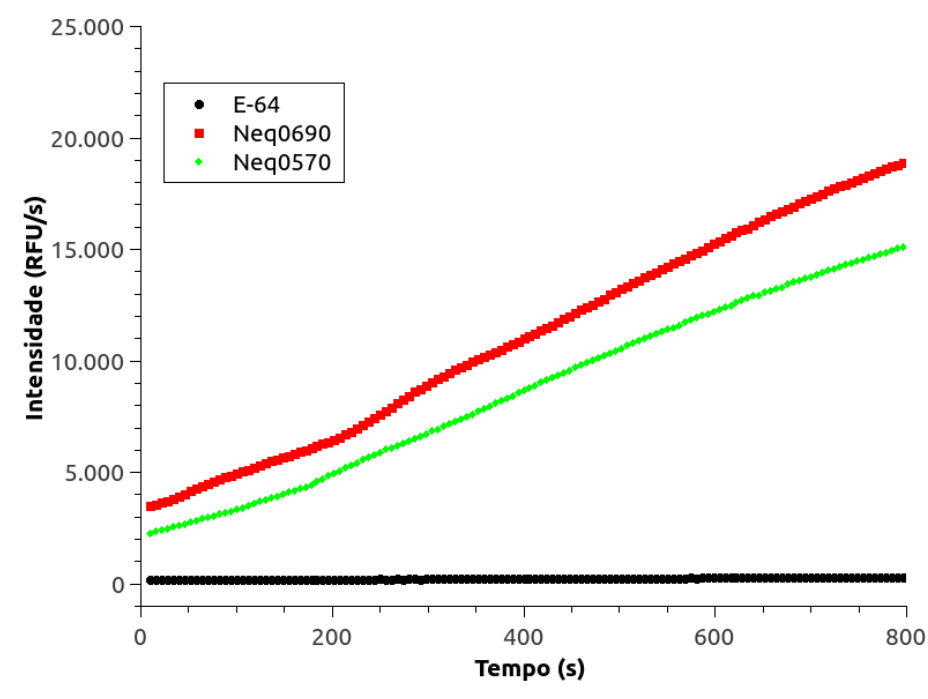

Figura 34- A reversibilidade do Neq0690 (em vermelho) para $L m$ CPB2.8 $\Delta$ CTE foi testada medindo-se a recuperação da atividade enzimática após uma rápida e extensa diluição do complexo enzima-inibidor. $\mathrm{O}$ inibidor foi incubado a uma concentração $10 x$ maior que o seu valor de $K_{\mathrm{i}}$ com $0,7 \mu \mathrm{M}$ de $\operatorname{LmCPB} 2.8 \Delta \mathrm{CTE}$ (100x a concentração requerida para o ensaio de atividade enzimática) por 30 minutos. A mistura foi, então, diluída por um fator de 100x no tampão de reação, contendo o substrato Z-Phe-Arg-AMC na concentração final de $7 \mu \mathrm{M}$. Como controles foram usados o Neq0570 (reversível - em verde) e o inibidor E-64 (irreversível - em preto). A recuperação da atividade enzimática após a diluição do complexo Neq0690- $\operatorname{m}$ CPB sugere um mecanismo de inibição reversível para o Neq0690.

\subsubsection{Análise estrutural do complexo $\operatorname{LmCPB}$-MMTS}

O MMTS (metanotiossulfonato de metila) tem sido amplamente empregado nos processos de purificação de cisteíno proteases da família da papaína em virtude de sua ação inibitória inespecífica sobre essa classe de enzimas. ${ }^{63}$ Assim, o uso desse inibidor após o processo de ativação enzimática tem como finalidade bloquear a degradação proteica decorrente da auto proteólise, mantendo a amostra homogênea e estável até o final do processo de purificação. Embora o seu mecanismo de inibição envolva a formação de uma ligação covalente com a cisteína catalítica, essa ligação pode ser facilmente revertida pela adição de um agente redutor no meio (geralmente o DTT) e, assim, a atividade enzimática pode ser reestabelecida (figura 37) 


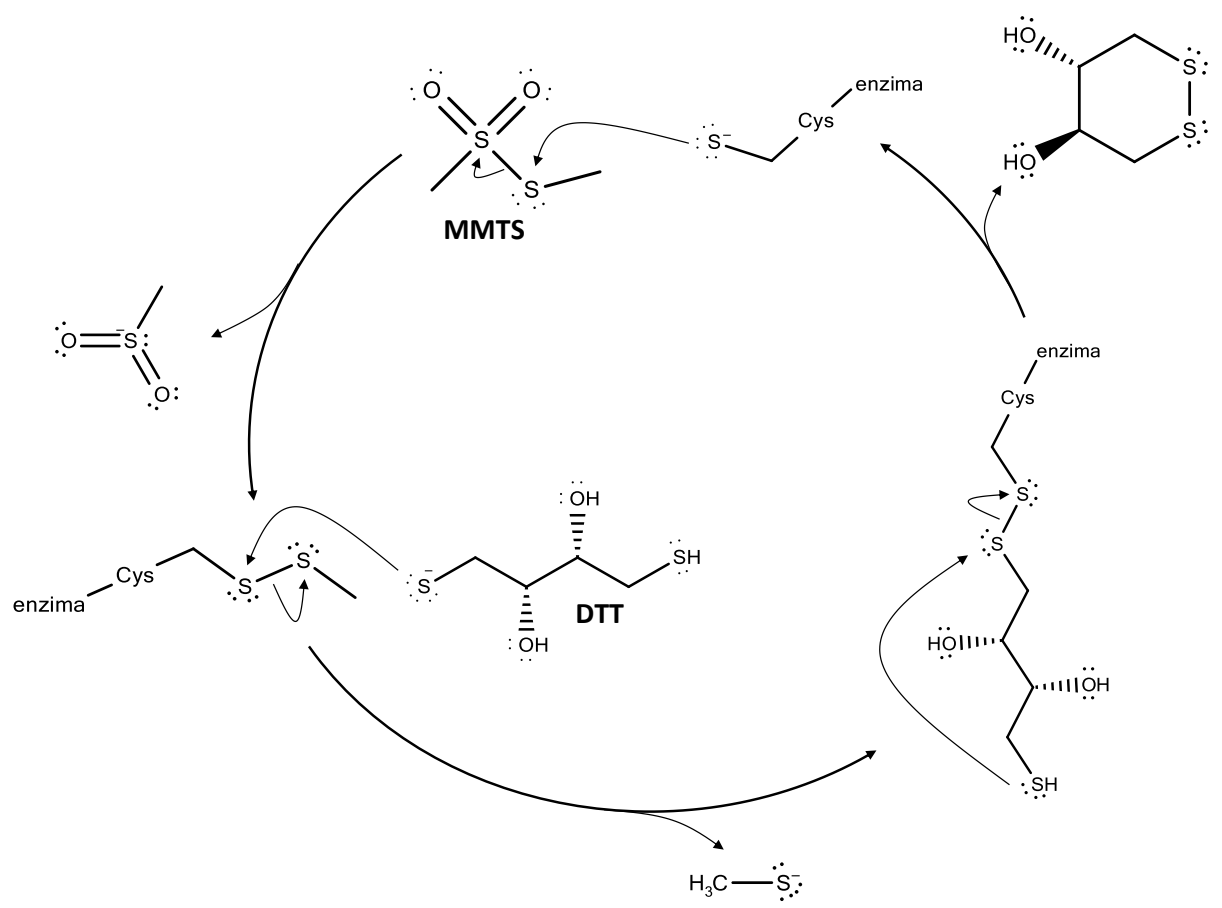

Figura 35 - Mecanismo de inibição de cisteíno proteases pelo MMTS. A reação pode ser revertida pela adição de agentes redutores como o DTT. ${ }^{84-63}$

Esse mecanismo de inibição permite explorar duas estratégias distintas nos estudos cristalográficos. A primeira envolve o tratamento da amostra com um agente redutor antes de se iniciar os experimentos de co-cristalização. O objetivo aqui é substituir o MMTS covalentemente ligado à cisteína catalítica pelo inibidor de interesse. Além disso, a presença de MMTS no meio pode ajudar o processo de cristalização por reduzir a auto proteólise durante a fase de formação de cristais. Essa estratégia tem sido empregada na produção de cristais de outras cisteíno proteases, como, por exemplo, a cruzaína (PDB: 3KKU, resolução de $1,28 \AA$ ). Nessa estrutura, o MMTS ligou-se à cisteína catalítica com uma ocupação de $30 \%$, sendo que os outros $70 \%$ corresponderam ao ligante B95. A segunda estratégia envolve a produção de cristais do complexo enzima-MMTS com o intuito de utilizá-los, posteriormente, em estudos de "soaking". A principal vantagem aqui se deve a produção de cristais com alto poder de difração a partir de uma única condição cristalográfica. Nessa estratégia, os cristais obtidos são incubados na solução de cristalização na presença de um agente redutor, como DTT. O DTT se difunde através dos canalículos de solvente presentes no cristal até alcançar o sítio ativo da enzima, onde remove o MMTS covalentemente ligado a cisteína catalítica. Em um segundo momento, esses cristais são transferidos para uma nova solução de cristalização, contendo o inibidor de interesse. A segunda estratégia foi adotada nesse trabalho e cristais da 
enzima LmCPB2.8 $\triangle \mathrm{CTE}$ em complexo com o inibidor MMTS foram obtidos $\mathrm{e}$ estruturalmente caracterizados.

A estrutura cristalográfica revela que o MMTS se ligou de forma covalente tanto a cisteína catalítica (Cys26) quanto a Cys205. A figura 38 mostra as características dos principais resíduos do sítio ativo e o modo de ligação do MMTS.

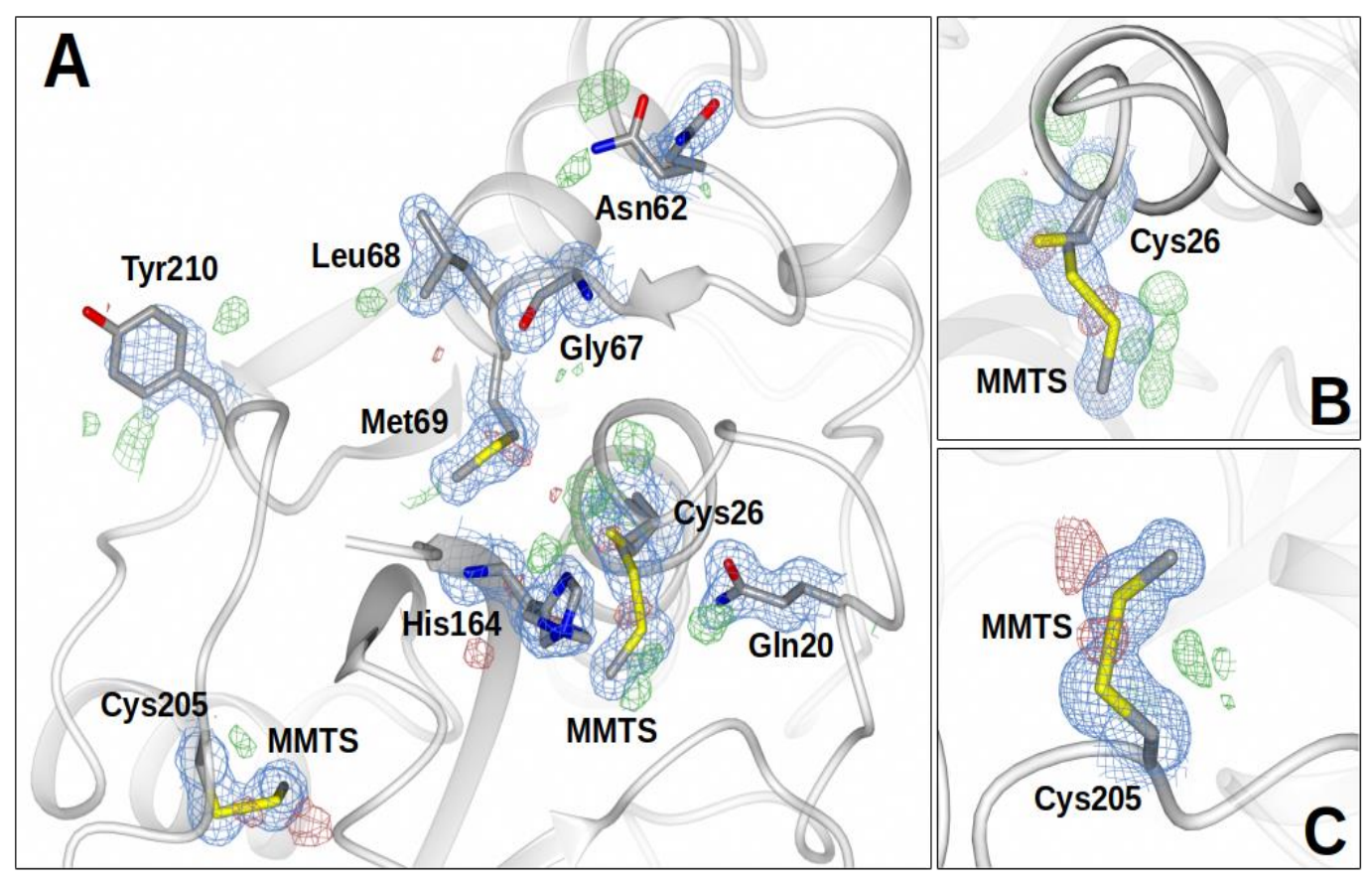

Figura 36 - Estrutura cristalográfica da enzima LmCPB2.8 $\triangle$ CTE em complexo com o MMTS. O mapa diferença $\mathrm{F}_{\mathrm{obs}}-\mathrm{F}_{\text {calc }}$ à $3 \sigma$ é mostrado para contornos positivos (em verde) e negativos (em vermelho). Em azul é exibido o mapa de densidade $2 \mathrm{~F}_{\mathrm{o}}-\mathrm{F}_{\mathrm{c}}$ contornados a $1 \sigma$. A figura $\mathbf{A}$ mostra os principais resíduos do sítio ativo, com destaque a alcanotiolação dos resíduos Cys26 e Cys205 pelo inibidor MMTS. A figura B mostra a cisteína catalítica em dois estados: livre e covalentemente ligada ao MMTS com uma ocupação de 50\%. A figura C mostra o resíduo de Cys205 covalentemente ligado ao MMTS.

O deslocamento de uma alça formada pelos resíduos Met200-Tyr210 foi observado após o alinhamento dos complexos LmCPB-Neq0690 e LmCPB-MMTS. Tal deslocamento foi uma consequência da ligação covalente do MMTS à Cys205, sendo responsável por alterações estruturais que se estenderam até o assoalho do subsítio S2, afetando resíduos importantes como a Tyr210 (figura 39). Vários estudos têm indicado que a Tyr210 é responsável pela especificidade da $L m \mathrm{CPB} 2.8 \Delta \mathrm{CTE}$ por seus substratos naturais.

Embora a ligação covalente do MMTS a resíduos de cisteína possa ser facilmente revertida em solução com o uso de agentes redutores como o DTT, não há evidências que as alterações conformacionais acima descritas possam ser revertidas no ambiente cristalino. 
Dado o papel fundamental do subsítio S2 nos processos de reconhecimento molecular da enzima, tais alterações estruturais podem inviabilizar o uso desses cristais para o estudo do modo de interação de novos inibidores através da técnica de "soaking" já discutida anteriormente.

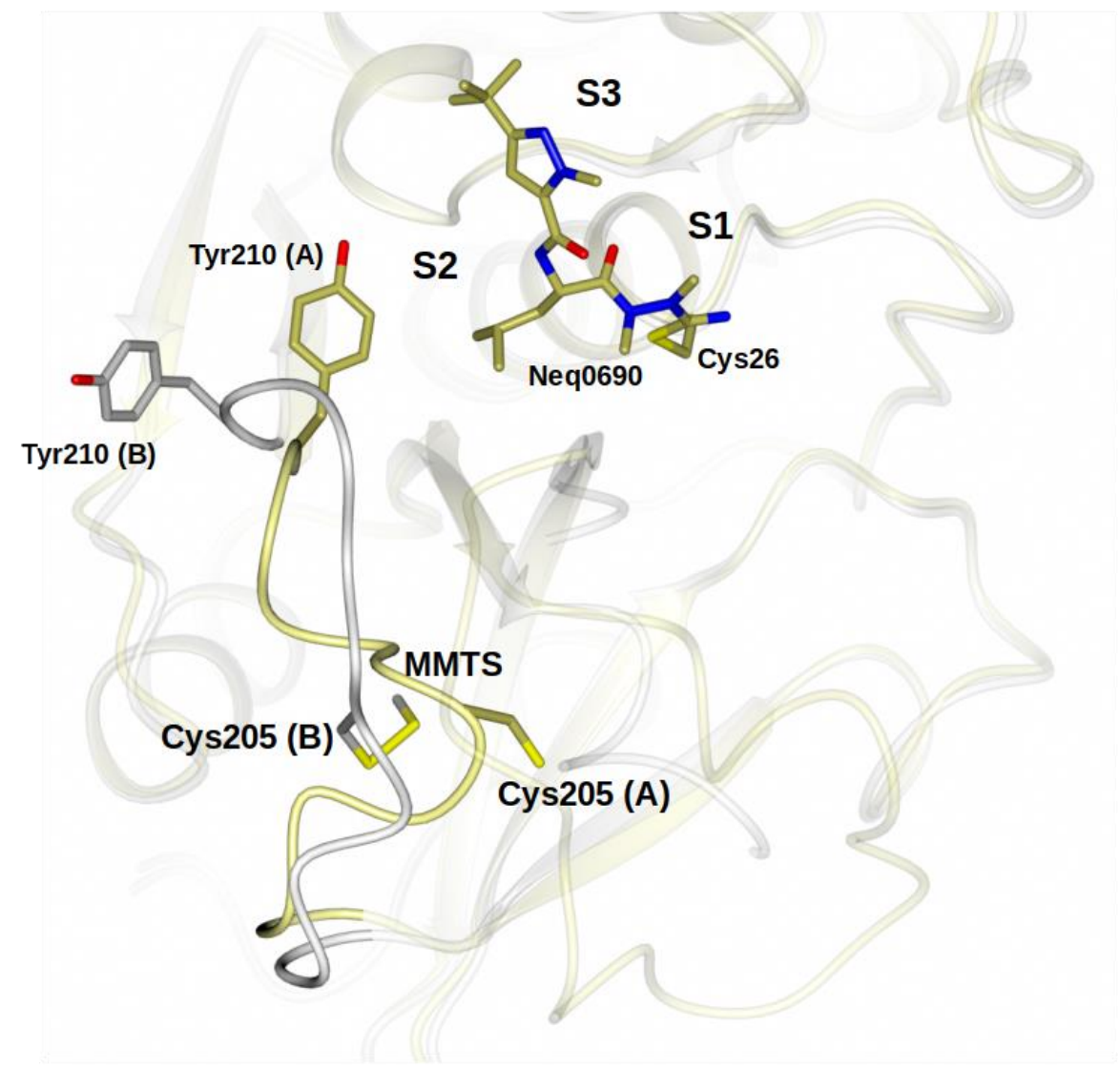

Figura 37 - Sobreposição estrutural dos complexos LmCPB-Neq0690 (em dourado) e LmCPB-MMTS (em prata). A ligação do MMTS ao resíduo de aminoácido Cys205(B) altera a conformação da Tyr210(B), comprometendo a estrutura do subsítio S2 da enzima $L m \mathrm{CPB} 2.8 \Delta \mathrm{CTE}$.

Outra característica estrutural importante envolve a ausência de densidade eletrônica para os resíduos TYR149-LYS160 (figura 40), observada durante o refinamento do complexo LmCPB-MMTS. Isso sugere que esse segmento peptídico tenha sido hidrolisado devido à atividade proteolítica residual, proveniente da inibição parcial da enzima pelo inibidor. A alta flexibilidade da extremidade formada pode justificar a conformação proibitiva adotada pelo resíduo MET147 observada no diagrama de Ramachandran. 


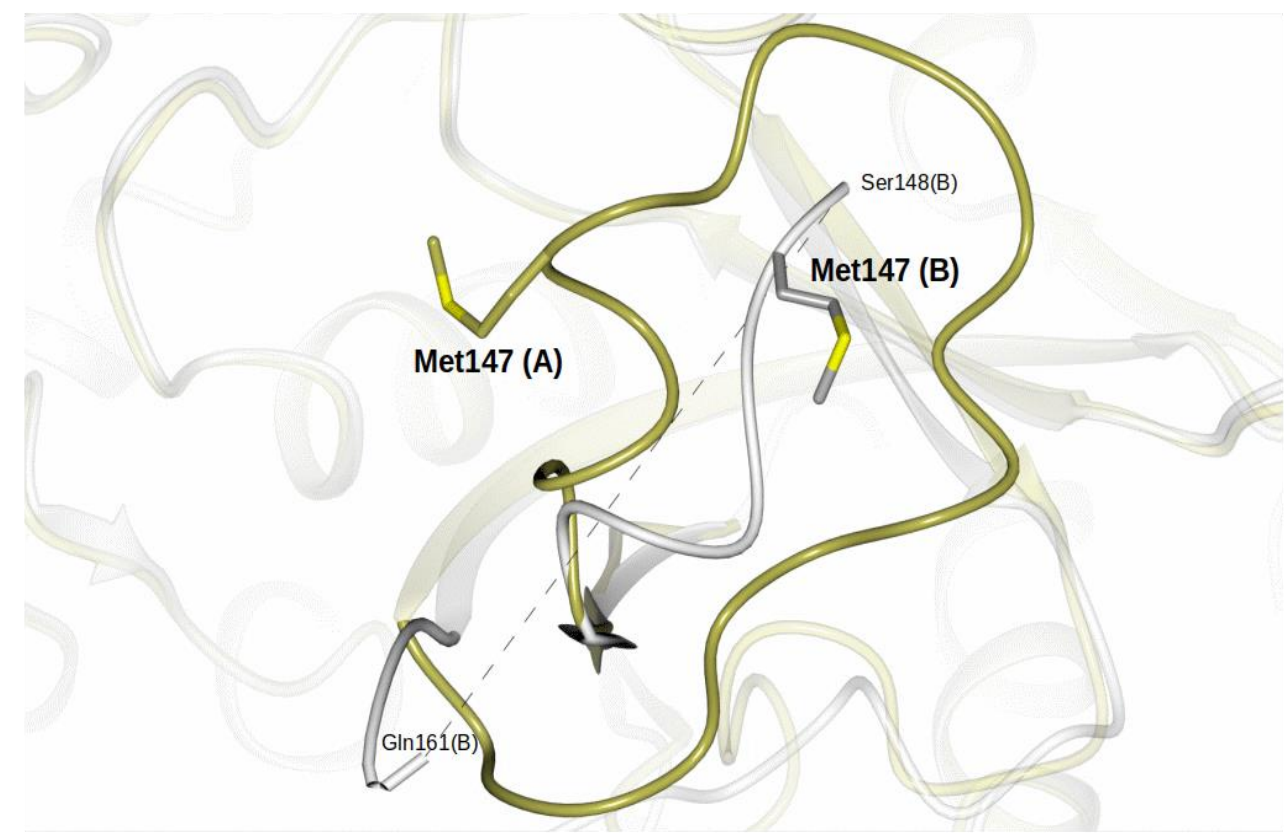

Figura 38 - Sobreposição estrutural dos complexos LmCPB-Neq0690 (em dourado) e LmCPB-MMTS (em prata). A figura destaca a ausência da alça composta pelos resíduos TYR149-LYS160 no complexo LmCPBMMTS. A alta flexibilidade da extremidade formada pode justificar a conformação proibitiva adotada pelo resíduo Met147(B) observada no diagrama de Ramachandran.

Adicionalmente, dois íons sulfatos provenientes da condição de cristalização foram encontrados fortemente associados a estrutura da enzima através de ligações de hidrogênio. $\mathrm{O}$ primeiro deles estabeleceu vários contatos com a cadeia principal através de interações com os resíduos de aminoácido Thr86, Val109, Val110, Gly111 e com a cadeia lateral do resíduo de aminoácido His85 (figura 41). O alinhamento com a estrutura do complexo LmCPBNeq0690, sugere que a interação desse grupo foi responsável pelo deslocamento de uma alça composta por 11 resíduos de aminoácidos que se inicia no resíduo Cys102 e termina na Gln113. Esse deslocamento justifica a desestruturação de uma folha- $\beta$ antiparalela formada pelos resíduos 110-113 e 83-85, assim como a posição proibitiva ocupada pelo resíduo Glu107 no diagrama de Ramachandran. O segundo íon sulfato se ligou no subsítio S1' através de ligações de hidrogênio com os resíduos Cys26, Trp27 e com a cadeia lateral da His164 (figura42). Essa interação pode ser um fator limitante para os estudos de socking com inibidores competitivos, haja vista que o inibidor de interesse deverá estabelecer interações suficientemente fortes para deslocar esse grupo de seu sítio de interação. 


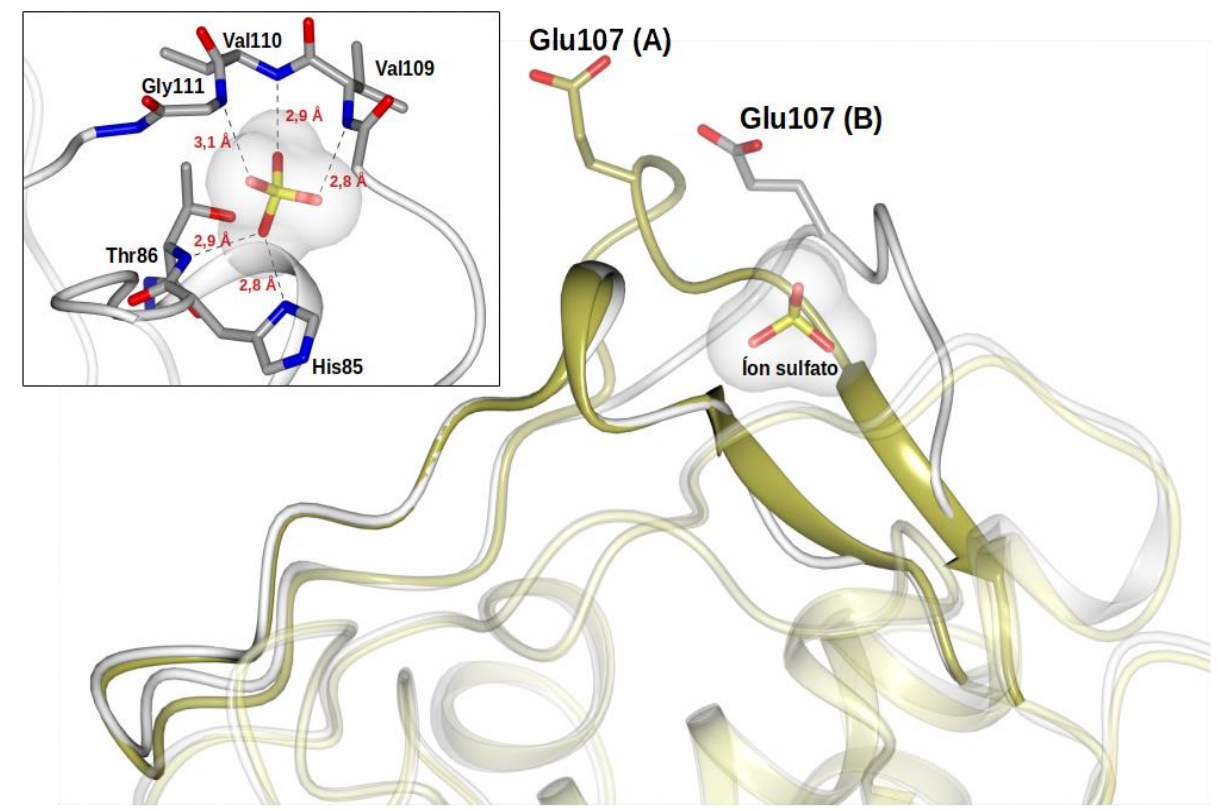

Figura 39 - Sobreposição estrutural dos complexos $L m$ CPB-Neq0690 (em dourado) e $L m C P B-M M T S$ (em prata). A figura destaca as modificações estruturais causadas pela interação do íon sulfato com dois seguimentos da cadeia polipeptídica do complexo LmCPB-MMTS formados pelos resíduos 109-111 e 85-86. Essa perturbação estrutural é responsável pelas alterações conformacionais do resíduo Glu107(B) observadas no diagrama de Ramachandran. $\mathrm{O}$ inserto detalha padrão de interação de ligação de hidrogênio entre o íon sulfato e os resíduos de aminoácidos Thr86, His85, Gly111, Val110 e V109.

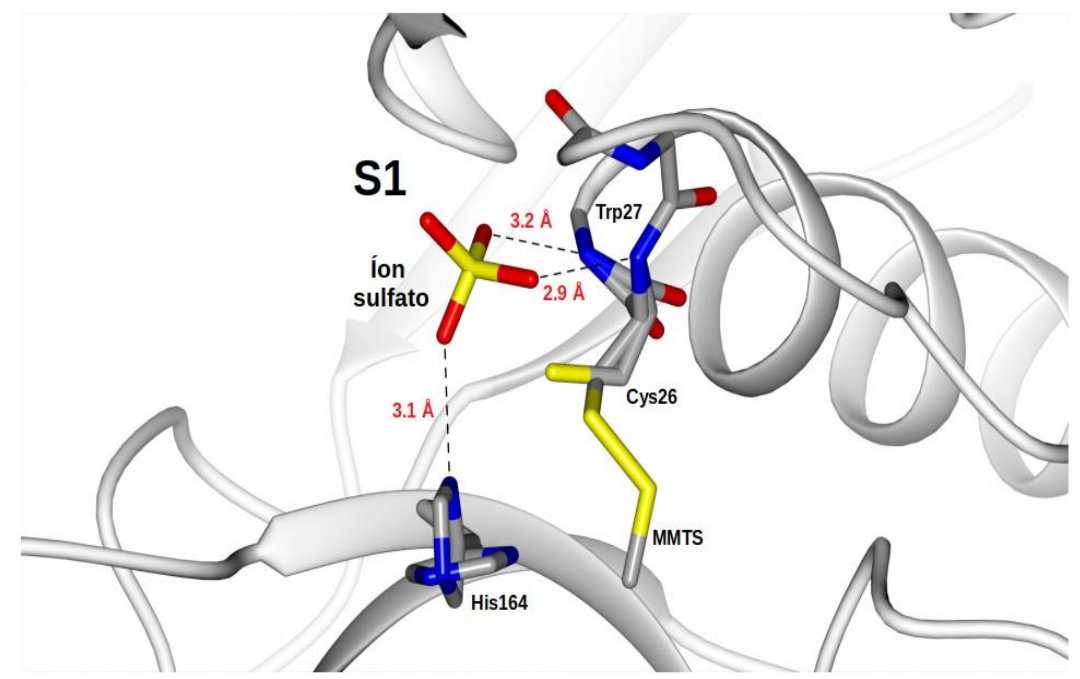

Figura 40 - Detalhamento do padrão de interação por ligação de hidrogênio entre o íon sulfato e os resíduos aminoácidos His164, Trp27 e Cys26 presentes no subsítio S1' da $L m$ CPB2.8 $\Delta$ CTE. 


\section{Conclusão e perspectivas}

Este trabalho concentrou-se fundamentalmente na descrição das relações estruturaatividade (SAR) de inibidores nitrílicos de cisteíno proteases especialmente relevantes no contexto de três doenças que acometem seres humanos: câncer (catepsina L), leishmanioses (LmCPB2.8 $\triangle \mathrm{CTE}$ ) e doença de Chagas (cruzaína). Modificações sistemáticas nas posições P1, P1', P2 e P3 do composto prototípico, Neq0409, revelaram de forma pormenorizada os padrões de especificidade característicos de cada uma das enzimas estudadas. Todos os ligantes avaliados atuaram através de um mecanismo covalente-reversível de inibição, envolvendo o ataque quimiosseletivo da cisteína catalítica ao carbono nitrílico. A substituição da aminonitrila em P1' pelo grupo azanitrila resultou em uma profunda modificação das interações ao nível do subsítio S1'. Esses inibidores passaram a apresentar uma cinética de interação lentamente reversível (do inglês slow binding) com valores de afinidades significativamente maiores do que aqueles apresentados por seus análogos aminonitrílicos. Já a substituição bioisostérica da ligação amida do esqueleto dipeptídico pelo grupo trifluoroetilamina resultou na síntese do Neq0659 que apresentou um perfil de inibição altamente seletivo para as enzimas parasitárias. De forma geral, as respostas às substituições feitas em P1 tenderam a ser concordantes entre as enzimas estudadas. Contudo, a inserção do grupo benzila produziu ganhos de afinidade significativamente melhores para as enzimas cruzaína e LmCPB2.8 $\triangle$ CTE. Embora, a maioria das modificações feitas em P2 conduziu a perdas de afinidade para os alvos avaliados, as inserções dos substituintes leucina, triptofano, cloro-finilalanina (para a catepsina L) e leucina, fenil benzoato (para LmCPB2.8 $\triangle \mathrm{CTE}$ ) foram relativamente bem toleradas. Já a cruzaína apresentou uma especificidade mais ampla para o subsítio S2, sendo capaz de interagir com os grupos leucina, tirosina, cloro-fenilalanina e triptofano nessa posição. De forma geral, todas as enzimas estudadas apresentaram ganhos de afinidade com a inserção dos grupos bromo piridina e 1-metil-3-terc-butil-pirazol em P3. Além disso, os substituintes 3-bromo fenil e 2-cloro fenil melhoraram a interação com a LmCPB2.8 $\triangle \mathrm{CTE}$ e catepsina $\mathrm{L}$ enquanto que a bifenila nessa posição produziu ganhos seletivos de afinidade para a LmCPB2.8 $\triangle$ CTE.

A ausência de informação estrutural para enzima LmCPB2.8 $\triangle \mathrm{CTE}$, bem como a necessidade de uma melhor compreensão dos processos físico-químicos envolvidos no mecanismo de reconhecimento molecular dessa enzima, exigiram a inserção desse trabalho na área de cristalografia de proteínas. Os estudos realizados durante o estágio de doutorado 
sanduíche na Universidade de Nottingham-Inglaterra, resultaram na obtenção de duas novas estruturas cristalográficas de raios-X para essa enzima em resoluções melhores que $1,5 \AA$. A obtenção do co-complexo de um dos mais potentes inibidores da LmCPB2.8 $\triangle$ CTE, o Neq0690, a 1,3 Å, permitiu a completa caracterização de seu modo de interação, revelando características únicas do processo de reconhecimento bimolecular. Além disso, uma nova janela de oportunidades abriu-se com a possibilidade do uso de ferramentas computacionais baseadas na estrutura do alvo para a pesquisa de novos agentes que atuem sobre cisteíno proteases. 


\section{REFERÊNCIAS BIBLIOGRÁFICAS}

1. KAMPHUIS, I. G.; KALK, K. H.; SWARTE, M. B. A.; DRENTH, J. Structure of papain refined at 1.65 Å resolution. Journal of Molecular Biology, v. 179, n. 2, p. 233-256, 1984.

2. DURRANT, J. D.; KERÄNEN, H.; WILSON, B. A.; MCCAMMON, J. A. Computational Identification of Uncharacterized Cruzain Binding Sites. PLOS Neglected Tropical Diseases, v. 4, n. 5, p. e676, 2010.

3. LALMANACH, G.; LECAILLE, F.; CHAGAS, J. R.; AUTHIÉ, E.; SCHARFSTEIN, J.; JULIANO, M. A.; GAUTHIER, F. Inhibition of Trypanosomal Cysteine Proteinases by Their Propeptides. Journal of Biological Chemistry, v. 273, n. 39, p. 25112-25116, 1998.

4. TURK, V.; TURK, B.; TURK, D. NEW EMBO MEMBER'S REVIEW: Lysosomal cysteine proteases: facts and opportunities. The EMBO Journal, v. 20, n. 17, p. 4629-4633, 2001.

5. BRIX, K.; DUNKHORST, A.; MAYER, K.; JORDANS, S. Cysteine cathepsins: Cellular roadmap to different functions. Biochimie, v. 90, n. 2, p. 194-207, 2008.

6. ENGEL, J. C.; DOYLE, P. S.; HSIEH, I.; MCKERROW, J. H. Cysteine Protease Inhibitors Cure an Experimental Trypanosoma cruzi Infection. The Journal of Experimental Medicine, v. 188, n. 4, p. 725-734, 1998.

7. MCKERROW, J. H.; ENGEL, J. C.; CAFFREY, C. R. Cysteine protease inhibitors as chemotherapy for parasitic infections. Bioorganic \& Medicinal Chemistry, v. 7, n. 4, p. 639644, 1999.

8. SELZER, P. M.; PINGEL, S.; HSIEH, I.; UGELE, B.; CHAN, V. J.; ENGEL, J. C.; BOGYO, M.; RUSSELL, D. G.; SAKANARI, J. A.; MCKERROW, J. H. Cysteine protease inhibitors as chemotherapy: Lessons from a parasite target. Proceedings of the National Academy of Sciences, v. 96, n. 20, p. 11015, 1999.

9. KERR, I. D.; LEE, J. H.; FARADY, C. J.; MARION, R.; RICKERT, M.; SAJID, M.; PANDEY, K. C.; CAFFREY, C. R.; LEGAC, J.; HANSELL, E.; MCKERROW, J. H.; CRAIK, C. S.; ROSENTHAL, P. J.; BRINEN, L. S. Vinyl Sulfones as Antiparasitic Agents and a Structural Basis for Drug Design. The Journal of Biological Chemistry, v. 284, n. 38, p. 25697-25703, 2009.

10. ENGEL, J. C.; DOYLE, P. S.; PALMER, J.; HSIEH, I.; BAINTON, D. F.; MCKERROW, J. H. Cysteine protease inhibitors alter Golgi complex ultrastructure and function in Trypanosoma cruzi. Journal of Cell Science, v. 111, n. 5, p. 597, 1998. 
11. FIELD, M. C.; HORN, D.; FAIRLAMB, A. H.; FERGUSON, M. A. J.; GRAY, D. W.; READ, K. D.; DE RYCKER, M.; TORRIE, L. S.; WYATT, P. G.; WYLLIE, S.; GILBERT, I. H. Anti-trypanosomatid drug discovery: an ongoing challenge and a continuing need. Nature reviews. Microbiology, v. 15, n. 4, p. 217-231, 2017.

12. MOTTRAM, J. C.; SOUZA, A. E.; HUTCHISON, J. E.; CARTER, R.; FRAME, M. J.; COOMBS, G. H. Evidence from disruption of the lmcpb gene array of Leishmania mexicana that cysteine proteinases are virulence factors. Proceedings of the National Academy of Sciences of the United States of America, v. 93, n. 12, p. 6008-6013, 1996.

13. BART, G.; FRAME, M. J.; CARTER, R.; COOMBS, G. H.; MOTTRAM, J. C. Cathepsin B-like cysteine proteinase-deficient mutants of Leishmania mexicana. Molecular and Biochemical Parasitology, v. 88, n. 1, p. 53-61, 1997.

14. MOTTRAM, J. C.; BROOKS, D. R.; COOMBS, G. H. Roles of cysteine proteinases of trypanosomes and Leishmania in host-parasite interactions. Current Opinion in Microbiology, v. 1, n. 4, p. 455-460, 1998.

15. SARAVIA, N. G.; ESCORCIA, B.; OSORIO, Y.; VALDERRAMA, L.; BROOKS, D.; ARTEAGA, L.; COOMBS, G.; MOTTRAM, J.; TRAVI, B. L. Pathogenicity and protective immunogenicity of cysteine proteinase-deficient mutants of Leishmania mexicana in nonmurine models. Vaccine, v. 24, n. 19, p. 4247-4259, 2006.

16. SUDHAN, D. R.; SIEMANN, D. W. Cathepsin L targeting in cancer treatment. Pharmacology \& therapeutics, v. 155, p. 105-116, 2015.

17. DENNEMÄRKER, J.; LOHMÜLLER, T.; MÜLLER, S.; AGUILAR STEPHANIE, V.; TOBIN DESMOND, J.; PETERS, C.; REINHECKEL, T. Impaired turnover of autophagolysosomes in cathepsin L deficiency. Biological Chemistry. v. 391. n. 82010. p. 913.

18. GOTTESMAN, M. M. Transformation-dependent secretion of a low molecular weight protein by murine fibroblasts. Proceedings of the National Academy of Sciences of the United States of America, v. 75, n. 6, p. 2767-2771, 1978.

19. DOHERTY, P. J.; HUA, L.; LIAU, G.; GAL, S.; GRAHAM, D. E.; SOBEL, M.; GOTTESMAN, M. M. Malignant transformation and tumor promoter treatment increase levels of a transcript for a secreted glycoprotein. Molecular and Cellular Biology, v. 5, n. 3, p. 466-473, 1985.

20. GORETZKI, L.; SCHMITT, M.; MANN, K.; CALVETE, J.; CHUCHOLOWSKI, N.; KRAMER, M.; GÜNZLER WOLFGANG, A.; JÄNICKE, F.; GRAEFF, H. Effective activation of the proenzyme form of the urokinase- type plasminogen activator (pro- uPA) by the cysteine protease cathepsin L. FEBS Letters, v. 297, n. 1-2, p. 112-118, 2002. 
21. EVERTS, V.; KORPER, W.; HOEBEN KEES, A.; JANSEN INEKE, D. C.; BROMME, D.; CLEUTJENS KITTY, B. J. M.; HEENEMAN, S.; PETERS, C.; REINHECKEL, T.; SAFTIG, P.; BEERTSEN, W. Osteoclastic Bone Degradation and the Role of Different Cysteine Proteinases and Matrix Metalloproteinases: Differences Between Calvaria and Long Bone. Journal of Bone and Mineral Research, v. 21, n. 9, p. 1399-1408, 2009.

22. GOULET, B.; SANSREGRET, L.; LEDUY, L.; BOGYO, M.; WEBER, E.; CHAUHAN, S. S.; NEPVEU, A. Increased Expression and Activity of Nuclear Cathepsin L in Cancer Cells Suggests a Novel Mechanism of Cell Transformation. Molecular Cancer Research, v. 5, n. 9, p. 899, 2007.

23. CHAVARRIA, G. E.; HORSMAN, M. R.; ARISPE, W. M.; KUMAR, G. D. K.; CHEN, S.-E.; STRECKER, T. E.; PARKER, E. N.; CHAPLIN, D. J.; PINNEY, K. G.; TRAWICK, M. L. Initial evaluation of the antitumour activity of KGP94, a functionalized benzophenone thiosemicarbazone inhibitor of cathepsin L. European Journal of Medicinal Chemistry, v. 58, p. 568-572, 2012.

24. KATUNUMA, N.; TSUGE, H.; NUKATSUKA, M.; ASAO, T.; FUKUSHIMA, M. Structure-Based Design of Specific Cathepsin Inhibitors and Their Application to Protection of Bone Metastases of Cancer Cells. Archives of Biochemistry and Biophysics, v. 397, n. 2, p. 305-311, 2002.

25. JACOBSEN, W.; CHRISTIANS, U.; BENET, L. Z. In Vitro Evaluation of the Disposition of A Novel Cysteine Protease Inhibitor. Drug Metabolism and Disposition, v. 28, n. 11, p. 1343, 2000.

26. CHOY, J. W.; BRYANT, C.; CALVET, C. M.; DOYLE, P. S.; GUNATILLEKE, S. S.; LEUNG, S. S. F.; ANG, K. K. H.; CHEN, S.; GUT, J.; OSES-PRIETO, J. A.; JOHNSTON, J. B.; ARKIN, M. R.; BURLINGAME, A. L.; TAUNTON, J.; JACOBSON, M. P.; MCKERROW, J. M.; PODUST, L. M.; RENSLO, A. R. Chemical-biological characterization of a cruzain inhibitor reveals a second target and a mammalian off-target. Beilstein Journal of Organic Chemistry, v. 9, p. 15-25, 2013.

27. GOUR-SALIN, B. J.; LACHANCE, P.; STORER, A. C. Inhibition of papain by peptide nitriles: conversion of the nitrile group into other functionalities via the papain:nitrile thioimidate ester adduct. Canadian Journal of Chemistry, v. 69, n. 8, p. 1288-1297, 1991.

28. QUESNE, M. G.; WARD, R. A.; DE VISSER, S. P. Cysteine protease inhibition by nitrile-based inhibitors: a computational study. Frontiers in Chemistry, v. 1, p. 39, 2013.

29. CHAPURLAT, R. D. Odanacatib: a review of its potential in the management of osteoporosis in postmenopausal women. Therapeutic Advances in Musculoskeletal Disease, v. 7, n. 3, p. 103-109, 2015.

30. NDAO, M.; BEAULIEU, C.; BLACK, W. C.; ISABEL, E.; VASQUEZ-CAMARGO, F.; NATH-CHOWDHURY, M.; MASSÉ, F.; MELLON, C.; METHOT, N.; NICOLL- 
GRIFFITH, D. A. Reversible Cysteine Protease Inhibitors Show Promise for a Chagas Disease Cure. Antimicrobial Agents and Chemotherapy, v. 58, n. 2, p. 1167-1178, 2014.

31. ASAAD, N.; BETHEL, P. A.; COULSON, M. D.; DAWSON, J. E.; FORD, S. J.; GERHARDT, S.; GRIST, M.; HAMLIN, G. A.; JAMES, M. J.; JONES, E. V.; KAROUTCHI, G. I.; KENNY, P. W.; MORLEY, A. D.; OLDHAM, K.; RANKINE, N.; RYAN, D.; WELLS, S. L.; WOOD, L.; AUGUSTIN, M.; KRAPP, S.; SIMADER, H.; STEINBACHER, S. Dipeptidyl nitrile inhibitors of Cathepsin L. Bioorganic \& Medicinal Chemistry Letters, v. 19, n. 15, p. 4280-4283, 2009.

32. EHMKE, V.; QUINSAAT, J. E. Q.; RIVERA-FUENTES, P.; HEINDL, C.; FREYMOND, C.; ROTTMANN, M.; BRUN, R.; SCHIRMEISTER, T.; DIEDERICH, F. Tuning and predicting biological affinity: aryl nitriles as cysteine protease inhibitors. Organic \& Biomolecular Chemistry, v. 10, n. 30, p. 5764-5768, 2012.

33. SCHRÖDER, J.; NOACK, S.; MARHÖFER, R. J.; MOTTRAM, J. C.; COOMBS, G. H.; SELZER, P. M. Identification of Semicarbazones, Thiosemicarbazones and Triazine Nitriles as Inhibitors of Leishmania mexicana Cysteine Protease CPB. PLoS ONE, v. 8, n. 10, p. e77460, 2013.

34. LÖSER, R.; FRIZLER, M.; SCHILLING, K.; GÜTSCHOW, M. Azadipeptide Nitriles: Highly Potent and Proteolytically Stable Inhibitors of Papain- Like Cysteine Proteases. Angewandte Chemie International Edition, v. 47, n. 23, p. 4331-4334, 2008.

35. GOLIĈNIK, M.; STOJAN, J. Slow- binding inhibition: A theoretical and practical course for students. Biochemistry and Molecular Biology Education, v. 32, n. 4, p. 228-235, 2006.

36. FRIZLER, M.; LOHR, F.; FURTMANN, N.; KLÄS, J.; GÜTSCHOW, M. Structural Optimization of Azadipeptide Nitriles Strongly Increases Association Rates and Allows the Development of Selective Cathepsin Inhibitors. Journal of Medicinal Chemistry, v. 54, n. 1, p. 396-400, 2011.

37. YANG, P. Y.; WANG, M.; LI, L.; WU, H.; HE CYNTHIA, Y.; YAO SHAO, Q. Design, Synthesis and Biological Evaluation of Potent Azadipeptide Nitrile Inhibitors and ActivityBased Probes as Promising Anti- Trypanosoma brucei Agents. Chemistry - A European Journal, v. 18, n. 21, p. 6528-6541, 2012.

38. PlOWRIGHT, A. T.; JOHNSTONE, C.; KIHLBERG, J.; PETTERSSON, J.; ROBB, G.; THOMPSON, R. A. Hypothesis driven drug design: improving quality and effectiveness of the design-make-test-analyse cycle. Drug Discovery Today, v. 17, n. 1, p. 56-62, 2012.

39. BLACK, W. C.; BAYLY, C. I.; DAVIS, D. E.; DESMARAIS, S.; FALGUEYRET, J.-P.; LÉGER, S.; LI, C. S.; MASSÉ, F.; MCKAY, D. J.; PALMER, J. T.; PERCIVAL, M. D.; ROBICHAUD, J.; TSOU, N.; ZAMBONI, R. Trifluoroethylamines as amide isosteres in inhibitors of cathepsin K. Bioorganic \& Medicinal Chemistry Letters, v. 15, n. 21, p. 47414744, 2005. 
40. KAWASAKI, Y.; CHUFAN, E. E.; LAFONT, V.; HIDAKA, K.; KISO, Y.; AMZEL, L. M.; FREIRE, E. How Much Binding Affinity Can be Gained by Filling a Cavity? Chemical biology \& drug design, v. 75, n. 2, p. 143-151, 2010.

41. CALIANDRO, R.; BELVISO, D. B.; ARESTA, B. M.; DE CANDIA, M.; ALTOMARE, C. D. Protein crystallography and fragment-based drug design. Future Medicinal Chemistry, v. 5, n. 10, p. 1121-1140, 2013.

42. DESCHAMPS, J. R. The role of crystallography in drug design. The AAPS Journal, v. 7, n. 4, p. E813-E819, 2005.

43. ZHENG, H.; HOU, J.; ZIMMERMAN, M. D.; WLODAWER, A.; MINOR, W. The future of crystallography in drug discovery. Expert opinion on drug discovery, v. 9, n. 2, p. 125-137, 2014.

44. ANDERSON, A. C. The Process of Structure-Based Drug Design. Chemistry \& Biology, v. 10, n. 9, p. 787-797, 2003.

45. DEREWENDA, Z. S. The use of recombinant methods and molecular engineering in protein crystallization. Methods, v. 34, n. 3, p. 354-363, 2004.

46. CHAYEN, N. E.; SARIDAKIS, E. Protein crystallization: from purified protein to diffraction-quality crystal. Nature Methods, v. 5, p. 147, 2008.

47. CHAYEN, N. E. Turning protein crystallisation from an art into a science. Current Opinion in Structural Biology, v. 14, n. 5, p. 577-583, 2004.

48. HAMMOND, C. The Basic of Crystallography and Diffraction. 3. ed.: Oxford University Press, 2009. v. 1. p. 264.

49. GIACOVAZZO, C. M., H. L.; VITERBO, D. Fundamentals of Crystallography. 2. ed. Oxford: IUCR - Oxford University Press, 2002. v. 1. p. 872.

50. MEYER, G. Review of Basic Concepts of Crystallography. An Outcome from Crystal Symmetry. Crystal Growth \& Design, v. 12, n. 11, p. 5833-5833, 2012.

51. MCPHERSON, A. Introduction to Macromolecular Crystallography. 2. ed. New Jersey, United States: John Wiley \& sons, Inc, 2009. v. 2. p. 280.

52. HUMPHREYS, C. The significance of Bragg's law in electron diffraction and microscopy, and Bragg's second law. Acta Crystallographica Section A, v. 69, n. 1, p. 4550, 2013. 
53. RUPP, B. Biomolecular Crystallography: Principles, Practice, and Application to Structural Biology. 1. ed.: Garland Science, Taylor \& Francis Group, LLC, 2009. v. 1. p. 800.

54. MCCOY, A. Solving structures of protein complexes by molecular replacement with Phaser. Acta Crystallographica Section D, v. 63, n. 1, p. 32-41, 2007.

55. ABERGEL, C. Molecular replacement: tricks and treats. Acta Crystallographica Section D: Biological Crystallography, v. 69, n. Pt 11, p. 2167-2173, 2013.

56. TAYLOR, G. L. Introduction to phasing. Acta Crystallographica Section D: Biological Crystallography, v. 66, n. Pt 4, p. 325-338, 2010.

57. WLODAWER, A.; MINOR, W.; DAUTER, Z.; JASKOLSKI, M. Protein crystallography for non-crystallographers, or how to get the best (but not more) from published macromolecular structures. The FEBS journal, v. 275, n. 1, p. 1-21, 2008.

58. URZHUMTSEVA, L.; AFONINE, P. V.; ADAMS, P. D.; URZHUMTSEV, A. Crystallographic model quality at a glance. Acta Crystallographica Section D, v. 65, n. 3, p. 297-300, 2009.

59. LEE, G. M.; BALOUCH, E.; GOETZ, D. H.; LAZIC, A.; MCKERROW, J. H.; CRAIK, C. S. Mapping Inhibitor Binding Modes on an Active Cysteine Protease via NMR Spectroscopy. Biochemistry, v. 51, n. 50, p. 10087-10098, 2012.

60. STUDIER, F. W. Protein production by auto-induction in high-density shaking cultures. Protein Expression and Purification, v. 41, n. 1, p. 207-234, 2005.

61. NIKOLOVA, N.; TENEKEDJIEV, K.; KOLEV, K. Uses and misuses of progress curve analysis in enzyme kinetics. Central European journal of biology, v. 3, n. 4, p. 345-350, 2008.

62. The Behavior and Significance of Slow- Binding Enzyme Inhibitors. Advances in Enzymology and Related Areas of Molecular Biology.

63. SMITH, D. J.; MIGGIO, E. T.; KENYON, G. L. Simple alkanethiol groups for temporary blocking of sulfhydryl groups of enzymes. Biochemistry, v. 14, n. 4, p. 766-771, 1975.

64. BATTYE, T. G. G.; KONTOGIANNIS, L.; JOHNSON, O.; POWELL, H. R.; LESLIE, A. G. W. iMOSFLM: a new graphical interface for diffraction-image processing with MOSFLM. Acta Crystallographica Section D: Biological Crystallography, v. 67, n. Pt 4, p. 271-281, 2011.

65. EVANS, P. An introduction to data reduction: space-group determination, scaling and intensity statistics. Acta Crystallographica Section D, v. 67, n. 4, p. 282-292, 2011. 
66. VAGIN, A. A.; STEINER, R. A.; LEBEDEV, A. A.; POTTERTON, L.; MCNICHOLAS, S.; LONG, F.; MURSHUDOV, G. N. REFMAC5 dictionary: organization of prior chemical knowledge and guidelines for its use. Acta Crystallographica Section D, v. 60, n. 12 Part 1, p. 2184-2195, 2004.

67. EMSLEY, P.; LOHKAMP, B.; SCOTT, W. G.; COWTAN, K. Features and development of Coot. Acta Crystallographica Section D: Biological Crystallography, v. 66, n. Pt 4, p. 486-501, 2010.

68. SANDERSON, S. J.; POLLOCK, K. G.; HILLEY, J. D.; MELDAL, M.; HILAIRE, P. S.; JULIANO, M. A.; JULIANO, L.; MOTTRAM, J. C.; COOMBS, G. H. Expression and characterization of a recombinant cysteine proteinase of Leishmania mexicana. Biochemical Journal, v. 347, n. Pt 2, p. 383-388, 2000.

69. AVELAR, L. A. A.; CAMILO, C. D.; DE ALBUQUERQUE, S.; FERNANDES, W. B.; GONÇALEZ, C.; KENNY, P. W.; LEITÃO, A.; MCKERROW, J. H.; MONTANARI, C. A.; OROZCO, E. V. M.; RIBEIRO, J. F. R.; ROCHA, J. R.; ROSINI, F.; SAIDEL, M. E. Molecular Design, Synthesis and Trypanocidal Activity of Dipeptidyl Nitriles as Cruzain Inhibitors. PLOS Neglected Tropical Diseases, v. 9, n. 7, p. e0003916, 2015.

70. FARADY, C. J.; CRAIK, C. S. Mechanisms Of Macromolecular Protease Inhibitors. Chembiochem : a European journal of chemical biology, v. 11, n. 17, p. 2341-2346, 2010.

71. LÖSER, R.; SCHILLING, K.; DIMMIG, E.; GÜTSCHOW, M. Interaction of Papain-like Cysteine Proteases with Dipeptide-Derived Nitriles. Journal of Medicinal Chemistry, v. 48, n. 24, p. 7688-7707, 2005.

72. KENNY, P. W.; MONTANARI, C. A.; PROKOPCZYK, I. M.; SALA, F. A.; SARTORI, G. R. Automated molecule editing in molecular design. Journal of Computer-Aided Molecular Design, v. 27, n. 8, p. 655-664, 2013.

73. CRAWFORD, J. J.; KENNY, P. W.; BOWYER, J.; COOK, C. R.; FINLAYSON, J. E.; HEYES, C.; HIGHTON, A. J.; HUDSON, J. A.; JESTEL, A.; KRAPP, S.; MARTIN, S.; MACFAUL, P. A.; MCDERMOTT, B. P.; MCGUIRE, T. M.; MORLEY, A. D.; MORRIS, J. J.; PAGE, K. M.; RIBEIRO, L. R.; SAWNEY, H.; STEINBACHER, S.; SMITH, C.; DOSSETTER, A. G. Pharmacokinetic Benefits of 3,4-Dimethoxy Substitution of a Phenyl Ring and Design of Isosteres Yielding Orally Available Cathepsin K Inhibitors. Journal of Medicinal Chemistry, v. 55, n. 20, p. 8827-8837, 2012.

74. BETHEL, P. A.; GERHARDT, S.; JONES, E. V.; KENNY, P. W.; KAROUTCHI, G. I.; MORLEY, A. D.; OLDHAM, K.; RANKINE, N.; AUGUSTIN, M.; KRAPP, S.; SIMADER, H.; STEINBACHER, S. Design of selective Cathepsin inhibitors. Bioorganic \& Medicinal Chemistry Letters, v. 19, n. 16, p. 4622-4625, 2009. 
75. CHEN, Y. T.; BRINEN, L. S.; KERR, I. D.; HANSELL, E.; DOYLE, P. S.; MCKERROW, J. H.; ROUSH, W. R. In Vitro and In Vivo Studies of the Trypanocidal Properties of WRR-483 against Trypanosoma cruzi. PLOS Neglected Tropical Diseases, v. 4, n. 9, p. e825, 2010.

76. GILLMOR, S. A.; CRAIK, C. S.; FLETTERICK, R. J. Structural determinants of specificity in the cysteine protease cruzain. Protein Science : A Publication of the Protein Society, v. 6, n. 8, p. 1603-1611, 1997.

77. ALVES, L. C.; MELO, R. L.; CEZARI, M. H. S.; SANDERSON, S. J.; MOTTRAM, J. C.; COOMBS, G. H.; JULIANO, L.; JULIANO, M. A. Analysis of the S2 subsite specificities of the recombinant cysteine proteinases CPB of Leishmania mexicana, and cruzain of Trypanosoma cruzi, using fluorescent substrates containing non-natural basic amino acids. Molecular and Biochemical Parasitology, v. 117, n. 2, p. 137-143, 2001.

78. PUZER, L.; COTRIN, S. S.; ALVES, M. F. M.; EGBORGE, T.; ARAÚJO, M. S.; JULIANO, M. A.; JULIANO, L.; BRÖMME, D.; CARMONA, A. K. Comparative substrate specificity analysis of recombinant human cathepsin V and cathepsin L. Archives of Biochemistry and Biophysics, v. 430, n. 2, p. 274-283, 2004.

79. JIA, Z.; HASNAIN, S.; HIRAMA, T.; LEE, X.; MORT, J. S.; TO, R.; HUBER, C. P. Crystal Structures of Recombinant Rat Cathepsin B and a Cathepsin B-Inhibitor Complex: IMPLICATIONS FOR STRUCTURE-BASED INHIBITOR DESIGN. Journal of Biological Chemistry, v. 270, n. 10, p. 5527-5533, 1995.

80. ALVES, L. C.; MELO, R. L.; SANDERSON, S. J.; MOTTRAM, J. C.; COOMBS, G. H.; CALIENDO, G.; SANTAGADA, V.; JULIANO, L.; JULIANO, M. A. S1 subsite specificity of a recombinant cysteine proteinase, $\mathrm{CPB}$, of Leishmania mexicana compared with cruzain, human cathepsin $\mathrm{L}$ and papain using substrates containing non- natural basic amino acids. European Journal of Biochemistry, v. 268, n. 5, p. 1206-1212, 2001.

81. LECAILlE, F.; CHOE, Y.; BRANDT, W.; LI, Z.; CRAIK, C. S.; BRÖMME, D. Selective Inhibition of the Collagenolytic Activity of Human Cathepsin K by Altering Its S2 Subsite Specificity. Biochemistry, v. 41, n. 26, p. 8447-8454, 2002.

82. TARALP, A.; KAPLAN, H.; SYTWU, I.-I.; VLATTAS, I.; BOHACEK, R.; KNAP, A. K.; HIRAMA, T.; HUBER, C. P.; HASNAIN, S. Characterization of the S Subsite Specificity of Cathepsin B. Journal of Biological Chemistry, v. 270, n. 30, p. 18036-18043, 1995.

83. SILVA, D. G.; RIBEIRO, J. F. R.; DE VITA, D.; CIANNI, L.; FRANCO, C. H.; FREITAS-JUNIOR, L. H.; MORAES, C. B.; ROCHA, J. R.; BURTOLOSO, A. C. B.; KENNY, P. W.; LEITÃO, A.; MONTANARI, C. A. A comparative study of warheads for design of cysteine protease inhibitors. Bioorganic \& Medicinal Chemistry Letters, v. 27, n. 22, p. 5031-5035, 2017. 
84. CLELAND, W. W. Dithiothreitol, a New Protective Reagent for SH Groups*. Biochemistry, v. 3, n. 4, p. 480-482, 1964. 